La Granja: Revista de Ciencias de la Vida, Vol. 23, Núm. 1 - 2016 CONTENIDO

- Editorial

Conservación

- El código de barras de ADN (barcoding): una herramienta para la investigación y conservación de la diversidad biológica en el Ecuador

Marco Altamirano-Benavides y Patricio Yanez M.

MANEJO DE SUELOS

- Descripción del manejo de suelos en sistemas de producción agrí́cola del sector Hamaca de la parroquia Atapirire, Municipio Miranda de Anzoátegui, Venezuela

Barlin Orlando Olivares

Monitoreo DE CALIDAD DE AIRE

- Análisis y revisión de la Red de Monitoreo de Calidad del Aire de la ciudad de Cuenca, Ecuador Rubén Jerves y Freddy Armijos-Arcos

ConTAMinación

- Absorción de plomo de suelos altamente contaminados en especies vegetativas usadas para consumo animal y humano

Elena Coyago y Sara Bonilla

- Evaluación química y microbiológica de la playa de "Los Esteros" en la ciudad de Manta Carlos Enrique González Arteaga e Hilda Yajaira González Arteaga

PIrólisis

- Aprovechamiento energético de residuos plásticos obteniendo combustibles líquidos por medio del proceso de pirólisis

Myriam Mancheno, Servio Astudillo, Pablo Arévalo, Inés Malo, Tania Naranjo y Johana Espinoza

MANEJO DE RESIDUOS

- Caracterización y cuantificación de residuos sólidos universitarios. Caso de estudio: Universidad Politécnica Salesiana, sede Quito, campus sur

Elena Coyago, Katty Gonzales, Edgar Heredia y Renato Sánchez

\section{OTRAS PUBLICACIONES DE LA UNIVERSIDAD}

UNIVERSITAS, Revista de Ciencias Sociales y Humanas ALTERIDAD, Revista de Educación

RETOS, Revista de Ciencia de la Administración y Economía INGENIUS, Revista de Ciencia y Tecnología

SOPHIA, Colección de Filosofía de la Educación

UTOPÍA, Revista de Pastoral Juvenil Universitaria

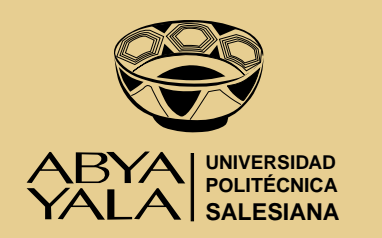

\section{REVISTA DE CIENCIAS DE LA VIDA}

CONSERVACIÓN

- El código de barras de ADN (barcoding): una herramienta para la investigación y conservación de la diversidad biológica en el Ecuador

MANEJO DE SUELOS

- Descripción del manejo de suelos en sistemas de producción agrícola del sector Hamaca de la parroquia Atapirire, Municipio Miranda de Anzoátegui, Venezuela

MONITOREO DE CALIDAD DE AIRE

- Análisis y revisión de la Red de Monitoreo de Calidad del Aire de la ciudad de Cuenca, Ecuador CONTAMINACIÓN

- Absorción de plomo de suelos altamente contaminados en especies vegetativas usadas para consumo animal y humano

- Evaluación química y microbiológica de la playa de "Los Esteros" en la ciudad de Manta

PIRóLISIS

- Aprovechamiento energético de residuos plásticos obteniendo combustibles líquidos por medio del proceso de pirólisis

MANEJO DE RESIDUOS

- Caracterización y cuantificación de residuos sólidos universitarios. Caso de estudio: Universidad Politécnica Salesiana, sede Quito, campus sur

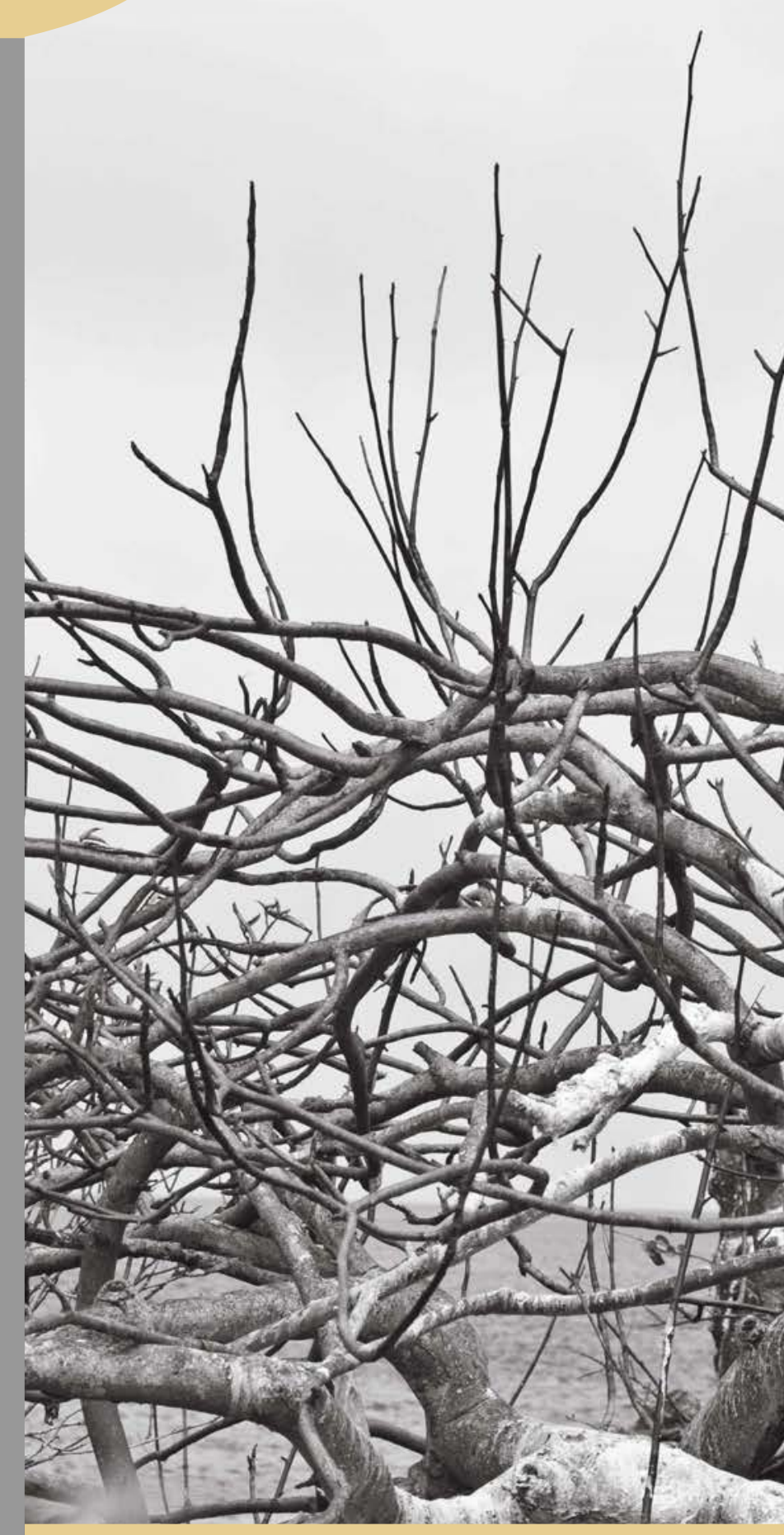

UNIVERSIDAD

Politécnica SAlesianA

ECUADOR

Indexada en DOAJ 


\section{LA GRANJA: REVISTA DE CIENCIAS DE LA VIDA}

La Granja Revista de Ciencias de la Vida • Volumen 23 • Número $1 \bullet$ enero - junio 2016 Revista semestral de Ciencias de la Vida de la Universidad Politécnica Salesiana del Ecuador. Publicación internacional bilingüe dedicada a estudios relacionados con ciencias físicas, químicas, biológicas, ambientales, de la salud, agronómicas, pecuarias y veterinarias. Las ideas y opiniones expresadas en las colaboraciones con de exclusiva responsabilidad de los autores y autoras.

\section{Consejo Editorial}

Ms.C. Sheila Serrano Vincenti, Editora

Universidad Politécnica Salesiana, Ecuador

Ph.D. Pablo Arévalo

Universidad Politécnica Salesiana, Ecuador

Ph.D. Fredi Portilla

Universidad Politécnica Salesiana, Ecuador

Ms.C. Lenin Ramírez

Universidad Politécnica Salesiana, Ecuador

Ms.C. Juan Loyola Illescas

Universidad Politécnica Salesiana, Ecuador

Ph.D. Paco Noriega Rivera

Universidad Politécnica Salesiana, Ecuador

Ph.D. María Elena Maldonado

Universidad Politécnica Salesiana, Ecuador

Ph.D. Ernesto Delgado

Universidad Politécnica Salesiana, Ecuador

Ph.D. Valentina Venturi

Universidad Politécnica Salesiana, Ecuador

Prof. Alessandro Medici

Universidad de Ferrara, Italia

Prof. Paola VitaFinzi

Universidad de Pavía, Italia

Dr. Flavio Contreras-Torres

Universidad Nacional Autónoma de México, México

M.Sc. León Escobar Moreira

Synaptronics, USA

Prof. Geovanni Vidari

Universidad de Pavía, Italia

Prof. Alencar Mello Proenca

Universidad Católica de Pelotas, Brasil

Prof. Miguel A. Altieri

Universidad de California, USA

Prof. Clara Inés Nicholls

Universidad de California, USA
Prof. Jaime Vadell Adrover

Universidad de las Islas Baleares, España

Ph.D. Marcos Villacís

Escuela Politécnica Nacional, Ecuador

Ph.D. Leonardo Basile

Escuela Politécnica Nacional, Ecuador

Ph.D. Lorena Meneses

Pontificia Universidad Católica del Ecuador, Ecuador

Dra. Silvia Pérez Damonte

Universidad de Buenos Aires, Argentina

Dr. Fernando Funes Monzote

Universidad de Matanzas, Cuba

Dr. Alessandra Guerrini

Universidad de Ferrara, Italia

Ph.D. Nicolás Vásquez

Escuela Politécnica Nacional, Ecuador

Prof. Giovanni Bernaccia

Universidad de Ferrara, Italia

Ph.D. Pamela Jaramillo

Mikuna-Food Science and Technology, Ecuador

M.Sc Adrian Troya

Escuela Pollitécnica Nacional, Ecuador

Dr. Luis F. Díaz Campodonico

Presidente, CalRecovery Inc., USA

Ph.D. Fernando Domínguez Castro

Escuela Politécnica Nacional, Ecuador

Ph.D. Juan Avellaneda Cevallos

Universidad Técnica Estatal del Quevedo, Ecuador

Ph.D. Lorenzo Guerrini

Universidad de Florencia, Italia

Ph.D. José Luis Santos

Escuela Politécnica del Litoral, Ecuador 


\section{LA GRANJA: \\ REVISTA DE CIENCIAS DE LA VIDA}

Volumen 23, Número 1, enero - junio 2016

ISSN Impreso: 1390-3799 • ISSN electrónico: 1390-8596

Indexada en:

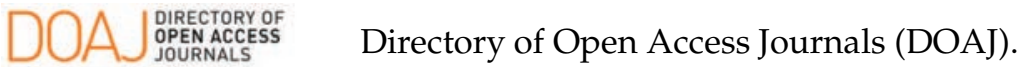

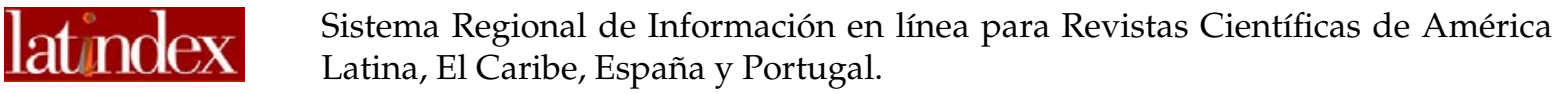

La administración de la LA GRANJA se realiza a través de los siguientes parámetros:

- La revista utiliza los sistemas anti-plagio académico

U R K U N D $\mathrm{y}$

\section{y}

Crossref Similarity Check

- Los artículos cuentan con código de identificación (Digital Object Identifier)

- El proceso editorial se gestiona a través del Open Journal System $\underset{\text { open Jumal system }}{\mathrm{OJS}}$

Es una publicación de acceso abierto (Open Access) con licencia Creative Commons

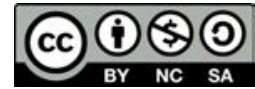

Las políticas copyright y de uso postprint, se encuentran publicadas en el Repositorio de Políticas de Autoarchivo SHERPA/ROMEO.

Los artículos de la presente edición pueden consultarse en: http:/ / revistas.ups.edu.ec/index.php/granja

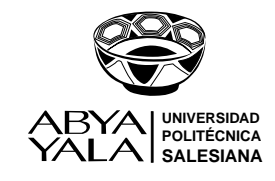

Universidad Politécnica Salesiana del Ecuador 


\section{Rector}

Javier Herrán Gómez, sdb

Turuhuayco 3-69 y Calle Vieja

Casilla Postal 2074

Cuenca, Ecuador

Teléfono: (+593 7) 2050000

Fax: (+593 7) 4088958

rpublicas@ups.edu.ee

Tiraje: 730 ejemplares

\section{Consejo de publicaciones}

Javier Herrán Gómez, sdb PRESIDENTE

Juan Pablo Salgado Juan Bottasso Boetti, sdb

Teodoro Rubio Martín José Juncosa Blasco René Unda Lara Jaime Padilla Verdugo Floralba Aguilar Gordón Sheila Serrano Vincenti

Fabricio Freire Morán John Calle Sigüencia Armando Grijalva Brito Andrea De Santis

Mónica Ruiz Vásquez

Luis Álvarez Rodas EDITOR GENERAL

\section{Foto de la portada}

Santiago Cárdenas

Diseño, diagramación y maquetación en $\mathrm{IAT}_{\mathbf{E}} \mathrm{X}$

Editorial Universitaria Abya-Yala

\section{Impresión}

Editorial Universitaria Abya-Yala

Av. 12 de Octubre N23-116 y Wilson

Quito, Ecuador

Teléfono: (02) 2506-247/(02) 2506-25

E-mail: editor@abyayala.org

Portal electrónico:

http://www.abyayala.org

El sistema tipográfico utilizado para componer esta revista fue LTEX, el cual es un sistema de composición orientado especialmente a la creación de libros y documentos científicos de alta calidad sobre software libre. 


\section{ÍNDICE}

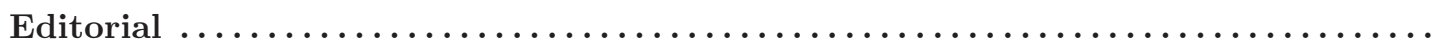

CONSERVACióN

El código de barras de ADN (barcoding): una herramienta para la investigación y conservación de la diversidad biológica en el Ecuador ......................... Marco Altamirano-Benavides y Patricio Yánez M.

Manejo de suelos

Descripción del manejo de suelos en sistemas de producción agrícola del sector Hamaca de la parroquia Atapirire, Municipio Miranda de Anzoátegui, Venezuela Barlin Orlando Olivares

Monitoreo DE CALIDAd DE AIRE

Análisis y revisión de la Red de Monitoreo de Calidad del Aire de la ciudad de

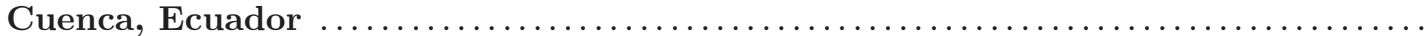

Rubén Jerves y Freddy Armijos-Arcos

Contaminación

Absorción de plomo de suelos altamente contaminados en especies vegetativas usa-

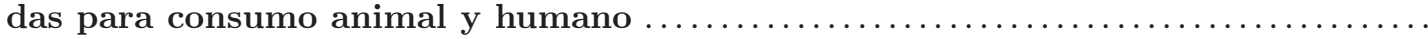
Elena Coyago y Sara Bonilla

Evaluación química y microbiológica de la playa de "Los Esteros" en la ciudad de Manta

Carlos Enrique González Arteaga e Hilda Yajaira González Arteaga

PIRÓLISIS

Aprovechamiento energético de residuos plásticos obteniendo combustibles líquidos

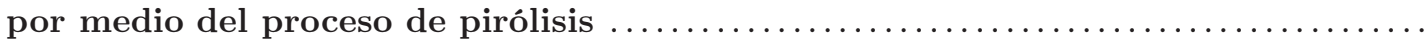
Myriam Mancheno, Servio Astudillo, Pablo Arévalo, Inés Malo, Tania Naranjo y Johana Espinoza

MANejo DE RESIDUOS

Caracterización y cuantificación de residuos sólidos universitarios. Caso de estudio: 68

Universidad Politécnica Salesiana, sede Quito, campus sur . . . . . . . . . . . . . Elena Coyago, Katty Gonzales, Edgar Heredia y Renato Sánchez

Normas para la presentación de los manuscritos 


\section{LA GRANJA: \\ REVISTA DE \\ Editorial \\ CIENCIAS DE LA VIDA}

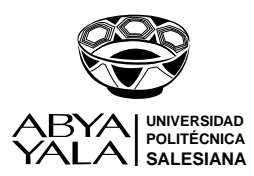

Estimadas y estimados lectores:

"Una revista científica es un órgano de comunicación especializado y global, es decir, es un libro en permanente construcción-escritura-donde todos quieren leer los avances y todos quieren contribuir a la construcción de la narrativa"; éstas fueron las palabras de Salvador Chávez, Director de Documentación y Contenido de REDALYC (Red de Revistas Científicas de América Latina y el Caribe, España y Portugal) en la última reunión mantenida con los miembros del Consejo de Publicaciones de la Universidad Politécnica Salesiana UPS.

$Y$ es que desde hace algunos años, se ha venido trabajando en buscar la indización de nuestras revistas científicas en los mejores y más representativos sistemas de información científica a nivel regional. Es así, como la Revista de Ciencias de la Vida, La Granja, conjuntamente con las otras cinco revistas científicas de la universidad, se encuentran ubicadas en Latindex y el Directory of Open Access Journals (DOAJ), por lo que son consideradas como publicaciones científicas de nivel regional.

El camino no ha sido fácil, ha implicado el mejoramiento de la calidad editorial en su totalidad, a través de la búsqueda de revisores más exigentes y comprometidos, así como la búsqueda de mayor calidad en los artículos científicos, incluso implementar nuevas tecnologías como el sistema editorial Open Journal System, y sobretodo, posicionar la revista a nivel nacional e internacional.

Sin embargo, ningún objetivo se podría lograr sin contar con los valiosos aportes de los científicos que han confiado en nuestra revista para divulgar sus hallazgos y disertaciones. Ellos son quienes "a hombros de gigantes" se aventuran en la creación de conocimiento científico.

Bajo este contexto, me permito presentar a los autores de este número, cuya temática gira en torno a la conservación y la contaminación. En primer lugar, presentamos a los investigadores ecuatorianos Marco AltamiranoBenavides y Patricio Yánez quienes proponen la inicia- tiva de secuenciación del ADN o "barcoding" como una herramienta que permite identificar la verdadera riqueza biológica del país, e incentivar la generación de bioconocimiento y su conservación. A continuación, Barlín Orlando Olivares, de la Universidad de Córdoba de España, describe el manejo de suelos en los sistemas de producción agrícola del sector Hamaca de Anzoátegui en Venezuela, utilizando el análisis por componentes principales; identificando de esta manera cuáles son las prácticas más influyentes para la conservación de suelos agrícolas.

Por otro lado, analizando la temática de la contaminación, los investigadores de la UPS, Rubén Jerves y Freddy Armijos-Arcos, presentan una revisión de la idoneidad de la red de monitoreo de la calidad del aire en la ciudad de Cuenca, en Ecuador. Mientras que Elena Coyago y Sara Bonilla, exponen los riesgos del consumo de especies vegetales como la acelga y la alfalfa, por su alta capacidad de absorción de plomo de suelos contaminados. En la misma temática, Carlos González Arteaga e Hilda González Arteaga, de la PUCE y la Universidad Laica Eloy Alfaro de Manabí, muestran la preocupante realidad de la evaluación química y microbiológica de las aguas de la playa "Los Esteros" en Manta.

Sin embargo, así como se presentan problemas, se presentan también soluciones. En este caso, los investigadores de la UPS, Myriam Mancheno, Servio Astudillo, Pablo Arévalo, Inés Malo, Tania Naranjo y Johana Espinoza, demuestran la eficacia de la pirolisis, no sólo como un método de reciclaje de residuos, sino como una fuente factible de elaboración de combustibles. Finalmente, Elena Coyago, Katty Gonzales, Edgar Heredia y Renato Sánchez nos muestran la manera más eficiente caracterizar los residuos sólidos generados en instituciones educativas.

Me despido, segura que disfrutarán y encontrarán útiles los aportes presentados y que podrán formar parte de vuestras investigaciones presentes y futuras.

Fís. Sheila Serrano Vincenti Ms.C EDITORA 


\title{
EL CÓDIGO DE BARRAS DE ADN(barcoding): UNA HERRAMIENTA PARA LA INVESTIGACIÓN Y CONSERVACIÓN DE LA DIVERSIDAD BIOLÓGICA EN EL ECUADOR
}

\author{
DNA BARCODING: A TOOL FOR RESEARCH AND CONSERVATION OF \\ BIODIVERSITY IN ECUADOR
}

Marco Altamirano-Benavides ${ }^{1,2,3, *}$ y Patricio Yánez M. ${ }^{1,4}$

${ }^{1}$ Carrera de Administración de Empresas Turísticas e Instituto de Investigaciones Científicas y Tecnológicas, Universidad Iberoamericana del Ecuador. 9 de Octubre N25-12 y Colón, Quito-Ecuador

${ }^{2}$ Facultad de Ciencias Agrícolas, Universidad Central del Ecuador, Ciudadela Universitaria-Jerónimo Leiton y Av. La Gasca s/n. Quito-Ecuador.

${ }^{3}$ Estación Científica Juri-Juri Kawsay, Universidad Central del Ecuador, Av. América N23-41 y Mercadillo. Quito-Ecuador

${ }^{4}$ Escuela de Biología Aplicada, Universidad Internacional del Ecuador, Av. Simón Bolívar s/n y Jorge Fernández, Quito-Ecuador.

*Autor para correspondencia: maltamirano@unibe.edu.ec

Manuscrito recibido el 15 de enero de 2016. Aceptado, tras revisión, el 10 de junio de 2016.

\begin{abstract}
Resumen
El Ecuador es un país considerado megabiodiverso por su alta riqueza de especies en varios grupos biológicos; sin embargo, aún se desconoce el número total de estas especies, en parte debido a la falta de fondos de investigación, complejidad taxonómica de algunos grupos y el relativo aislamiento del país en relación a iniciativas científicas mundiales. Solamente la creación de un sistema de identificación de especies que incluya las características del espécimen voucher, muestras de tejidos y la secuencia de Barcodes permitiría llegar a determinar la verdadera riqueza biológica del Ecuador. El presente trabajo aborda algunos aspectos sobre la iniciativa mundial del «Código de Barras del ADN», se hace hincapié en sus potenciales aplicaciones en torno a la investigación para la conservación de la diversidad biológica del Ecuador. Esta iniciativa propone emplear información dentro de una misma región génica (gen mitocondrial del Citocromo c Oxidasa I = COI), en todas las especies vivientes y con condiciones de secuenciación universalmente aceptadas y estandarizadas. Esta herramienta científica no pretende sustituir la taxonomía alfa y la filogenia, sino más bien agilizar las tareas de identificación, especialmente en el campo de la Biomedicina (identificación de patógenos, parásitos y vectores), el control de plagas (cualquiera sea su estado de desarrollo ontogenético), detección de especies invasivas, estudios sobre conservación de la biodiversidad y sanción de delitos ambientales. La integración del «Código de barras del ADN», el trabajo de campo, las colecciones de museos y la investigación científica resultan imprescindibles para que esta herramienta redunde en avances significativos en la generación de bioconocimiento en el Ecuador.
\end{abstract}

Palabras claves: diversidad biológica, conservación, complejidad taxonómica, Código de Barras de ADN, gen mitocondrial COI, bioconocimiento. 


\begin{abstract}
Ecuador is considered a mega-biodiverse country by its high species richness in several biological groups, however even the total number of these species is unknown, in part because of the lack of budget for doing research, taxonomic complexity and the relative isolation of the country in relation to global scientific initiatives. We are convinced that only the creation of a species identification system that includes the specimen "voucher", tissue samples and barcodes sequences allow determine the true biological richness of Ecuador. This manuscript deals with some issues of the DNA barcode initiative, focusing on its potential applications to conservation of the biological diversity of Ecuador. This initiative proposes using information within the same gene region (Cytocrome c Oxidase I= COI mitochondrial gene), in all living species and under standard conditions of sequencing. DNA Barcoding does not attempt to replace alpha taxonomy or phylogeny, but this will allow accelerate the task of identification, particularly, in the fields of Biomedicine (identification of pathogens, parasites and vectors), Pest Control (in all ontogenetic stages), detection of invasive species, studies on Biodiversity Conservation, and for prosecution of environmental crimes. The integration of «DNA barcode», field work, collections of museums and scientific research are essential to make a fruitful impact on the bioknowledge generation in Ecuador.
\end{abstract}

Keywords: biological diversity, conservation, taxonomic impediment, DNA Barcoding, COI mitochondrial gen, bioknowledge.

Forma sugerida de citar: $\quad$ Altamirano, M. y P. Yánez. 2016. El código de barras de ADN(barcoding): Una herramienta para la investigación y conservación de la diversidad biológica en el Ecuador. La Granja: Revista de Ciencias de la Vida. Vol. 23(1): 5-14. ISSN: 1390-3799. 


\section{Introducción}

La diversidad biológica es, en esencia, la variedad de la vida que sostiene a nuestro planeta. Este concepto fue acuñado en 1985 por el famoso ecólogo-entomólogo Edward O. Wilson e involucra varios niveles de organización biológica, desde especies (plantas, animales, hongos, microrganismos) que comparten un espacio en un tiempo determinado, su variabilidad genética, así como las diferentes variedades de comunidades, ecosistemas y biomas donde viven estas especies. Además, también incluye los procesos ecológicos y evolutivos que moldean la composición, estructura y función de estos niveles de organización biológica (Kim y Byrne, 2006; Pérez-Schultheiss, J, 2009).

Estudiar cómo estos tres atributos (composición, estructura y función) de las especies pueden cambiar espacial y temporalmente, influenciados por factores antrópicos o estocásticos, ha sido el reto permanente de los naturalistas, biólogos y ecólogos desde los tiempos de Charles Darwin y George Wallace, quienes analizaron e infirieron los procesos ecológicos y evolutivos que promueven el incremento/disminución de la diversidad biológica y cómo ésta se distribuye en el planeta.

En la actualidad no cabe la menor duda de que la diversidad biológica es esencial para la sobrevivencia y bienestar económico de la humanidad debido a los bienes y servicios que nos proporcionan los ecosistemas funcionalmente estables (Singh, J, 2002; Yánez, P, 2014a).

En teoría existen artificios matemáticos y estadísticos con implicaciones ecológicas y evolutivas que permiten medir y mapear la diversidad biológica a diferentes escalas de análisis. La diversidad alfa por ejemplo mide las especies presentes en una localidad, mientras que la diversidad beta mide el recambio de especies de una localidad a otra, y la diversidad gamma en cambio mide las especies presentes en una región/bioma (Margules y Pressey, 2000; Mace, G, 2004; Yánez, P, 2014a). Las dos primeras son el resultado de procesos ecológicos, mientras que la tercera deriva de procesos evolutivos que involucran aspectos de historia natural e historia geológica. Sin embargo, para caracterizar adecuadamente estos diferentes tipos de diversidad, no hay que olvidar que primero es necesario conocer la identidad de las especies; trabajo que según (Pimm y Lawton, 1998; Giangrande, A, 2003) debe ser realizado por taxónomos.
Según (Green, S, 1998), una gran cantidad de especies permanecen desconocidas. Se calcula que en la Tierra se han descrito alrededor de 1,7 millones de organismos vivos; sin embargo, estimaciones realizadas indican que el número mundial de especies podría ser de aproximadamente 10 millones (Wilson, E, 2000, 2004). Es decir, nuestro conocimiento de la diversidad biológica se basa en menos del $20 \%$ de lo que realmente existe (Kim y Byrne, 2006) y en consecuencia existe una alta probabilidad de que muchas de estas especies podrían extinguirse aún antes de que sean descubiertas (Pimm y Raven, 2000).

Algunas estimaciones sugieren que a una tasa de descripción que históricamente ha sido de 7000 especies por año ¡nos tomaría 1429 años completar el inventario de la vida! Sin embargo, se ha sugerido que con el desarrollo de nuevas herramientas de análisis y tecnologías, este lapso de tiempo podría reducirse a 25 años (Wilson, E, 2004; Kim y Byrne, 2006; Pérez-Schultheiss, J, 2009).

Desde hace algunos años, pero principalmente en la última década, los análisis moleculares han demostrado ser muy eficientes y eficaces para resolver problemas taxonómicos en grupos crípticos, dilucidando así la filogenia y la filogeografía de las especies y fortaleciendo la sistemática y ecología como disciplinas científicas complementarias (Lanteri, A, 2007). Sin embargo, los métodos moleculares tradicionales no son estandarizados y se requiere de mucho tiempo y presupuesto para realizar los análisis (Hebert et al., 2003a).

Si bien es cierto que la idea de utilizar secuencias de ADN específicas para la identificación rápida de especímenes no es fundamentalmente nueva (Moritz y Cicero, 2004), lo que es innovador del Código de Barras de ADN es que propone usar información dentro de una misma región génica, en todos los taxones y con condiciones de secuenciación universalmente aceptadas y estandarizadas y a una relación costo-eficiencia relativamente bajo. Además, el protocolo destaca la necesidad de relacionar esta información con ejemplares "vouchers" depositados en museos (Lanteri, A, 2007). (Hebert et al., $2003 a, b)$ lo definen como un "identificador universal" de especies que utiliza una región génica estándar/universal de 648 pares de bases en el Cito Cromo Oxidasa 1 Mitocondrial (COI) que está presente en todos los organismos y que es lo suficientemente variable y específico para cada especie animal.

El uso del COI está resultando muy eficaz en la 
identificación de aves, mariposas, anfibios, peces, moscas y otros grupos de animales (Hebert et al., 2003a,b); sin embargo, su universalidad es controvertida cuando se trata de plantas superiores, donde el COI es altamente invariante ya que evoluciona muy lentamente (Moritz y Cicero, 2004). La alternativa ha sido emplear dos regiones de genes en el cloroplasto (matK y rbcL) consideradas como las regiones estándar/universales para este grupo de organismos (Chase et al., 2005; Lanteri, A, 2007).

Controversial o no, el Ecuador básicamente está aislado y al margen de toda esta iniciativa científica mundial que promueve la colaboración internacional de museos de historia natural, herbarios, repositorios de material biológico, sitios de estudio de inventarios biológicos, entre otros, en estrecha colaboración con expertos y/o especialistas en genómica, taxonomía, electrónica y ciencias de la computación, principalmente.

Por lo tanto, el objetivo de este artículo es el de sumarse a esta iniciativa y buscar promover el uso del Código de Barras de ADN como una línea y/o herramienta de análisis e investigación para estudios de la diversidad biológica, así como empezar el análisis de sus implicaciones en conservación, su impacto dentro de la sociedad y su contribución para delimitar un marco legal que permita sancionar delitos ambientales.

\section{Resultados y discusión}

A pesar del creciente y exitoso uso del Código de Barras de ADN en la última década, principalmente en proyectos de investigación y conservación de la diversidad biológica efectuados en diferentes escalas de análisis, existen algunos investigadores que todavía subestiman los verdaderos alcances que tiene y los aportes que esta herramienta está realizando al conocimiento científico de la vida silvestre a nivel mundial. Solo el hecho de que contribuye a determinar el estatus taxonómico de una especie mediante el análisis de una secuencia corta de ADN de condiciones uniformes en un sitio especifico del genoma, es de por sí un paso enorme para la ciencia.

En general, un proyecto de Código de Barras de ADN de la Vida Silvestre debe involucrar:

Los especímenes: presentes en museos de historia natural, herbarios, zoológicos, acuarios, colecciones de tejidos congelados, bancos de semillas, colecciones de cultivos tipo y otros repo- sitorios de materiales biológicos; todos ellos constituyen un conjunto muy valioso de especímenes a veces ya identificados, a veces todavía por identificarse.

Los análisis de laboratorio: los protocolos de laboratorio para obtener secuencias de código de barras de ADN de estas muestras no son complicados. Los laboratorios de biología molecular mejor equipados pueden producir una secuencia de código de barras de ADN en unas pocas horas.

La Base de Datos: es uno de los componentes más importantes en una Iniciativa de Código de Barras, esta base se fundamenta en la construcción de una biblioteca de referencia pública de identificadores de especies que podrían ser utilizados para asignar especímenes desconocidos a especies conocidas. Actualmente, hay dos bases de datos principales del código de barras que cumplen este papel:

- La base de datos de secuencias de nucleótidos de colaboración internacional es una asociación entre el GenBank en USA, el Laboratorio Europeo de Biología Molecular y el Banco de Datos de ADN de Japón.

- La base de datos del Código de Barras de la Vida (BOLD) fue creado y es mantenido por la Universidad de Guelph en Ontario.

El análisis de datos: los especímenes se identifican efectuando una búsqueda del registro referencial más cercano/parecido que se encuentra en la base de datos. El Grupo de Trabajo de Análisis de CBOL (Consortium for the Barcode of Life) ha creado el portal del Código de Barras de la Vida, el cual ofrece a los investigadores nuevos y más flexibles formas de almacenar, gestionar, analizar y publicar sus datos.

A continuación se realiza un análisis de las principales fortalezas de esta herramienta científica bajo tres criterios primordiales: a. Investigación para la conservación de la diversidad biológica del Ecuador, b. Socialización, acceso y democratización del bio-conocimiento y, c. Como herramienta técnicocientífica de peritaje en delitos ambientales. 


\subsection{Investigación para la conservación de la diversidad biológica}

a. El Código de Barras de ADN trabaja con fragmentos de material biológico: ésta es una de sus principales virtudes, ya que permite la identificación de las especies inclusive a partir de material biológico incompleto, dañado o en estado inmaduro. Por tanto, las implicaciones que se derivan de ello en campos como el de la investigación, conservación, manejo y control de fauna y flora silvestres son muy importantes.

b. Cacería furtiva y tráfico de especies de flora y fauna en Ecuador, al igual que en muchos de los países en vías de desarrollo, existe un mercado negro de especímenes de vida silvestre que alienta el tráfico de animales y plantas o de sus elementos constitutivos (carne, huesos, plumas, huevos, larvas, pieles, uñas, cuernos, picos, semillas, plántulas), de los cuales se fabrican una serie de artículos o simplemente son consumidos como proteína. El Código de Barras de ADN puede detectar e identificar cuáles son las especies que están bajo mayor presión de tráfico a partir del análisis de estos elementos constitutivos. Un caso específico que podría ser resuelto con el uso de esta herramienta es la pesca ilegal del pepino de mar y el aleteo de tiburón en las Islas Galápagos: una vez creada la BIBLIOTECA DE CÓDIGO DE BARRAS de las especies endémicas, nativas, terrestres y marino-costeras de las Islas, sería fácil implementar un sistema de monitoreo y control de las rutas y destinos finales de estos recursos biológicos, muestreando por ejemplo todos los mercados que vendan productos de mar a lo largo de las costas de Ecuador y países vecinos.

c. Identificación de plagas que afectan cultivos (Seguridad Alimentaria): es conocido que las plagas que afectan a una gran variedad de cultivos en zonas andino-tropicales son regularmente huevos, larvas o propágulos de insectos, bacterias y hongos, que son mucho muy difíciles de identificar debido al estadio temprano de desarrollo, o porque son organismos poco estudiados y complejos sobre los cuales no existe casi información, o simplemente porque no existe el especialista (Taxónomo) que pueda identificarlos. El Código de Barras de ADN podría dilucidar este problema sin contratiempos, ya que la región génica están- dar/ universal no cambia en ninguna de las fases de desarrollo de la especie; por lo tanto, la especie plaga puede ser identificada a partir de sus larvas, huevos o propágulos.

d. Detección temprana y control de especies invasivas: uno de los mayores retos para los Sistemas de Control y Cuarentena de especies introducidas es detectar e identificar las potenciales especies invasivas y las rutas de invasión utilizadas más frecuentemente. Las especies invasivas se caracterizan por colonizar fácilmente sistemas biológicos insulares y se dispersan rápidamente formando poblaciones viables en todas las rutas de invasión. El Código de Barras de ADN puede identificar la población de origen de las especies invasivas y, por lo tanto, la potencial ruta de invasión; con esta información los Sistemas de Control y Cuarentena pueden prevenir que continúen las invasiones a ecosistemas importantes pero muy frágiles como las Islas Galápagos.

e. Estudios de ecología trófica: la aplicación del Código de Barras de ADN en estudios ecológicos es crucial, principalmente en los estudios de las interacciones entre los organismos dentro de la cadena trófica. Por ejemplo, la determinación de la dieta alimenticia, mediante el análisis del contenido estomacal, de un depredador nativo, endémico o introducido suele ser una tarea difícil de realizar, porque dependiendo del grupo taxonómico los individuos consumidos por un depredador están parcial o totalmente digeridos/degradados: es decir, generalmente solo se puede encontrar dentro del tracto digestivo del animal analizado a partes del cuerpo o una masa gelatinosa de tejidos, lo cual minimiza las posibilidades de identificación de la especie presa, así como de la frecuencia de su consumo por parte del predador. Las implicaciones de este tipo de estudios en la conservación de la diversidad biológica de sistemas insulares oceánicos (Islas Galápagos, Isla de La Plata) o continentales (ecosistemas nativos aislados) son críticas, ya que nos permitirían determinar cualitativa y cuantitativamente los impactos causados por depredadores invasivos sobre los tres atributos principales de organización biológica: estructura, composición y función de las especies.

f. Diferenciando especies crípticas: el Código de Barras de ADN puede distinguir la identidad taxonómica de una especie dentro de un complejo 
de especies crípticas. Usualmente muchas especies morfológicamente similares tienen un rango amplio de distribución geográfica y aunque se podría inferir que algunas de sus poblaciones distribuidas a lo largo de este gradiente geográfico/latitudinal tienen sus propias trayectorias ecológicas y evolutivas, no se ha logrado dilucidar si han sufrido suficientes cambios como para ser categorizadas a nivel específico y/o subespecífico. Son muchos los ejemplos en la fauna y flora donde de una "sola especie" se han logrado identificar dos o más identidades taxonómicas diferentes, lo cual es una contribución muy significativa para el conocimiento y real estimación de la biodiversidad local, regional y continental. En nuestro país, en los últimos años, la descripción de nuevas especies de anfibios y reptiles ubicadas inicialmente en complejos de especies crípticas (por su similitud fenotípica) es muy notorio.

g. Desenmascarando especies ocultas: existen casos en los cuales se puede generalizar el nivel de toxicidad o parasitismo de una especie dañina a un grupo de especies cercanas taxonómicamente, sin que esto se necesariamente verdad; por tanto, resulta crucial identificar con exactitud cuáles son las especies perjudiciales y cuales no para la salud o el bienestar humanos o de otras especies útiles o emblemáticas; dicho de otra manera: desenmascarar especies que parecen inofensivas pero que realmente son nocivas para otras especies y/o para el ser humano. Tal es el caso del mosquito Anopheles, vector de transmisión de la malaria humana, presente en Ecuador: de las 450 especies conocidas dentro de este género, apenas unas cuantas transmiten la enfermedad. Otro caso interesante es el de la enfermedad conocida como "Fiebre Chikungunya", reportada en el país hace unos meses y cuyo vector de transmisión aparentemente es el mosquito Aedes aegypti. Este tipo de estudios se vuelven fundamentales cuando los organismos expanden su distribución geográfica horizontal o altitudinalmente, debido al Calentamiento Global del Planeta.

\subsection{Socialización, acceso y democratización del bio-conocimiento}

a. El uso del Código de Barras de ADN reduce la ambigüedad de la información sobre el estado de conser- vación de especies y ecosistemas: la creación de bibliotecas digitales de códigos de barras de ADN de especies endémicas, nativas e introducidas en áreas protegidas públicas (SNAP, PANE entre otras) y privadas (Red de Bosques Privados, por ejemplo) o en ecosistemas frágiles, proveerán una base de datos científica referencial que facilitará la correcta identificación de las especies, su fluctuación poblacional y distribución geográfica a diferentes escalas de análisis espacio-temporal. Inclusive, nos permitirá determinar la dinámica de procesos ecológicos y evolutivos derivados del Calentamiento Global que están provocando las disminución poblacional y extinción de especies tales como anfibios y reptiles; y en otros casos medir el avance o retroceso de especies invasivas, principalmente en ambientes insulares. Es decir, nos permitirá realizar un análisis espaciotemporal del impacto de factores estocásticos y antrópicos sobre la diversidad biológica y ecológica a diferentes niveles de organización. Esta información se torna crucial en la elaboración de planes de manejo y programas de investigación para la conservación de la diversidad biológica del Ecuador.

b. Incremento y mejoramiento del conocimiento sobre la Diversidad Biológica: la existencia en el Planeta solo de alrededor de 1,7 millones de especies bien identificadas limita, aún, a los expertos y/o especialistas a realizar identificaciones morfológicas solo de una pequeña parte, principalmente de los reinos animal y vegetal. Se estima que faltan por ser bien identificadas varios millones de especies más; por lo tanto, los investigadores deberían equiparse o ser equipados con una herramienta tan fuerte como el Código de Barras de ADN (y el conocimiento, la tecnología e infraestructura que esto amerite) para acelerar la identificación de los especímenes incompletamente identificadas que reposan en museos y herbarios de historia natural y de las potenciales nuevas especies que se espera colectar e identificar en un futuro cercano. En países como Ecuador, considerado mega-biodiverso (debido a que posee entre el 10 y $16 \%$ de la diversidad biológica mundial) pero al mismo tiempo con presiones sociales y económicas permanentes; el acelerar la tasa de descripción de nuevas especies es un reto con muchas implicaciones, pero que debe realizarse de manera inmediata. 
c. Democratiza el acceso a la información científica: tener una biblioteca estandarizada de Códigos de Barras de ADN permitirá que mucha más gente, no exclusivamente investigadores y/o científicos, pueda reconocer y llamar por su nombre a las especies que existen en su entorno. Esto hará posible la identificación de especies sin importar que estas sean abundantes, raras, endémicas, nativas o invasivas. De esta manera mayor número de personas podrán apreciar y entender el valor de la diversidad biológica a diferentes escalas: local, regional, continental y global.

d. Demostrar y fortalecer el valor de las colecciones científicas de historia natural: la creación de una Biblioteca de Código de Barras de ADN comienza con la recopilación de información y material biológico de cientos de miles y/o millones de especímenes almacenados en museos, herbarios, jardines botánicos, zoológicos, centros de rescate y otros repositorios de material biológico. Sacar a luz la importancia de estos repositorios de material genético permitirá que estas instituciones científicas reciban el reconocimiento y el apoyo financiero para cumplir con sus objetivos, a veces poco valorados, de preservar y custodiar la biodiversidad de la Tierra y en general cuidar de este patrimonio de la humanidad.

e. Elaboración de una enciclopedia de biodiversidad del Ecuador: contar con una Biblioteca de Códigos de Barras de ADN unida y/o enlazada a los centros de preservación de especímenes "vouchers" y a su nomenclatura científica actualizada en los repositorios de material biológico, promoverá el acceso público al bioconocimiento. De esta manera, se puede crear una enciclopedia de la biodiversidad del Ecuador en línea con información de cada una de las especies de flora y fauna existentes en los diferentes ecosistemas del país.

\subsection{Herramienta de peritaje en delitos am- bientales}

La pesca y la cacería ilegal, así como la comercialización y consumo de los especímenes capturados, en ecosistemas y áreas protegidas de vital importancia para la conservación de la diversidad biológica tales como los bosques húmedos tropicales, los bosques secos, los páramos húmedos y las Islas Galápagos, son difíciles de evidenciar y sancionar de acuerdo a la normativa legal ambiental. Similar caso sucede con el mercado negro de especies silvestres o sus elementos constitutivos (carne, huesos, plumas, huevos, larvas, pieles, uñas, cuernos, picos, semillas, plántulas), su comercialización ha sido una actividad lucrativa y a veces el modus vivendi de muchos habitantes de las zonas rurales del país. La captura, caza y extracción de animales y plantas del medio silvestre para el comercio constituyen la segunda amenaza para la supervivencia de especies de fauna y flora, después de la destrucción de su hábitat. Tanto es así, que el tráfico de animales y plantas silvestres es el tercer mayor comercio ilegal del mundo, superado sólo por el tráfico de drogas y de armas.

En este escenario, es donde el uso del "Barcoding" se vuelve crucial para sancionar los delitos ambientales ya citados; por lo tanto, esta herramienta de análisis sería la base del peritaje legal que las instituciones pertinentes del Estado deberían realizar. Es obvio que se trata de un trabajo en equipo que incluiría a las autoridades/especialistas del Área Protegida o de la región geográfica de interés: Policía Ambiental, Ministerio de Ambiente a través de los puntos focales CITES y Diversidad Biológica, Fiscalía Ambiental, entre otros.

\section{Conclusiones y recomendaciones}

El enfrentar una crisis de conservación de la diversidad biológica a nivel mundial, pero particularmente a nivel local o regional, amerita diferentes enfoques de análisis de sus causas y consecuencias. En países considerados megabiodiversos como el nuestro la generación de bioconocimiento es todavía insuficiente, aunque se ha incrementado ostensiblemente en las últimas dos décadas, como para poder cuantificar la verdadera riqueza biológica que poseemos en Ecuador y dimensionar la importancia de los procesos ecológicos y evolutivos en los diferentes niveles de organización biológica. Por lo tanto, el desarrollo y uso progresivo del "Barcoding" en Ecuador atacaría y/o redundaría en la solución de los siguientes problemas: 


\subsection{Falta de una política de investiga- ción pública y privada que estimu- le y financie proyectos de investiga- ción/aplicación del Código de Barras de ADN (Barcoding) de la vida silvestre}

Si bien es conocido que el presente gobierno ha declarado a la diversidad biológica como un recurso estratégico para el desarrollo del país, poco es lo que realmente se ha invertido en cumplir con este objetivo. La necesidad de generar el "Inventario Nacional de Biodiversidad" que incluya ecosistemas terrestres, acuáticos y marinos, se vuelve cada vez más críticamente necesaria. Un verdadero inventario debe incluir el espécimen voucher, muestras de tejidos, por lo menos la secuencia 3'-5' (COI) del Código de Barras de ADN de la especie y datos ecológicos y biogeográficos asociados; los cuales deben ser depositados y custodiados en Museos de Historia Natural, Herbarios y Repositorios de Material Genético que posean una excelente infraestructura física y técnica, con personal técnico-científico capacitado y que cumpla con estándares internacionales.

Dentro de este contexto, proyectos sobre Barcoding de especies endémicas y /o amenazadas (según los criterios UICN o CITES), o que estén presentes en ecosistemas reconocidos a nivel mundial como Galápagos, se convierten en prioridad.

\subsection{Falta de datos}

Datos confiables sobre la diversidad taxonómica y ecológica siguen siendo insuficientes (Yánez, P, 2014b). Es conocido el sesgo biogeográfico que existe en el país, en el que pocas regiones han sido ampliamente estudiadas y cuentan con grandes colecciones científicas de historia natural, mientras que de otras casi no existe información. Igual situación sucede con algunos grupos taxonómicos sobre los cuales todavía existen grandes vacíos de información como en insectos, reptiles, anfibios, en relación con otros mejor estudiados como aves y mamíferos sobre los cuales se tiene importante información. Desafortunadamente, la mayoría de las colecciones científicas de historia natural realizadas hasta la década de 1980-1990 carecen de muestras de tejidos y secuencias de Barcoding, lo que dificulta tener un verdadero inventario de las diferentes localidades y regiones del país. Proyectos para colectar nuevos vouchers y muestras de tejidos, de los cuales se pueda obtener las secuencias $3^{\prime}-5^{\prime}$ (COI) del Código de
Barras de ADN de las especies, deben ser realizados.

\subsection{Falta de masa crítica de investigadores en esta línea de investigación}

Algunos especialistas como (Yánez, P, 2014b) enuncian que una gran mayoría de empleados gubernamentales y no gubernamentales, tales como guardaparques, investigadores, técnicos de organizaciones conservacionistas, encargados de museos, herbarios, zoológicos, entre otros, están capacitados solo en forma parcial o limitada para afrontar los graves y a veces vertiginosos problemas de conservación de la diversidad biológica del país.

A este problema hay que sumar que el Código de Barras de ADN de la vida silvestre (Barcoding) es una herramienta de análisis de la biodiversidad relativamente nueva en el mundo de la ciencia y que a pesar de su probada utilidad y eficacia en este tipo de estudios todavía no es ampliamente aceptada por la comunidad científica. Sin bien es cierto que no se necesita ser un experto en taxonomía o biología molecular para realizar los análisis de Barcoding de las especies, si se necesita una infraestructura física y técnica de última generación que permitan procesar y generar de manera confiable y rápida las secuencias del Código de Barras de ADN. En Ecuador, muchos investigadores desconocen lo que es el Barcoding, sus implicaciones y beneficios; por lo tanto, no existen especialistas/investigadores en este campo investigativo, a pesar de que a nivel latinoamericano ya se han realizado grandes avances en el uso del Barcoding, principalmente en Argentina, Brasil, México, Colombia con el aval institucional, científico y financiero del Consortium for the Barcode of Life (CBOL), el International Barcode of Life (IBOL), Smithsonian Institute, University of Guelph, entre las más importantes. A nivel de Estados Unidos, Asia y Europa, la generación de barcodes de la vida silvestre es impresionante y sigue en aumento.

\subsection{La falta de taxónomos o el "impedi- mento taxonómico"}

La taxonomía es la ciencia encargada de clasificar y poner nombre a todos los organismos vivos que habitan nuestro Planeta. Los grandes vacíos en el conocimiento de la diversidad biológica, asociados a la disminución de la cantidad de taxónomos activos 
constituyen lo que se conoce como el "impedimento taxonómico".

Por su naturaleza de ciencia principalmente descriptiva, actualmente la taxonomía es considerada como una disciplina poco competitiva y anticuada, por lo que ha perdido gran parte del apoyo financiero y político necesario para su desarrollo. Este abandono de la taxonomía también se ha revelado en las mallas curriculares universitarias, lo que actualmente produce generaciones de biólogos con una escasa comprensión de los métodos para la clasificación e identificación de organismos. La correcta identificación de los diferentes organismos que habitan un área es de vital importancia para su conocimiento, valoración y protección. Es complejo saber si una especie se extingue, a menos que se hayan realizado estudios científicos que involucren una correcta identificación taxonómica de la misma: es decir necesitamos todavía y con urgencia formar buenos taxónomos! Y si éstos están entrenados con el manejo adecuado del Barcoding, mucho mejor.

\subsection{Falta de presupuesto}

Al ser una línea de investigación básicamente desconocida para las instituciones del Estado responsables de promover y generar bioconocimiento, es difícil que ellas financien de manera específica proyectos para generar barcodes de la vida silvestre de Ecuador, mismas que involucrarían la realización de nuevas colecciones científicas, muestras de tejidos, secuenciación del 3'-5'COI, implementación de laboratorios moleculares de última generación, desarrollo de infraestructura física, entre otras. Las instituciones estatales, tales como la SENESCYT y otras, deberían efectuar para ello alianzas estratégicas con organismos tales como el CBOL, IBOL, Smithsonian Institute, University of Guelph, los cuales lideran a nivel mundial la generación de barcodes de la vida silvestre. Estos organismos/instituciones tienen fondos disponibles para estudios y proyectos de Barcoding; además, financian la implementación de laboratorios de biología molecular en los países donde se ha reconocido e incluido al Barcoding dentro de los programas de investigación prioritarios a nivel nacional.

Uno de los objetivos fundamentales sería que las instituciones estatales encargadas de incentivar la generación de bioconocimiento por sí mismas o en alianza con los organismos internacionales ya citados asignen un presupuesto exclusivo para proyec- tos de Barcoding; de esta manera se puede motivar a los investigadores ecuatorianos a desarrollar este campo de investigación: la generación de barcodes de la vida silvestre y a la vez formar y capacitar a nuevos talentos dentro de esta área pujante de la ciencia.

\section{Referencias}

Chase, M., N. Salamin, M. Wilkinson, J. Dunwell, R. Kesanakurthi, N. Haidar y V. Savolainen. 2005. Land plants and DNA barcodes: short-term and long-term goals. Phil. Trans. R. Soc. B. 360: 18891895.

Giangrande, A. 2003. Biodiversity, conservation, and the "taxonomic impediment". Aquatic Conservation: Marine and Freshwater Ecosystems. 13: 451-459.

Green, S. 1998. The taxonomic impediment in orthopteran research and conservation. Journal of Insect Conservation. 2: 151-159.

Hebert, P., A. Cywinska, S. Ball y J. de Waard. 2003a. Biological identification through DNA bar codes. Proc. R. Soc. B. 270: 313-321.

Hebert, P., S. Ratnasingham y J. de Waard. 2003b. Barcoding animal life: cytochrome oxidase subunit 1 divergences among closely related species. Proc. R. Soc. B. 270 (Suppl. 1): S96-S99.

Kim, K. y L. Byrne. 2006. Biodiversity loss and the taxonomic bottleneck: emerging biodiversity science. Ecological Research. 21: 794-810.

Lanteri, A. 2007. Código de Barras de ADN y sus posibles aplicaciones en el campo de la Entomología. Rev. Soc. Entomol. Argent. 66 (3-4): 15-25.

Mace, G. 2004. The role of taxonomy in species conservation. Philosophical Transactions of the Royal Society of London. B 359: 711-719.

Margules, C. y R. Pressey. 2000. Systematic conservation planning. Nature. 405: 243-253.

Moritz, C. y C. Cicero. 2004. DNA barcoding: promise and pitfalls. PloS. Biol. 2: 1529-1531.

Pérez-Schultheiss, J. 2009. Biodiversidad, Taxonomía y el Valor de los Estudios Descriptivos. Boletín de Biodiversidad de Chile. 1(1): 1-14. 
Pimm, S. y J. Lawton. 1998. Planning for biodiversity. Science. 279: 2068-2069.

Pimm, S. y P. Raven. 2000. Extinction by numbers. Nature. 403: 843-845.

Singh, J. 2002. The biodiversity crisis: a multifaceted review. Current Science. 82(6): 638-647.

Wilson, E. 2000. A global biodiversity map. Science. Yánez, P. 2014b. Un vistazo a la conservación Bio289: 2279.
Wilson, E. 2004. Taxonomy as fundamental discipline. Philosophical Transactions of the Royal Society of London. B 359: 739.

Yánez, P. 2014a. Ecología y biodiversidad: un enfoque desde el neotrópico. Quito: UNIBE/UIDE. página 172. lógica del Ecuador. Qualitas. 7: 80-84. 
DOI:10.17163/lgr.n23.2016.02

\title{
DESCRIPCIÓN DEL MANEJO DE SUELOS EN SISTEMAS DE PRODUCCIÓN AGRÍCOLA DEL SECTOR HAMACA DE ANZOÁTEGUI, VENEZUELA
}

\author{
DESCRIPTION OF SOIL MANAGEMENT IN AGRICULTURAL PRODUCTION \\ SYSTEMS OF SECTOR HAMACA IN ANZOÁTEGUI, VENEZUELA
}

Barlin Orlando Olivares*

Investigador. Programa de Doctorado en Ingeniería Agraria, Alimentaria, Forestal y del Desarrollo Rural Sostenible. Universidad de Córdoba (UCO), España. Teléfono: +58 4243173568; Fax: +58 2432692621

*Autor para correspondencia: barlinolivares@gmail.com

\begin{abstract}
Resumen
En el presente trabajo se aborda la descripción del manejo de suelos en los sistemas de producción agrícola a través del uso del método de Análisis de Componentes Principales (ACP), utilizando como paso particular el Sector Hamaca de la parroquia Atapirire, municipio Miranda del estado Anzoátegui. La metodología se fundamentó en las visitas al azar a veinte unidades de producción agrícola. El instrumento de recolección de información fue la encuesta estructurada. Mediante el ACP se seleccionaron los primeros cinco componentes que explican el $93 \%$ de la variación total. Se evidenció la poca rotación de cultivos, cultivos asociados en pequeñas áreas y ganadería extensiva. El manejo de suelos está orientado a la realización de las labores de cultivo en contenidos de humedad inadecuados; implementos poco adaptados al suelo, escasa presencia de residuos vegetales, quema de residuos y alto uso de enmiendas y agroquímicos.
\end{abstract}

Palabras claves: análisis de componentes principales, sustentabilidad, suelos. 


\begin{abstract}
In this paper the description of soil management is addressed in agricultural production systems through the use of the method of Principal Component Analysis (PCA) using as a particular step Sector Hamaca Atapirire parish, municipality Miranda State Anzoátegui. The methodology is based on random visits to twenty units of agricultural production. The data collection instrument was a structured survey. PCA by the first five components explained 93\% of the total variation was selected. The lack of crop rotation, intercropping in small areas and ranching are evident. Soil management is aimed at making the work of inadequate crop moisture content; implements ill-adapted to the ground, scarcity of plant residues, waste burning and amendments and high use of agrochemicals.
\end{abstract}

Keywords: principal component analysis, sustainability, soil.

Forma sugerida de citar: $\quad$ Olivares, B. 2016. Descripción del manejo de suelos en sistemas de producción agrícola del sector Hamaca de Anzoátegui, Venezuela. La Granja: Revista de Ciencias de la Vida. Vol. 23(1): 15-27. ISSN: 1390-3799. 


\section{Introducción}

Según estudios realizados por el Ministerio del Ambiente y los Recursos Naturales (2005), Venezuela cuenta con apenas $2 \%$ de su territorio de tierras sin limitaciones para el desarrollo agrícola, mientras que el $98 \%$ presenta alguna limitación bien sea por relieve, baja fertilidad, mal drenaje y aridez o escasez de lluvia. Esta condición hace que la actividad agrícola, si no es llevada bajo preceptos de sostenibilidad, genere procesos de degradación que desmejoran significativamente la calidad de las tierras.

En este orden de ideas, en el país se han venido desarrollando, un conjunto de sistemas de producción, que responde a las condiciones de clima y suelos de las diferentes áreas productivas; la mayoría de ellos altamente dependientes del periodo lluvioso, predomina el monocultivo con poca diversidad genética, y con prácticas de manejo generalmente deficiente, a lo cual se atribuyen los indicios de degradación y contaminación de suelos y aguas y la vulnerabilidad debido a la homogeneidad de los materiales genéticos, destacan en ese sentido los cultivos anuales mecanizados (cereales y oleaginosas), desarrollados en zonas planas de mediana a alta fertilidad.

Los suelos tropicales son intervenidos por el hombre para realizar actividades agrícolas o pecuarias, iniciándose los procesos de degradación, caracterizados por la pérdida de las propiedades físicas, químicas y biológicas que bajo condiciones naturales, los mantenían en equilibrio con los factores agresivos del medio ambiente (Pla, I, 1990; Rodríguez y J.C.Rey, 2004).

De acuerdo a los aportes de Pla, (1988), Pla, (1990), Mogollón y Comerma, (1994), Rodríguez et al., (1996), Fernández et al., (1998), Rodríguez y Rey, (2004), las tierras de uso agrícola están severamente degradadas debido a un uso excesivo de maquinarias e insumos (fertilizantes y pesticidas), entre otros aspectos; las necesidades crecientes de tierras para desarrollos urbanos e industriales se cubren muchas veces a costa de pérdidas de tierras de alta capacidad agrícola esto ha sucedido con la mayoría de las tierras de la Mesa de Guanipa.

Bajo los lineamientos del Proyecto Nacional Simón Bolívar (2007-2021), se establece en esta nueva etapa, las bases solidas para la evaluación de los ecosistemas de sabana, y la generación de tecnologías para su aprovechamiento, teniendo como fun- damento la preservación del medio ambiente y el uso racional de insumos. Obteniendo el desarrollo de proyectos orientados al estudio y generación de información que contribuyen a las mejoras de los sistemas agro-pastoriles o adopción de sistemas integrales que garanticen su sostenibilidad.

En la actualidad, el manejo sostenible de los suelos es una expresión cada vez más utilizada a nivel mundial para indicar, justamente, la excelencia en el tratamiento de las tierras con el propósito de obtener bienes y servicios de los ecosistemas sin comprometer el estado de sus recursos naturales renovables y su capacidad de resiliencia (Urquiza et al., 2011). Esta investigación desarrollada en el sector Hamaca, promueve la caracterización de experiencias claves para el desenvolvimiento de prácticas adecuadas para el recurso suelo. En términos generales el objetivo de este estudio es describir el manejo del suelo en unidades de producción agrícola ubicadas en el sector Hamaca de la parroquia Atapirire del municipio Francisco de Miranda, proporcionando una base racional para el uso y manejo sostenible de este recurso.

\section{Metodología}

\subsection{Descripción del área de estudio}

El sector Hamaca está ubicado en la parroquia Atapirire del municipio Francisco de Miranda, estado Anzoátegui; posee un extensión de 6.473 hectáreas, con un altitud de 356 m.s.n.m y de latitud: 8.43352 y longitud: $-64,3706$ (Figura 1). Posee un clima tropical lluvioso (Aw) con vegetación típica de sabana, de acuerdo al sistema de clasificación de Köppen (Strahler y Strahler, 1989). Esta localidad se encuentra al sur del estado Anzoátegui, el cual tiene una marcada estacionalidad de la precipitación, debida a la acción alternada de la zona de convergencia intertropical. El periodo lluvioso concentra más del $85 \%$ del total anual de precipitación, mientras que en los meses secos llueve muy poco; es muy frecuente que en los meses de febrero y marzo la lluvia registrada sea de cero milímetros (Caraballo et al., 2005).

Los suelos representativos de esta parte del municipio Francisco de Miranda presentan un pH ácido entre 4,0-5,1; contenidos de fósforo inferiores a los $(5 \mu g / g)$, calcio $(10-70 \mu g / g)$, magnesio (5-60 $\mu g / g)$, potasio $(10-30 \mu g / g)$, hierro $(0,5-30 \mu g / g)$, manganeso $(0,5-12 \mu \mathrm{g} / \mathrm{g})$, cinc $(0,1-1 \mu \mathrm{g} / \mathrm{g})$, bajos 


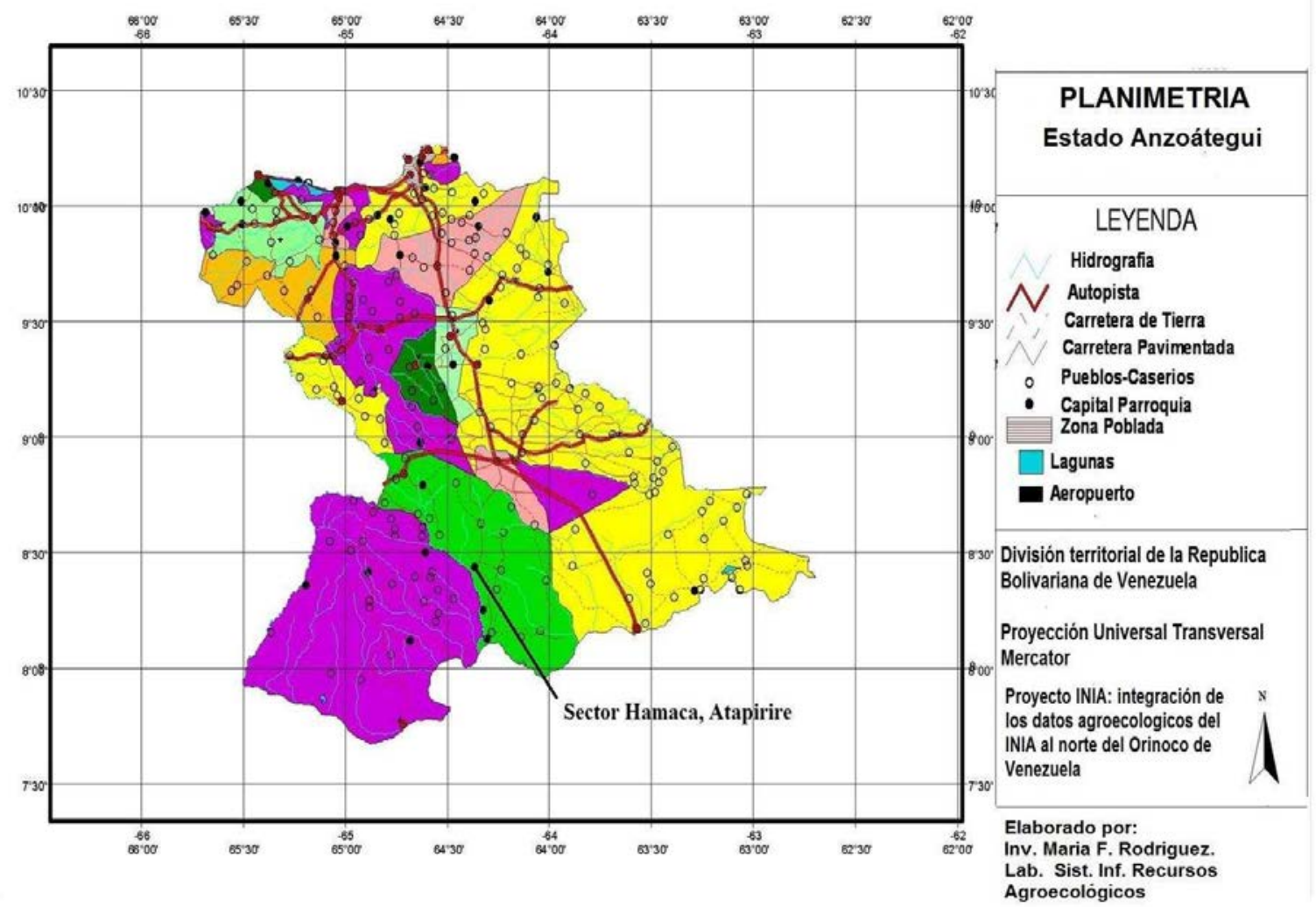

Figura 1. Ubicación del sector Hamaca, parroquia Atapirire del municipio Francisco de Miranda, Anzoátegui, Venezuela (Fuente: Rodríguez y Rey, 2004)

contenidos de Materia Orgánica (0,1-1,3\%), aluminio intercambiable entre $0,1-1 \mathrm{meq} / 100 \mathrm{~g}$ de suelo $\mathrm{y}$ conductividad eléctrica entre 0,1 y $0,3 \mathrm{ds} / \mathrm{m}$. Estos suelos corresponden a los órdenes Entisoles, Ultisoles y Oxisoles (grandes grupos Quartzipsamments, Kandiustuits y Haplustox).

La Figura 2 muestra la clasificación de tierras en el estado Anzoátegui, de acuerdo a su capacidad de uso según Comerma y Arias (1971). Dentro de las principales ventajas, Mogollón y Comerma (1994), Rodríguez et al., (1996), señalan las extensas áreas planas que no requieren de costosas inversiones en adecuación de tierras; los suelos livianos y profundos, de fácil mecanización, lo cual permite el cultivo de grandes áreas; suelos bien drenados, facilitando el ingreso de maquinarias al terreno poco tiempo después de ocurrir las lluvias; agua subterránea abundante y de buena calidad.

La vegetación típica de las sabanas, está repre- sentada por gramíneas y algunas especies arbustivas, por su ubicación dentro de la zona de vida conocida como bosque seco tropical (Holdridge, L, 1957). Esta vegetación es bastante pobre en cuanto a densidad, pero su composición es variada. Primeramente es de notar la escasez de vegetación alta, cuyas especies más importantes son las que se mencionan en la Tabla 1.

Tabla 1. Vegetación característica de las sabanas orientales, Anzoátegui, Venezuela.

\begin{tabular}{ll}
\hline \multicolumn{1}{c}{ Nombre vulgar } & \multicolumn{1}{c}{ Nombre científico } \\
\hline Chaparo curata & Curatela americana \\
Alcornoque & Bowdichia virgilioides \\
Tortolito & Casearia silvestris \\
Chaparro Manteco & Byrsonima crassifolia \\
Merey & Anacardium ocidentale \\
\hline
\end{tabular}



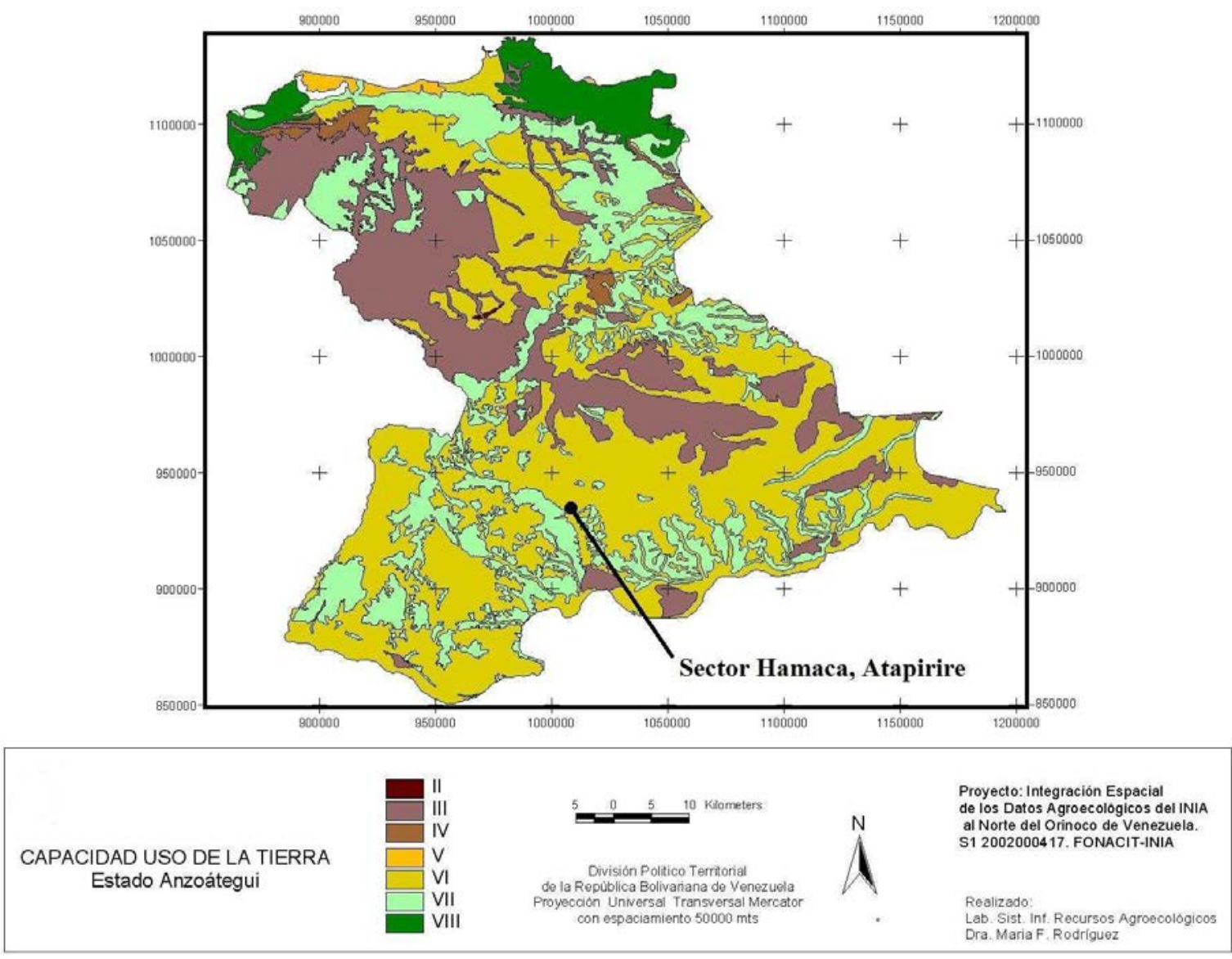

Figura 2. Capacidad de uso de las tierras en la Mesa de Guanipa, Anzoátegui. (Fuente: Rodríguez y Rey, 2004)

El relieve se caracteriza por la presencia de grandes extensiones planas, interrumpidas en la zona central por los bordes mesa, algunos de estos bordes mantienen su perpendicularidad, a pesar de estar sometidos a intensos procesos erosivos que han ido suavizando esta forma de relieve. También se puede decir que son llanuras disectadas, el paisaje predominante es la altiplanicie de la mesa disecta$\mathrm{da}$, con limitaciones de relieves quebrados que corresponden de relieves planos a relieves moderadamente disectados.

En general esta localidad pertenece a una de las zonas de importancia agrícola en el sur de Anzoátegui, este último es considerado uno de los estados venezolanos de gran relevancia para el desarrollo agrícola, tanto por su extensión como por el potencial de sus tierras, especialmente en las áreas de valles, planicies aluviales y mesas no disectadas. Las unidades de tierra de la zona de interés se encuentran bajo diferentes usos agropecuarios tales como:
Fríjol (Vigna sinensis), Maíz (Zea mays), Ganadería (pasto), Soya (Glicine max), Sorgo (Sorghum bicolor) y Yuca (Manihot esculenta) entre otros.

\subsection{Análisis multivariado por compo- nentes principales}

Los resultados de la información recolectada en las unidades de producción encuestadas fueron analizados mediante el Análisis de Componentes Principales (ACP), el cual representa una técnica matemática que no requiere un modelo estadístico para aplicar la estructura probabilística de los errores. Este análisis es aplicado cuando se desea conocer la relación entre elementos de una población y se sospecha que en dicha relación influye de manera desconocida un conjunto de variables o propiedades de los elementos (Pla, L, 1986; Demey et al., 1994, 1995; Ramos et al., 2004). 
(Demey et al., 1994) indican que mediante el ACP se pueden encontrar nuevas variables denominadas $Y(k), k=1, \ldots, p$; que sean combinaciones lineales de las variables originales $X(j)$, en el estudio de un conjunto de $(n)$ individuos, donde se le imponen a este sistema ciertas condiciones que permitan satisfacer los objetivos del análisis por componentes principales. Por su parte Pla (1986) señala en la Ecuación 1, que esto implica encontrar $(p \times p)$ constantes tales que:

$$
Y(k)=\sum_{j=1}^{p} l(j k) X(j) \quad k=1, \ldots, p .
$$

Donde $l_{(j k)}$ es cada una de esas constantes. Debido a la sumatoria, en cada nueva variable $Y_{(k)}$ intervienen todos los valores de las variables originales $X_{(j)}$. El valor numérico de la $l_{(j k)}$ indicará el grado de contribución que cada variable original aporta a la nueva variable definida por la transformación lineal. Puede expresarse la transformación lineal de componentes principales en términos matriciales: $Y_{(n \times p)}=X_{(n \times p)} L_{(p \times p)}$.

La metodología realizada se basó en técnicas de generación de datos, tanto cualitativos como cuantitativos, mediante una encuesta estructurada considerando características sociodemográficas y del ámbito legal o jurídico en la comunidad, con preguntas con respuestas indicadas binominalmente. El diseño de la encuesta se realizó siguiendo los lineamientos propuestos en distintos trabajos realizados en el área por investigadores tales como Letson et al., (2001), Eakin y Conley (2002) y Rivarola et al., (2002). Este estudio está referido a veinte productores y productoras responsables, encargados de las unidades de producción agrícola (10 encuestados en el primer semestre del 2013 y los otros 10 encuestados en el primer semestre del 2014). El Instrumento seleccionado para obtener la información fue el cuestionario, a través de la cual se recogieron datos para un total de 13 variables.

Las variables consideradas estuvieron relacionadas a dos aspectos, el primero relacionado con las características de producción y manejo de suelo en la finca: edad del fundo (EDF), superficie aprovechable (SUP), tipo de cultivo (TDC), asociación de cultivo (ADC), riego (RIE), asociación agriculturaganadería (GYA), tipo de maquinaria (MAQ), uso de maquinaria pesada (MPES), contenido de humedad adecuado para las labores de preparación de suelo (ChumA), aplica abono orgánico (AAO), practica la quema de residuos de cosecha (PQR), Conoce los productos biológicos (CPB), aplicación de productos biológicos (APB).

La matriz de datos $X$ está constituida por el conjunto de vectores de las observaciones $X_{[i j]}, j=$ $1, \ldots, p$ y donde cada vector $X_{[i j]}$ presenta la variable j-ésima para todas las observaciones y donde $X$, es la matriz de datos formada por " $n$ " observaciones con " $p$ " variables (20 observaciones por 13 variables estudiadas).

Utilizando el software Infostat versión 9.0 (2008), se generaron los valores propios y proporción de la varianza explicada calculada a partir de la matriz de correlación; la proporción de la variación original explicada por cada componente principal de la matriz de correlación o matriz de determinación. El mismo programa genera el gráfico tipo $X Y$ entre el primer y los demás componentes principales.

\section{Resultados y discusiones}

Para seleccionar el número de componentes a incluir se utilizó el criterio de Kaiser, que incluye sólo aquellos cuyos valores propios fueron mayores a 1 (Demey et al., 1994); en este estudio, el análisis muestra cinco componentes que explican el $93.0 \%$ de la variación, considerada como una proporción significativa del total, tal como se indica en la Tabla 2. Los componentes resultantes en este estudio representan el resultado de una combinación lineal de las variables en donde cada una tiene una ponderación diferente, en proporción a las magnitudes de cada elemento que conforma el autovector respectivo.

En función a lo descrito anteriormente, el primer componente es aquel que posee el mayor porcentaje de aporte a la varianza de la respuesta y en consecuencia explicitaría la mayor capacidad de los datos en el estudio, la cual es de $32.0 \%$ del total. $\mathrm{Al}$ revisar la matriz de correlación de las variables originales (Tabla 3) se observa que dos características que determinan la mayor variabilidad en este componente son: la práctica de quema de residuos con $46.0 \%$ y el uso de la maquinaria pesada para realizar la preparación de suelo (MPES) con un coeficiente de $41.0 \%$.

La mayoría de los productores encuestados manifestaron practicar la quema de residuos de cosecha en la zona. El fuego en las sabanas, puede ori- 
ginarse de manera natural o provocada como una práctica cultural, afecta anualmente parte importante de estas formaciones vegetales. En este orden de ideas, cierto tipo de sabanas presentan una capacidad de recuperación vigorosa después de sufrir los impactos causados por la quema, sin embargo algunas inspecciones en la zona de estudio evidenciaron que la recuperación de la vegetación se lleva a cabo de manera lenta. Por otra parte, en la actualidad ocurre un proceso progresivo de eliminación física de sabanas para dar lugar a potreros o áreas cultivables en la localidad bajo estudio.

Tabla 2. Valores propios y proporción de la varianza explicada calculada a partir de la matriz de correlación.

\begin{tabular}{cccc}
\hline Componente & Valor & Proporción & $\begin{array}{c}\text { Proporción } \\
\text { acumulada }\end{array}$ \\
\hline 1 & 4,14 & 0,32 & 0,32 \\
2 & 3,41 & 0,26 & 0,58 \\
3 & 2,04 & 0,16 & 0,74 \\
4 & 1,45 & 0,11 & 0,85 \\
5 & 1,01 & 0,08 & 0,93 \\
6 & 0,59 & 0,05 & 0,97 \\
7 & 0,28 & 0,02 & 0,99 \\
8 & 0,08 & 0,01 & 1,00 \\
\hline
\end{tabular}

Tabla 3. Correlaciones con las variables originales.

\begin{tabular}{lccccc}
\hline & \multicolumn{5}{c}{ Componentes Principales } \\
\cline { 2 - 6 } Variables & C1 & C2 & C3 & C4 & C5 \\
\hline EDF & $-0,2$ & $-0,44$ & $-0,04$ & 0,19 & $-0,26$ \\
SUP & $-0,13$ & $-0,18$ & $-0,41$ & 0,57 & 0,02 \\
TDC & 0,25 & 0,05 & $-0,35$ & 0,22 & 0,52 \\
ADC & 0,11 & $-0,31$ & 0,19 & $-0,52$ & 0,05 \\
RIE & $-0,18$ & 0,37 & 0,22 & 0,06 & 0,45 \\
MAQ & 0,02 & 0,46 & $-0,26$ & $-0,12$ & $-0,34$ \\
GYA & 0,25 & 0,22 & 0,41 & 0,2 & 0,24 \\
MPES & 0,41 & $-0,09$ & 0,25 & 0,27 & $-0,14$ \\
CHumA & $-0,34$ & 0,33 & 0,13 & 0,15 & $-0,2$ \\
AAO & $-0,41$ & 0,09 & $-0,25$ & $-0,27$ & 0,14 \\
PQR & 0,46 & $-0,03$ & $-0,19$ & $-0,11$ & $-0,1$ \\
CPB & $-0,22$ & $-0,06$ & 0,44 & 0,27 & $-0,19$ \\
APB & $-0,25$ & $-0,39$ & 0,11 & $-0,04$ & 0,41 \\
\hline
\end{tabular}

Con relación al segundo componente, este explica un $26.0 \%$ de la variabilidad total, relacionado con el riego $(37.0 \%)$ y el contenido de humedad del suelo al momento de hacer las labores en campo (33.0\%). De acuerdo a lo anterior, el riego por medio del pivote central en esta zona y en otras de la Mesa de Guanipa solo es utilizado por aquellos productores con grandes extensiones de tierras cultivadas, por lo general cereales y leguminosas. Por su parte, los productores que desarrollan la agricultura de secano están sujetos a los periodos de disponibilidad de humedad en la zona, sin embargo, la mayoría de los entrevistados manifestaron que realizan la preparación de suelos incluso fuera de los periodos de humedad adecuados para estas condiciones de clima, esto se debe principalmente a el retraso en los créditos agrícolas por medio de los organismos oficiales y en ocasiones por desconocimiento del régimen de lluvias en el área de estudio o incluso por la variabilidad natural de la precipitación.

En la Figura 3a, se muestran las variables asociadas a los dos primeros componentes, entre las cuales las variables: uso de maquinaria pesada y la quema de residuos son las que mayormente intervienen en esta asociación.

El tercer componente interpreta el $16.0 \%$ de la variabilidad total. Esta referido a la variable asociada al conocimiento de los productos biológicos para el manejo de cultivo (44.0\%) y la asociación de la agricultura con la ganadería $(41.0 \%)$. En la relación con el uso agrícola, los principales cultivos anuales que han desarrollado en la zona de estudio son: Sorgo (Sorghum vulgares L.) Maní (Arachis hipogea L), Caraota (Phaseolus vulgaris), Patilla (Citrullus lanatus), así como algunas hortalizas en zonas cercanas a ríos y morichales, en la actualidad solo la patilla y la yuca es considerado un cultivo rentable. La superficie sembrada ha disminuido drásticamente en algunos casos y en otros se ha dejado de sembrar totalmente. La falta de recursos económicos y problemas en la comercialización, han sido las causas principales de la casi desaparición de la actividad agrícola en la zona.

En la Figura 3b, se muestran las variables asociadas al primer componente y su relación con el tercer componente. La problemática ya descrita ha obligado a los productores a apoyarse en la ganadería, por tener esta región mayor capacidad de ajuste a los vaivenes económicos y políticas del estado. Esto plantea la necesidad de establecer pastizales al menor costo posible. 

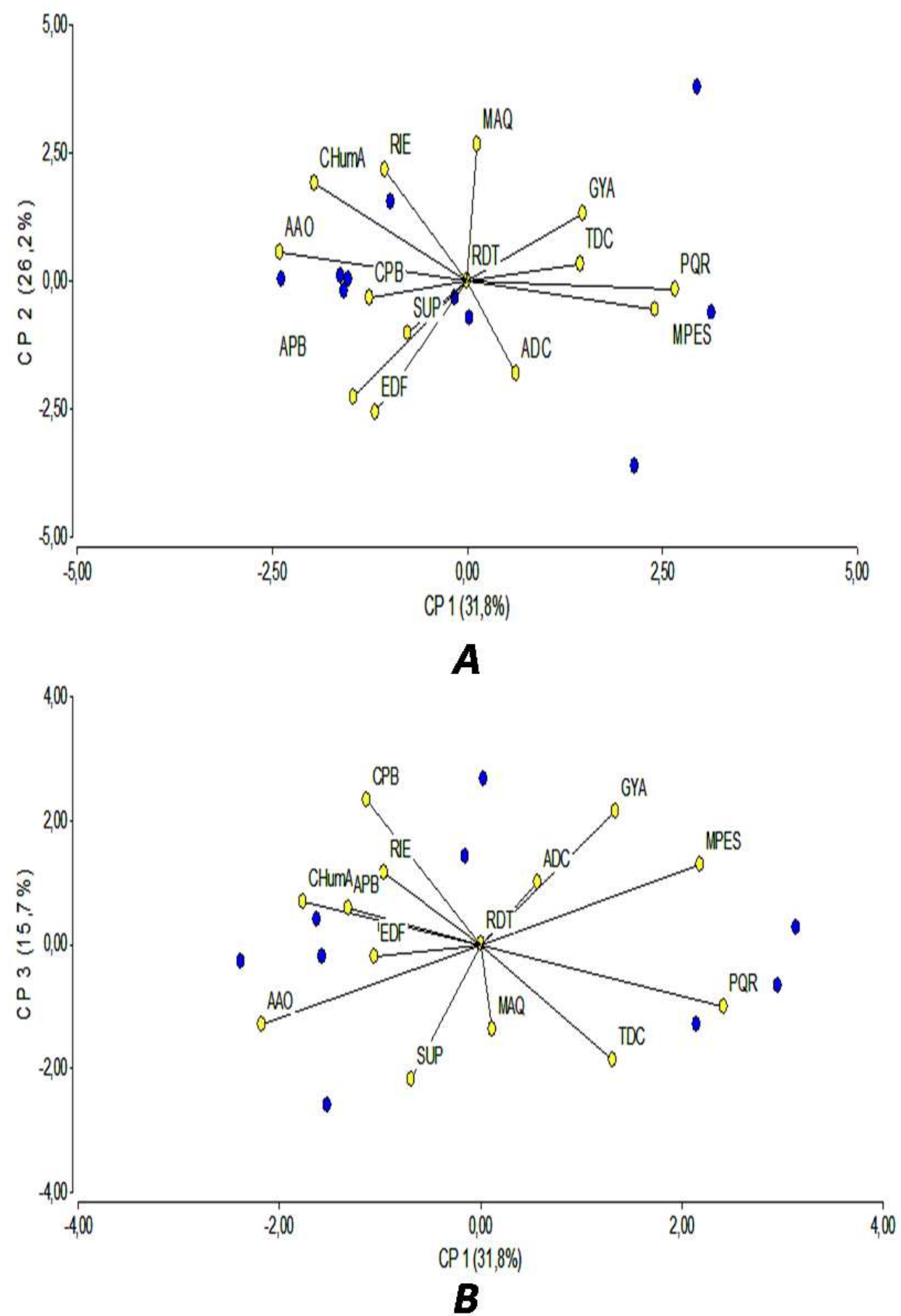

Figura 3. Representación bivariada de las variables asociadas a los dos primeros componentes principales. (A). primer y segundo componente. (B). primer y tercer componente. 


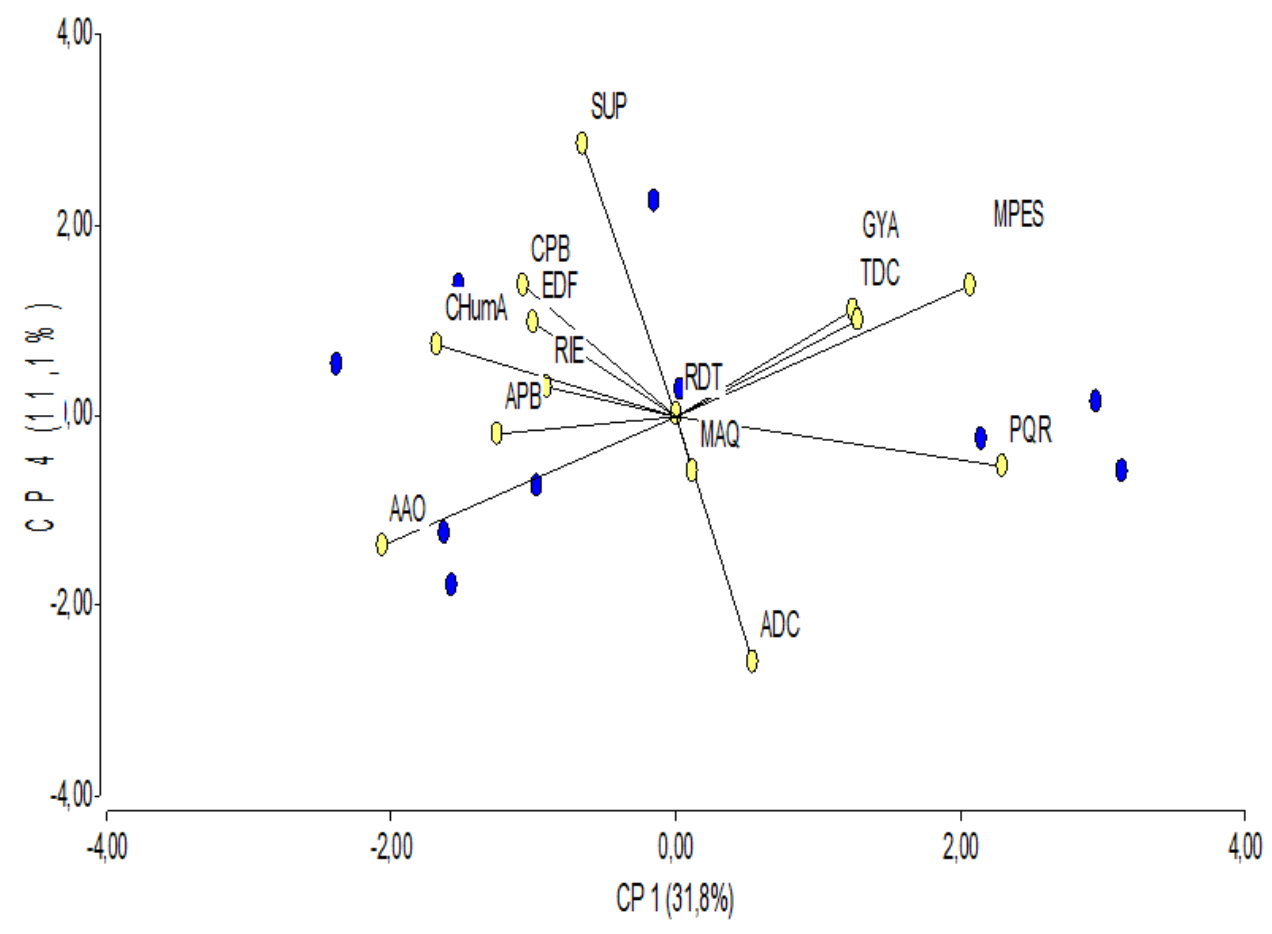

$\boldsymbol{A}$

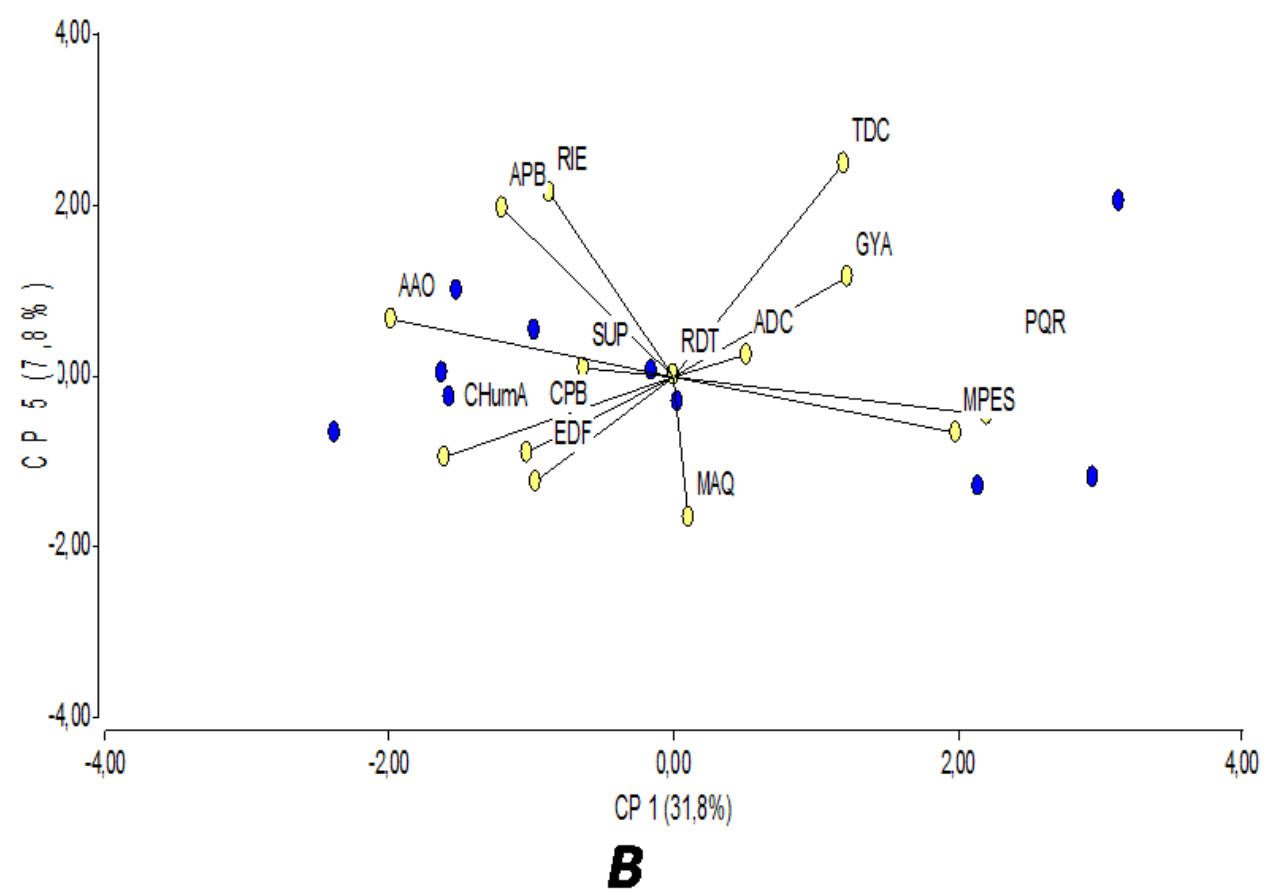

Figura 4. Representación bivariada de las variables asociadas del primer componente. A. primer y cuarto componente. B. primer y quinto componente. 
Actualmente las explotaciones pecuarias representan el uso más generalizado de la tierra y se utilizan principalmente las especies nativas que tienen baja capacidad de carga animal como fuente de alimentación. Sin embargo, los productores de mayores recursos han introducido especies forrajeras $\mathrm{CO}^{-}$ mo: suazi (Digitaria swazilandensis), Barrera (Brachiaria decumbens), Brizantha (Brachiaria Brizantha), pasto aguja (Brachiaria humidicola).

El cuarto componente representa un $11.0 \%$ de la variabilidad total. Se presenta con valor positivo las variable asociada a la superficie aprovechable (57.0\%). Por lo general en el área de estudio las superficies aprovechables van desde 100 a 200 ha.

Las sabanas orientales, son el asiento de la actividad ganadera. Es en ella donde se practica la ganadería extensiva; es decir, la cría de ganado vacuno en grandes extensiones de tierra. Este tipo de ecosistema se caracteriza por presentar un tipo de vegetación integrada por variedades de gramíneas que constituyen el alimento natural (pastos) del ganado. Sin embargo, la riqueza alimentaria de algunas de ellas es baja, esto es debido a la pobreza de los suelos. Tal característica, asociada al tipo de ganadería que se practica; es decir, la extensiva o tradicional, hace necesaria la existencia de grandes extensiones de terreno para la alimentación de los rebaños, porque deben pastar libremente. Por eso, se pueden observar latifundios, es decir, grandes extensiones de tierra en manos de un propietario.

Por último, el quinto componente explica el $8.0 \%$ de la varianza total, referido a la variable: Tipo de cultivo $(52.0 \%)$ y la aplicación de productos biológicos (41.0\%). En su mayoría, los sistemas de producción de la zona son agrícolas, desarrollando diferentes cultivos y gramíneas para la alimentación animal.

Las Figuras 4a y 4b, muestran que los sistemas de producción están representados por un conjunto de actividades agrícolas, pecuarias y no agrícolas. Por lo tanto, pueden ser caracterizados como una combinación de diversos subsistemas en Atapirire. En primer lugar, los sistemas de cultivos: definidos al nivel de las parcelas, explotadas de manera homogénea, con las mismas tecnologías y sucesiones de cultivos. También los sistemas de crianza, definidos al nivel de los hatos o rebaños, incluyendo los sistemas de transformación, representados por los productos agropecuarios (transformación de cereales, fabricación de quesos, entre otros); y por último, las actividades no agrícolas: pequeños negocios, ar- tesanía, venta de fuerza de trabajo en la ciudad, y las actividades domésticas que contribuyen a la reproducción del sistema de producción.

Los distintos componentes se resumen en la (Tabla 4), de acuerdo a su importancia y significación. En términos generales se puede observar que a medida que la proporción de la varianza se aleja del componente principal, es explicado en un sentido amplio por las variables más relevantes de los componentes. En síntesis, del análisis de la matriz de correlación entre las variables originales y los componentes principales, se puede observar que los valores más altos del primer componente, son los que determinan la precisión con respecto al manejo de suelos en las unidades de producción del Sector Hamaca.

En función a lo anterior Pla (1988) señala que se requiere urgente decisiones en cuanto al uso racional de la tierra, tanto de nuevos desarrollos agrícolas como cuando se requiera introducir cambios en su uso y manejo. Estas decisiones deben basarse en medios efectivos para evaluar y manejar los limitados recursos de suelos aptos para la agricultura en Venezuela.

De acuerdo a Rodríguez et al., (1996) En la región de estudio no hay tradición en el uso de sitemas agropastoriles, lo común ha sido una división evidente entre el agricultor y el ganadero. El primero se ha dirigido hacia el monocultivo, con utilización intensiva de abonos, plaguicidas, el maquinismo y un pequeño número de especies y de variedades vegetales; mientras que el segundo ha sustentado su explotación en los pastos nativos y/o cultivados. Sin embargo, se han observado experiencias como: el establecimiento de pastas mediante siembra simultánea con cultivos como sorgo y maíz, que ha resultado una práctica muy común en la región; y la siembra de merey intercalado con pastos del género Brachiaria.

$\mathrm{Al}$ analizar la crisis del sector agropecuario estatal, y evaluar la permanencia de los sistemas de producción, se hace evidente que una de las explotaciones que han sobrevivido a ella es la ganadería bovina para carne, que es una de las más importantes y constituye la opción más favorable a tenerse en cuenta en un sistema de producción agropastoril.

El uso y manejo sostenible del suelo deben mantener la potencialidad biofísica del suelo y al mismo tiempo permitir la diversificación del sistema agrícola de explotación considerándose, en primer lugar la expansión de la superficie agrícola, la intro- 
Tabla 4. Interpretación de los primeros cuatro componentes principales vía matriz de correlación (R).

\begin{tabular}{lcl}
\hline Componente & $\begin{array}{c}\text { Porcentaje de } \\
\text { explicación }\end{array}$ & Interpretación \\
\hline $\begin{array}{l}\text { Primero } \\
\text { Segundo }\end{array}$ & 32.0 & Uso de maquinaria pesada y la quema de residuos \\
Tercero & 16.0 & $\begin{array}{l}\text { Aso del riego y contenido de humedad adecuado del suelo para las la- } \\
\text { bores agrícolas }\end{array}$ \\
buarto & 11.0 & $\begin{array}{l}\text { Superficie aprovicos para el manejo de cultivo } \\
\text { Quinto }\end{array}$ \\
\hline
\end{tabular}

Total de varianza $\quad 93.0 \%$

ducción de variedades mejoradas, el uso de técnicas de riego, la aplicación de fertilizantes orgánicos y biofertilizantes y por último, la racionalización de prácticas de laboreo fundamentalmente.

Las altas aplicaciones de fertilizantes y enmiendas, junto al control de plagas y enfermedades, han sido aspectos de los paquetes tecnológicos que han dado lugar a un uso elevado de agrotóxicos e intensiva mecanización agrícola, generando problemas de degradación de suelos en el oriente venezolano (Torres et al., 2005). La aplicación de fertilizantes nitrogenados y fosfatados inorgánicos de forma excesiva inhiben los procesos que sustentan la fertilidad natural de los suelos, mientras que el manejo agroecológico puede favorecerlos (España et al., 2006, López et al., 2007; Toro et al., 2008, López, 2010); lo cual permite a los cultivos expresar mecanismos tales como exudación de ácidos orgánicos, activación de enzimas como la fosfatasa ácida y cambios en el $\mathrm{pH}$ del suelo, mejoras en la estructura del suelo, entre otros (López et al., 2010).

Es importante señalar que cualquier suelo puede soportar cualquier tipo de uso agrícola siempre que se le suministren los inputs necesarios (Rodríguez et al., 1996). Éstos pueden ser de tal magnitud que determinen las condiciones básicas de explotación, ya que cada unidad de tierra cuenta con sus propias potencialidades y limitaciones y cada tipo de uso con sus propios requerimientos biofísicos. Puesto que el objetivo fundamental en la protección del suelo es minimizar costos socio-económicos y ambientales mediante la predicción de la capacidad inherente de cada unidad de tierra para soportar el uso y manejo específicos durante un largo plazo de tiempo sin causar deterioro. La protección del suelo requiere mejorar el uso agrícola del mismo a través de la planificación y el manejo sostenibles (De la Rosa et al., 2004, López et al., 2010).

\section{Conclusiones}

De acuerdo a la información suministrada por los productores en la Mesa de Guanipa, el manejo del suelo se desarrolla en función a las limitaciones o están relacionadas con la textura arenosa de sus primeros horizontes, lo que implica que estos suelos presentan bajo contenido de elementos químicos esenciales como $\mathrm{Ca}, \mathrm{Mg}, \mathrm{K}$ y $\mathrm{P}$, lo cual representa la justificación por la aplicación excesiva de fertilizantes y de enmiendas, así mismo, los suelos de esta región mayormente son de reacción acida y de baja capacidad de retención de humedad, lo cual genera como mayor consecuencia la disminución de la eficiencia de la fertilización que realizan dichos productores. Se observó en los recorridos realizados en las unidades de producción que los suelos presentan débil estructura, bajo contenido de materia orgánica, que en conjunto con las condiciones climáticas de fuertes lluvias y vientos, facilitan los procesos de encostramiento, escurrimiento superficial y erosión hídrica en las zonas con poca o escasa cobertura vegetal.

De acuerdo a las entrevistas, se determinó que estos suelos de las sabanas orientales presentan cierta susceptibilidad a la compactación del subsuelo específicamente, debido en esencia tanto a las propiedades físicas como al uso excesivo de maquinarias y presencia de grava en horizontes cercanos a la superficie. Esto genera principalmente problemas con la facilidad de penetración del sistema radical 
en las plantas. En general la actividad tanto agrícola como pecuaria en la Mesa de Guanipa no ha sido manejada de manera correcta debido a la falta de asistencia técnica o capacitación dirigida a los productores, sin embargo las políticas gubernamentales que se han llevado a cabo en la última década han estado enmarcadas en tener una agricultura sustentable donde el hombre así como también el ambiente, se benefician de la mejor manera, es decir, utilizando productos biológicos tale como: (humus, Trichoderma sp, bacterias antagonistas, extractos naturales, entre otros) logrando de esta manera la obtención de alimentos más saludables para el consumo humano.

\section{Referencias}

Caraballo, L., M. Pérez y M. Marcano. 2005. Régimen y distribución de las lluvias en El Tigre, estado Anzoátegui, Venezuela. Boletín Geominas. 3(37): 67-72.

Comerma, J. y L. F. Arias. 1971. Un sistema para evaluar las capacidades de uso agropecuario de los terrenos en Venezuela. En: I Seminario sobre clasificación interpretativa de suelos con fines agropecuarios. Sociedad Venezolana de la Ciencia del Suelo (Mimeografiado). Maracay.

De La Rosa, D., F. Mayol, E. Díaz-Pereira, M. Fernández y D. Jr. De La Rosa. 2004. A land evaluation decision support system (MicroLEIS DSS) for agricultural soil protection. Environmental Modelling \& Software. (19): 929-942. URL: www.micoleis.com, Consulta: 18 de abril de 2011.

Demey, J., Y. Prada y L. Pla. 1995. Grupo de estaciones con patrones homogéneos de precipitación del estado Falcon-Venezuela. Agronomía Trop. 45(1): 95-120. URL: http:/ /sian.inia.gob.ve/repositorio/revistas_ci/ Agronomia\%20Tropical/at4501/arti/demey_j .htm, Consulta: 07 de febrero de 2011.

Demey, J. R., M. Adams y H. Freites. 1994. Uso del método de análisis de componentes principales para la caracterización de fincas agropecuarias. Agronomía Trop. 44(3): 475-497. URL: http:/ /sian.inia.gob.ve/repositorio/revistas_ci/ Agronomia\%20Tropical/at4403/Arti/demey_j .htm, Consulta: 07 de febrero de 2011.
Eakin, H. y J. Conley. 2002. Climate variability and the vulnerability of ranching in southeastern Arizona: a pilot study. Clim Res. (21): 271-281.

España, M., E. Cabrera de Bisbal y M. López. 2006. Study of nitrogenfixation by tropical legumes in acid soil from venezuelan savannas using $15 \mathrm{~N}$. Interciencia. 31(3): 197-201.

Fernández, F. y J. Rey. 1998. Aplicación de un sistema informático integrado la evaluación de la degradación medio ambiental el trópico. Maracay. Venezuela. Memorias: 117.

Holdridge, L. 1957. Determination of world plant formation from simple climatic data. Science. 105(27): 367-368.

Infostat. 2008. Infostat for Windows Version 9.0. Grupo Infostat. Inc. Facultad de Ciencias Agricolas. Universidad. Nacional de Córdoba. Argentina.

Letson, D., I. Llovet, G. Podesta, F. Royce, V. Brescia, D. Lema y G. Parellada. 2001. User perspectives of climate forecast: crop producers in Pergamino, Argentina. Clim Res. (19): 57-67.

López, M., I. López de Rojas, M. España, A. Izquierdo y L. Herrera. 2007. Efecto de la fertilización inorgánica sobre la disponibilidad de nutrimentos en el suelo, nivel nutricional de la planta y hongos micorrizícos arbusculares en plantaciones de Theobroma cacao L. Agronomía Trop. 57(1): 31-43.

López, M., B. Rodríguez y M. España. 2010. Tecnologías generadas por el Inia para contribuir al manejo integral de la fertilidad del suelo. Agronomía Tropical. 60(4): 315-330.

López, M. 2010. Manejo agroecológico del sistema sorgo-frijol. Efecto sobre la fertilidad del suelo y microorganismos con potencial para biofertilizar agroecosistemas venezolanos. Tesis de doctorado. Postgrado en Ciencia del Suelo. Maracay, Ven. Universidad Central de Venezuela. página 210.

Ministerio del Ambiente y los Recursos Naturales (MARN). 2005. Primera Comunicación Nacional en cambio climático de Venezuela. Programa de las naciones unidas para el desarrollo. Fondo Mundial para el medio ambiente: 135. 
Mogollón, Y. y J. Comerma. 1994. Suelos de Venezuela. Editorial Exlibris. Maracay. Venezuela.

Pla, I. 1990. La degradación y el Desarrollo agrícola de Venezuela. Agronomía Tropical. 40: 7-27.

Pla, I. 1998. Desarrollo de índices y modelos para el diagnóstico y prevención de la degradación de suelos agrícolas en Venezuela. Ediciones Banco Consolidado. Caracas Venezuela. página 40.

Pla, L. 1986. Análisis multivariado: método de componentes principales. Departamento de asuntos científicos y tecnológicos. Organización de Estados Americanos. Washington, D.C. EE.UU. página 97.

Ramos, C., M. A. Gomez y A. De Ascencao. 2004. Caracteres morfológicos determinantes en dos poblaciones de cacao criollo del occidente de Venezuela. Agronomía Trop. 54(1): 45-62. URL: http:/ / www.scielo.org.ve/scielo.php?script=sci_ arttext\&pid=S0002-192X2004000100004\&lng=es\& nrm=iso, Consulta: 20 de abril de 2011.

Rivarola, A., M. Vinocur y R. Seiler. 2002. Uso y demanda de información agrometeorológica en el sector agropecuario del centro de la Argentina. Rev. Arg. De Agrometeorología. 2(2): 143-149.

Rodríguez, M. y J.C.Rey. 2004. Delimitación de zonas frágiles de Venezuela. (Mimeografiado). INIA-CENIAP. página 11.

Rodríguez, T., D. Sanabria y L. Navarro. 1996. Nuevos enfoques en el Manejo de Sabanas en los Llanos Orientales Venezolanos. Centro de Investigaciones Agropecuarias del Estado Anzoátegui. Rev. Divulga. 52. URL: http://sian.inia.gob.ve/repositorio/revistas_tec/ FonaiapDivulga/fd52/sabanas.htm, Consulta: 20 de abril de 2011.

Strahler, A. y A. Strahler. 1989. Geografía Física. España: Editorial Omega S.A. Tercera Edición.

Toro, M., I. BazóÂ y M. López. 2008. Micorrizas arbusculares y bacterias promotoras del crecimiento vegetal, biofertilizantes nativos de sistemas agrícolas bajo manejo conservacionista. Agronomía Trop. 58(3): 215-221.

Torres, R., A. FlorentinoÂ y M. López. 2005. Pérdidas de suelo y nitrógeno por escorrentía en un Ultisol degradado bajo diferentes condiciones de cobertura vegetal en Chaguaramas-Guárico. Agronomía Trop. 55(4): 475-496.

Urquiza, N., C. Alemán, L. Flores, M. Ricardo y Y. Aguilar. 2011. Manual de procedimientos para manejo sostenible de tierras. Cuba: Editorial CIGEA. 


\title{
ANÁLISIS Y REVISIÓN DE LA RED DE MONITOREO DE CALIDAD DEL AIRE DE LA CIUDAD DE CUENCA, ECUADOR
}

\author{
ANALYSIS AND REVIEW OF THE AIR QUALITY MONITORING NETWORK, IN \\ CUENCA CITY, ECUADOR
}

\author{
Rubén Jerves*, Freddy Armijos-Arcos**
}

Grupo de Investigación de Biotecnología Ambiental INBIAM, Universidad Politécnica Salesiana, Calle Vieja 13-30 y Elia Liut, 59372862213.

*Autor para correspondencia: rjerves@ups.edu.ec*,f.armijos.arcos@gmail.com**

Manuscrito recibido el 8 de julio de 2014. Aceptado, tras revisión, el 14 de marzo de 2016

\section{Resumen}

El presente artículo analiza la estructura y conformación de la Red de Monitoreo de Calidad del Aire de Cuenca respecto a estándares, normas y recomendaciones nacionales e internacionales, incluyendo sus métodos de monitoreo, y la idoneidad o no del emplazamiento de las actuales estaciones de monitoreo, ofreciendo recomendaciones para mejorar la representatividad de las mismas.

Palabras claves: estaciones meteorológicas, red de monitoreo, calidad del aire, Cuenca

\begin{abstract}
The following article analyze the structure and conformation of the Air Quality Monitoring Network of Cuenca, comparing them with national and international standards, laws and recommendations; this includes monitoring methods, site criteria fulfillment of monitoring stations and recommendations to improve this spacial representation.

Keywords: meteorological stations, monitoring network, air quality, Cuenca

Forma sugerida de citar: Jerves, R. y F. Armijos. 2016. Análisis y revisión de la red de monitoreo de calidad del aire de la ciudad de Cuenca, Ecuador. La Granja: Revista de Ciencias de la Vida. Vol. 23(1): 28-38. ISSN impreso: 1390-3799. ISSN electrónico: 1390-8596.
\end{abstract}




\section{Introducción}

La ciudad de Cuenca, se encuentra al sur de los Andes del Ecuador a una altura de $2550 \mathrm{~m}$ sobre el nivel del mar, su población es de aproximadamente 400000 habitantes, y su area urbana corresponde a $84.6 \mathrm{~km}^{2}$.

El principal objetivo de la Red de Monitoreo de Cuenca es determinar la calidad del aire en la ciudad y compararla con normas y recomendaciones nacionales e internacionales. La Red de Monitoreo permite establecer programas generales y específicos para mejorar la calidad del aire en la ciudad así como comparar los resultados registrados con los obtenidos en ciudades de similares características. La calidad del aire en una ciudad como Cuenca depende de diferentes factores como distancia a las principales fuentes emisoras, emisiones, topografía y meteorología. Sin embargo no es fácil seleccionar estaciones de monitoreo que den una representación de la calidad del aire en la ciudad. El presente artículo analiza la estructura y conformación de actual Red de Monitoreo, acorde a la metodología propuesta.

\section{Metodología}

El planteamiento básico al establecer estaciones de monitoreo es seleccionar ambientes típicos y característicos de diferentes partes de la ciudad; de manera que, cada estación de medición obtenga datos que representen zonas de similares características. Otro aspecto a considerar es la meteorología de manera especial la dirección y velocidad de los vientos que son los que influyen en la distribución y dispersión de los contaminantes.

Una vez definidas las características de la ciudad, el análisis se centra en la estructura y conformación de la actual Red de Monitoreo instalada en la ciudad de Cuenca en base a los siguientes criterios: 1) los contaminantes analizados; 2) los métodos de monitoreo; 3) la escala de representación espacial; y 4) los criterios de emplazamiento y operación.

Para ello se analiza la metodología dada por la Agencia de Protección Ambiental de los Estados Unidos, US-EPA, descrita en el documento 40 CFR Parte 58 anexos D y E para el diseño de redes de monitoreo del recurso aire (US-EPA, 2007a;US-EPA, 2007b), la metodología de la Agencia Ambiental de la Unión Europea, EEA, descrita en el reporte técnico No. 12 "Monitoreo de la Calidad del Aire y Redes de Información" (EEA, 1999); referente a los métodos de monitoreo y sus características, se consideraron las recomendaciones establecidas por la Organización Mundial de la Salud (OMS) en la Actualización Global del 2005 de los Lineamientos para la Calidad del Aire (WHO, 2006) y en el Informe de Monitoreo de la calidad del aire para la Evaluación del impacto en la salud (WHO, 1999), y referente a la operación y mantenimiento a lo establecido en el Manual de Aseguramiento de Calidad para Sistemas de Medición de la Contaminación del Aire de la US-EPA (US-EPA, 2013).

Los niveles de concentración de los contaminantes en el aire que se analizan en la ciudad de Cuenca son Dióxido de Azufre $\mathrm{SO}_{2}$, Dióxido de Nitrógeno $\mathrm{NO}_{2}$, Ozono $\mathrm{O}_{3}$, Material Particulado $P M_{10}$ y $P M_{2,5}$, Partículas Sedimentables $P S$, Compuestos Orgánicos Volátiles COV, y Monóxido de Carbono CO (Red de Monitoreo de Calidad del Aire, 2015).

Los métodos de monitoreo pueden ser divididos en cuatro tipos, los cuales cubren una amplio rango de costos y niveles de precisión, elegir incorrectamente puede llevar a una complicación innecesaria del sistema, un pobre rendimiento de la red, una limitada utilidad en los datos y una pérdida de dinero (WHO, 1999). La Tabla 1 muestra los diferentes métodos de monitoreo.

La escala de representación espacial se definen para cada uno de los contaminantes acorde a la legislación ecuatoriana (MAE,2014), las escalas establecidas (US-EPA, 2007b) se muestran en la Tabla 2 .

En lo relacionado a los criterios de microemplazamiento de cada monitor se analizan los requisitos de población, concentración del contaminante, distancias de separación entre las vías de tráfico y los monitores, altura desde el suelo al analizador, distancia horizontal y vertical de las estructuras de apoyo al analizador, distancia de árboles u otros obstáculos hacia el analizador y espacio libre al ingreso del monitor frente a las condiciones de monitoreo actuales, además de las recomendaciones para operación y mantenimiento establecidas en (US-EPA, 2007a) y las recomendaciones específicas de los fabricantes de los equipos de la red de monitoreo utilizada en Cuenca. 
Tabla 1. Métodos de Monitoreo

\begin{tabular}{|c|c|c|}
\hline MÉTODO & VENTAJAS & DESVENTAJAS \\
\hline \multirow[t]{6}{*}{$\begin{array}{l}\text { Muestreadores } \\
\text { pasivos }\end{array}$} & $\begin{array}{l}\text { Muy Bajo Costo-10 a } 70 \text { USD por } \\
\text { muestreador- }\end{array}$ & $\begin{array}{l}\text { No validados para algunos contami- } \\
\text { nantes }\end{array}$ \\
\hline & Instalación Sencilla & Sólo proveen promedios mensuales o \\
\hline & No depende de fuentes de energía eléc- & semanales \\
\hline & trica & El análisis de laboratorio y ubicación \\
\hline & Pueden ser instaladas en gran número & $\begin{array}{l}\text { de muestreadores conlleva campañas } \\
\text { intensas }\end{array}$ \\
\hline & & $\begin{array}{l}\text { Las bases de datos de resultados se } \\
\text { actualizan con lentitud }\end{array}$ \\
\hline \multirow{5}{*}{$\begin{array}{l}\text { Muestreadores } \\
\text { activos }\end{array}$} & Bajo Costo -1000 a 3000 USD por mues- & Provee promedios diario \\
\hline & treador instalado- & El análisis de laboratorio y ubicación \\
\hline & Fácil Operación & de muestreadores conlleva campañas \\
\hline & Permite bases de datos históricas & intensas \\
\hline & & $\begin{array}{l}\text { Las bases de datos de resultados se } \\
\text { actualizan con lentitud }\end{array}$ \\
\hline \multirow{5}{*}{$\begin{array}{l}\text { Analizadores } \\
\text { automáticos }\end{array}$} & Validados para varios parámetros & Complejos \\
\hline & Alto rendimineto & Costo Elevado -10000 a 15000 USD \\
\hline & Provee datos horarios & por analizador- \\
\hline & Las bases de datos de resultados pue- & Requiere personal calificado \\
\hline & den ser provistas vía on-line & $\begin{array}{l}\text { Altos costos recurrentes - } \\
\text { mantenimiento, calibración, operación- }\end{array}$ \\
\hline \multirow{5}{*}{$\begin{array}{l}\text { Sensores } \\
\text { remotos }\end{array}$} & Mediciones de multiples parámetros & Muy complejos y costosos -alrededor \\
\hline & Proporciona una amplia gamma de re- & de 100000 USD- \\
\hline & sultados & Soporte, Operación, Calibración y Vali- \\
\hline & Útiles, incluso ante fuentes contami- & \\
\hline & nantes cercanas & $\begin{array}{l}\text { No suelen servir como método de refe- } \\
\text { rencia para el cumplimiento de niveles } \\
\text { de inmisión a largo plazo }\end{array}$ \\
\hline
\end{tabular}

Tabla 2. Escalas de Monitoreo

\begin{tabular}{ll}
\hline \multicolumn{1}{c}{ ESCALA } & \multicolumn{1}{c}{ REPRESENTACIÓN ESPACIAL } \\
\hline Micro-escala & Representa un área de 0 a 100 metros a la redonda. \\
Escala Media & Representa un área desde $100 \mathrm{~m}$ hasta $0.5 \mathrm{~km}$. \\
Escala Vecinal & Usos de suelos uniformes, representa áreas desde $0.5 \mathrm{~km} \mathrm{a} 4.0 \mathrm{~km}$ a la redonda \\
Escala Urbana & $\begin{array}{l}\text { Representa áreas desde } 4.0 \mathrm{~km} \text { hasta } 50 \mathrm{~km} \text { dentro de una ciudad. } \\
\text { Escala Regional }\end{array}$ \\
& $\begin{array}{l}\text { Define usualmente un área rural de razonables características geográficas simi- } \\
\text { lares, sin grandes fuentes de emisión y que se extiende de decenas a centenas } \\
\text { de kilómetros. }\end{array}$ \\
\hline
\end{tabular}


Figura 1. Usos del Suelo de la Ciudad de Cuenca

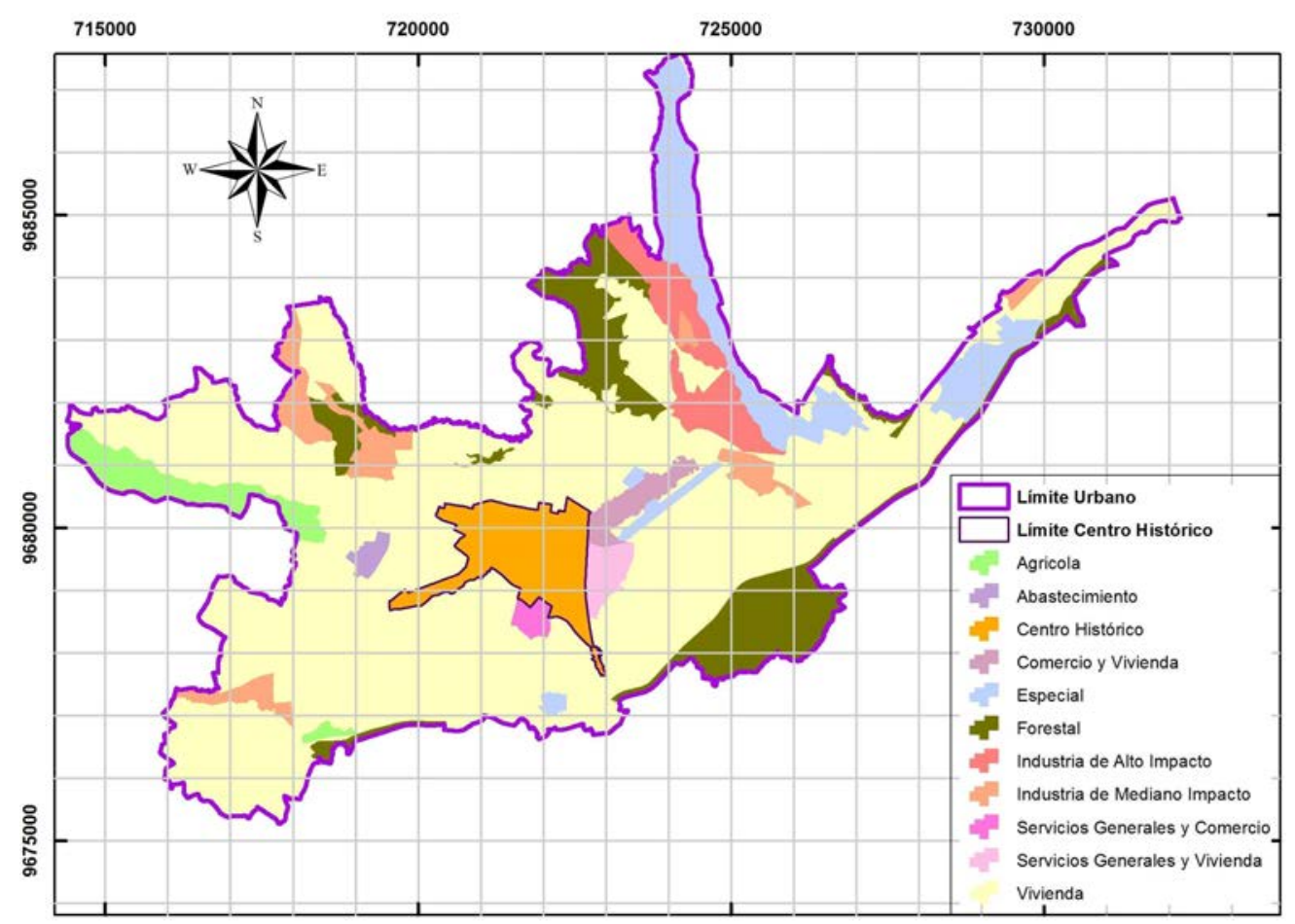

\section{Discusión}

\subsection{Caracterización urbana}

Las principales características urbanas de la ciudad de Cuenca que pueden influenciar en la calidad del aire son: usos de suelos, densidad urbana, ubicación de las fuentes puntuales de emisión (industrias y gasolineras) y el tráfico vehicular.

Referente al uso y ocupación de suelos en Cuenca, se encuentran definidos en el Plan de Ordenamiento Territorial del Cantón Cuenca (GAD Municipal de Cuenca, 1998), donde se establecen zonas de uso mayoritario como: industrial de mediano y alto impacto, comercial, residencial o de vivienda, servicios, de protección forestal, agrícolas y zonas mixtas. La Figura 1 muestra la distribución espacial del uso de suelo, actualización 2007.

Respecto a la densidad poblacional se han tomado los datos del Censo de Población y Vivienda del 2010 a escala zonal (INEC, 2010). La figura 2 muestra la distribución espacial de las densidades, se puede observándose que las mayores densidades se concentran en la zona céntrica de la ciudad.

Como fuentes puntuales de emisión se identifican las industrias, y las gasolineras. La industria en la Ciudad de Cuenca se desarrolla principalmente en el Parque Industrial, ubicado al Noreste de la ciudad, donde funcionan aproximadamente 145 industrias (CGA), y además en la Zona Franca, ubicada al Suroeste de la ciudad pero fuera del perímetro urbano. Las estaciones de servicio -gasolineras- por otra parte se distribuyen por las arterias viales de la ciudad (Red de Monitoreo de Calidad del Aire, 2013b). La figura 3 muestra la ubicación de las fuentes puntuales de emisión en Cuenca.

Entre las vías de mayor tráfico con un promedio diario de 25000 vehículos/día a 40000 vehículos/día se destacan el eje vial exterior compuesto por la Avenida Circunvalación y la Avenida de Las Américas, el eje interno lo componen en el sentido Norte-Sur la Avenida Huayna Capac y la Avenida Solano, y en el sentido Este-Oeste las Avenidas España, la Avenida 12 de Abril y la Avenida Remigio Crespo, además se observa alto tráfico en la Avenida Ordoñez Lasso que conecta la parte oeste de la ciudad con el eje vial externo. En lo referente al Centro Histórico, éstas tienen un tráfico medio de 10000 vehículos/día (GAD Municipal de Cuenca, 2013). La composición vial de Cuenca se muestra en la figura 4. 
Figura 2. Densidad Poblacional de la Ciudad de Cuenca

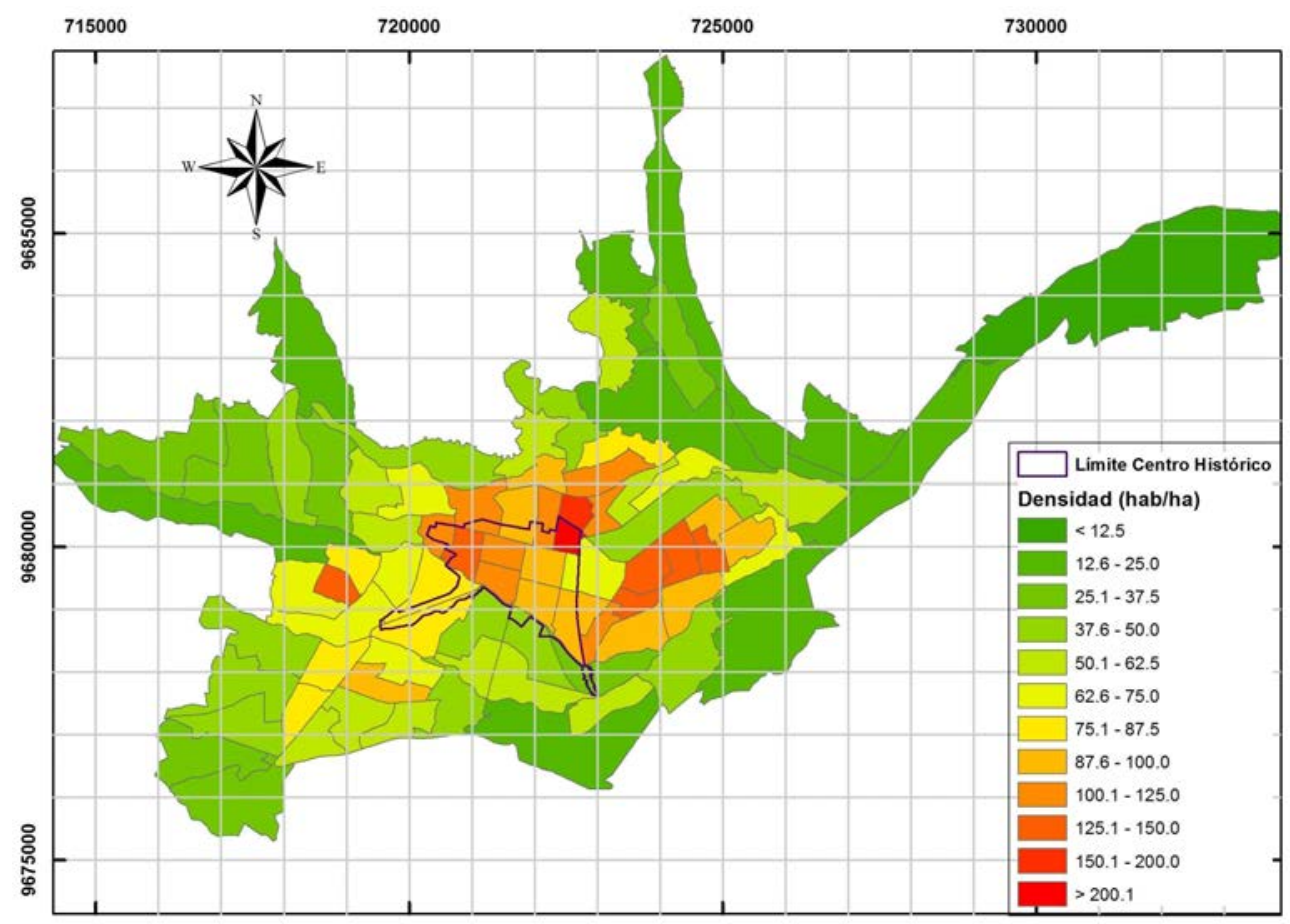

Figura 3. Ubicación de las Industrias y Estaciones de Servicio en Cuenca

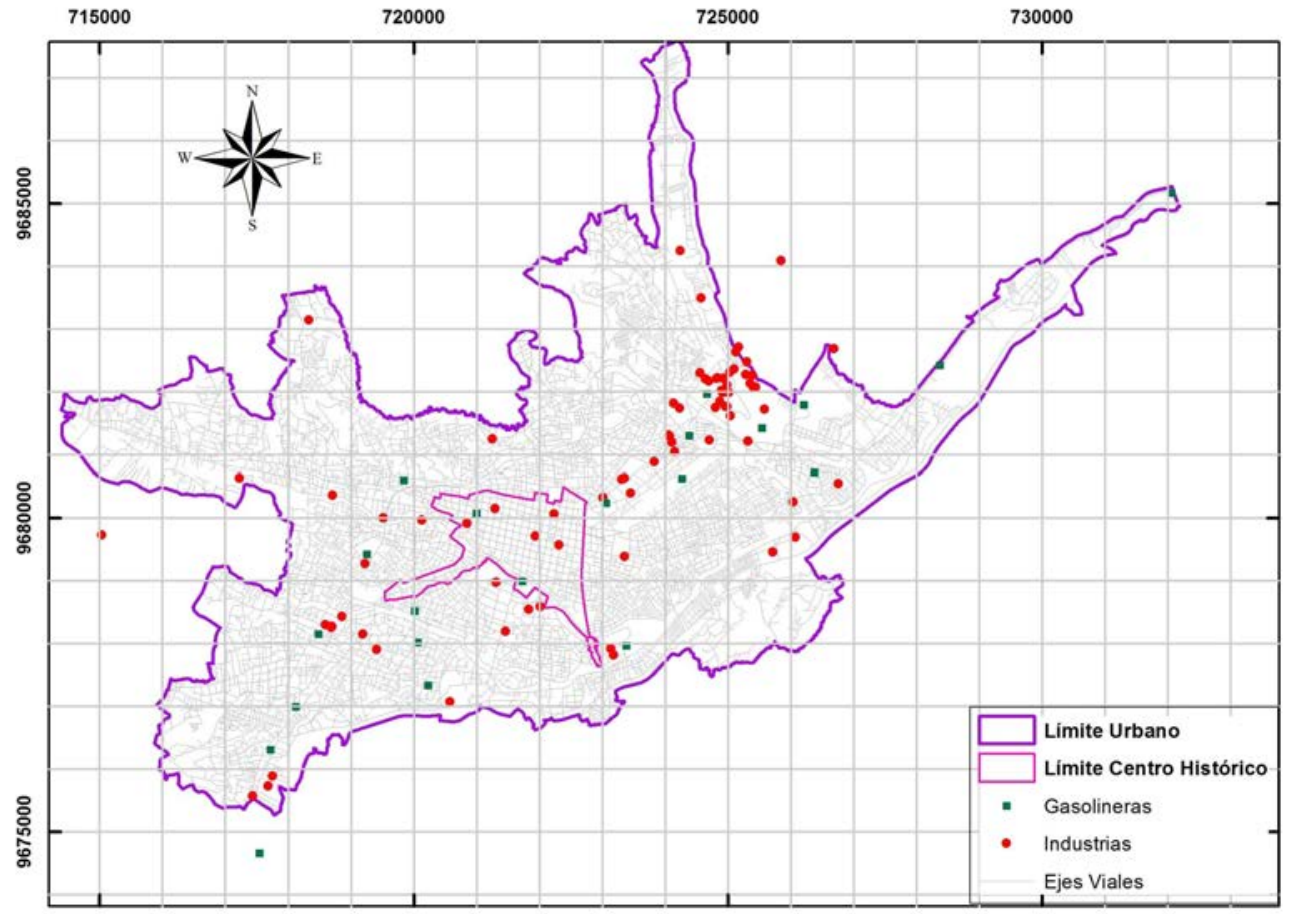


Figura 4. Principales Vías de Cuenca y Su tráfico

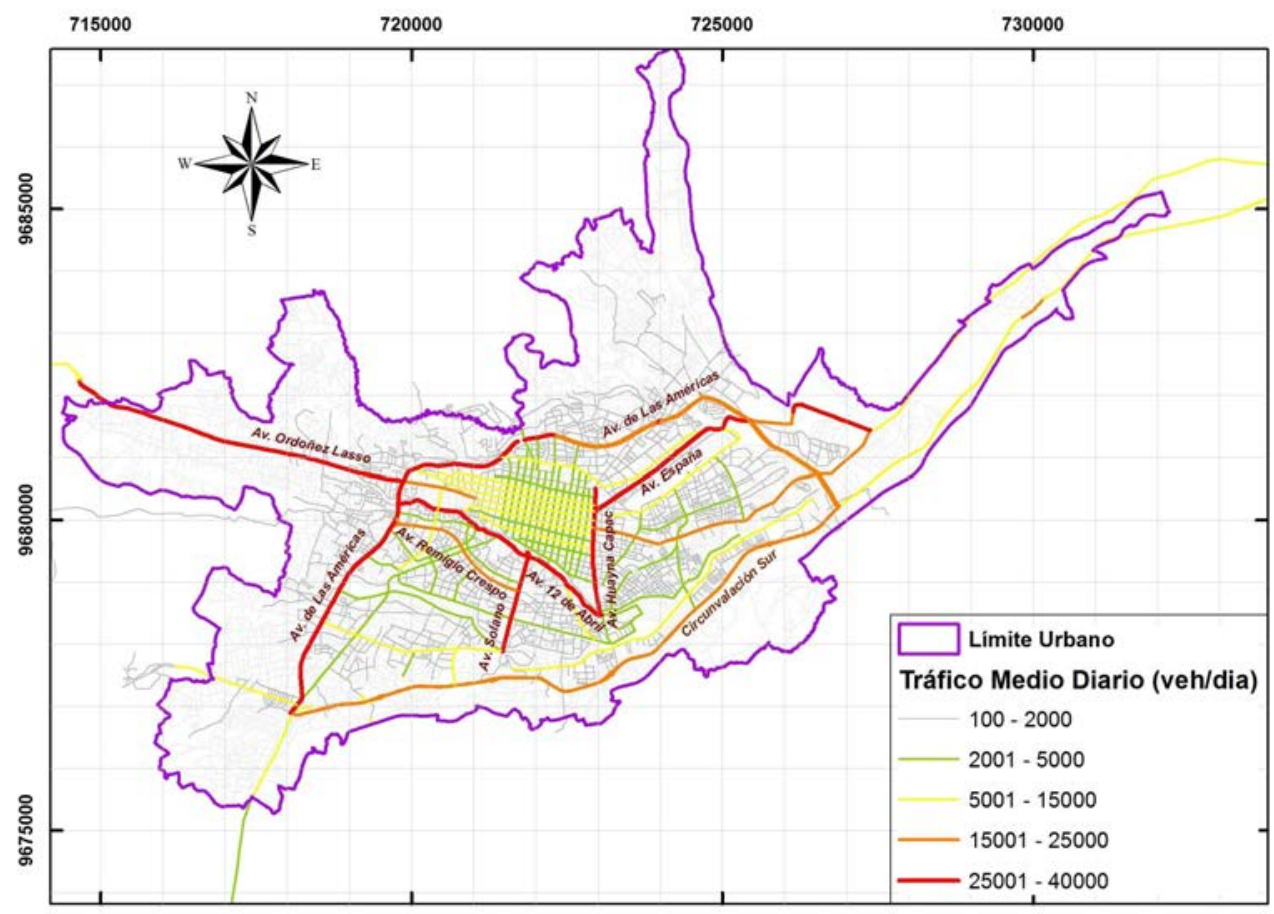

Figura 5. Rosa de los Vientos. Cuenca. Período 1990-2011

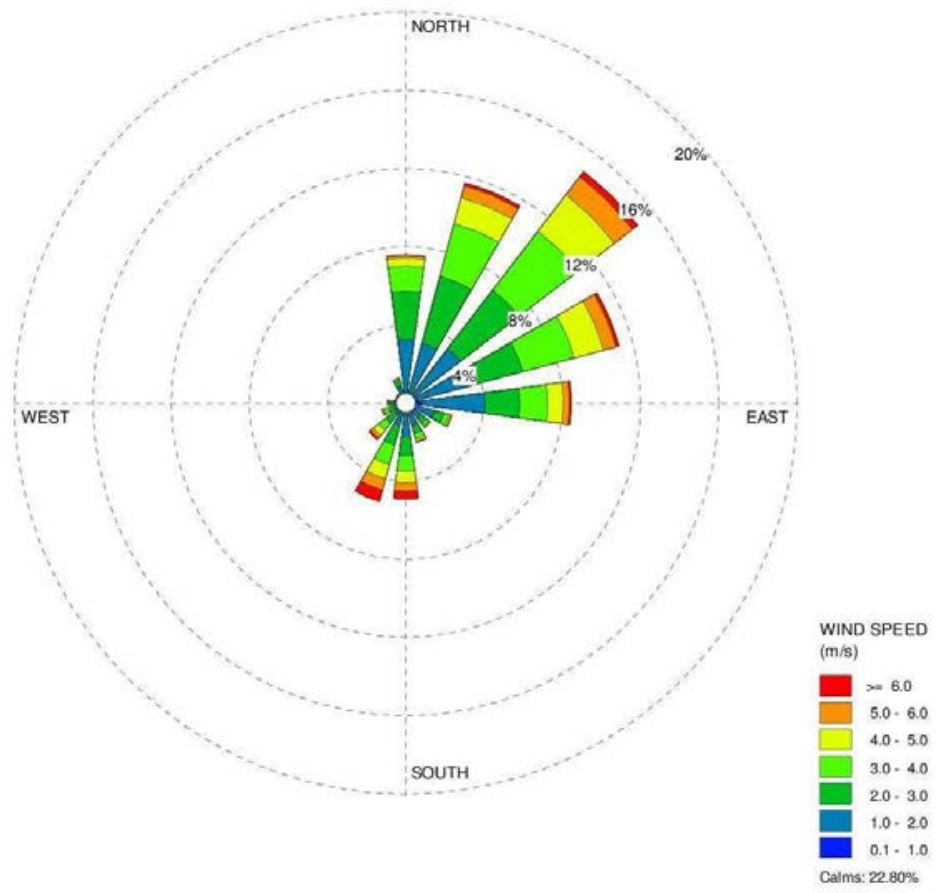


Concerniente a la meteorología, se recopiló y procesó la información de las estaciones meteorológicas del Aeropuerto Mariscal Lamar, para el período 1990 a 2011 (Fundación Natura, CUENCAIRE, and Comisión de Gestión Ambiental. Municipio de Cuenca CGA 2009), y del Municipio de Cuenca, para el período 2012-2014 (Fundación Natura, CUENCAIRE y Comisión de Gestión Ambiental. Municipio de Cuenca CGA 2009; Red de Monitoreo de Calidad del Aire, 2011b; Red de Monitoreo de Calidad del Aire, 2013b), las cuales cuentan con información horaria para los períodos analizados; aunque el Instituto Nacional de Meteorología e Hidrología no dispone de información horaria, o únicamente la desgloza en 3 horas para cada día, se han utilizado los promedios anuales y mensuales para corroborar la información de las estaciones utilizadas (INAMHI, 2012). Se destaca que la dirección dominante del viento es noreste con un vector resultante de $36^{\circ}$ y una velocidad promedio de $1.95 \mathrm{~m} / \mathrm{s}$, la temperatura promedio anual es de $16.1^{\circ} \mathrm{C}$, y la precipitación media anual oscila entre los 700 y 1000 mm/año. La figura 5 muestra la rosa de los vientos obtenida para el período de 1990 a 2011, con información horaria.

\subsection{Estructura y Conformación de la Red}

El diseño inicial de la red de monitoreo de calidad del aire (Ibarra, 2007), que opera desde 2008, concebía 18 puntos distribuidos por la ciudad, las características de esta red incluían: 1 estación automática de monitoreo, ubicada en el centro de la ciudad, que registre las concentraciones de $\mathrm{PM}_{2,5}, \mathrm{NO}_{2}, \mathrm{SO}_{2}$, $\mathrm{O}_{3}$, y una escala de representación urbana. 3 monitores activos para la medición de $P M_{10}$, y 3 monitores pasivos automáticos con su recolector de datos para la medición de $C O$, ubicadas en al noreste en el sector del parque industrial, en el centro de la ciudad junto a la estación automática, y al suroeste con una escala de representación espacial de tipo urbana. 13 puntos ubicados en diferentes partes de la ciudad con una superficie de representación vecinal de $2.2 \mathrm{~km}$ a la redonda de su emplazamiento, los contaminantes medidos son $\mathrm{SO}_{2}, \mathrm{O}_{3}$ y $\mathrm{NO}_{2} \mathrm{em}$ pleando muestreadores pasivos de difusión. 9 puntos de medición de Material Particulado Sedimentable $P S$, distribuidos junto a los monitores pasivos, y con escala de representación vecinal. 1 punto para medición a microescala en la zona céntrica de la ciudad, con la finalidad de registrar el efecto callecañón, en el cual se determina por muestreadores pasivos la concentración de $\mathrm{NO}_{2}, \mathrm{SO}_{2}$ y PS. 1 punto para determinar las concentraciones de fondo, ubicado fuera de Cuenca a $2 \mathrm{~km}$ del límite de la zona urbana, este punto mide $\mathrm{O}_{3}$ mediante monitores pasivos y $P S$.

La red de monitoreo inició la operación de la primera etapa en 2008, la misma que contaba con un total de 18 puntos: 17 puntos de monitoreo mediante muestreadores de difusión pasiva y 1 punto de determinación de la concentración de fondo; 15 puntos de medición de depósito de partículas sedimentables y 3 puntos con monitores activos de $P M_{10}$ (CUENCAIRE, 2009). La primera etapa excluía, respecto al diseño, la instalación estación automática, la misma que entraría en funcionamiento en una segunda etapa de operación que inició en 2012. En el año 2011, se añadió un punto de monitoreo de difusión pasiva y de partículas sedimentables, ubicado en el Cebollar -CEB-, posteriormente, en el año 2014, se añadió un punto de similares características en Misicata -MIS-.

De esta manera, al año 2014, los puntos de vigilancia aumentaron de 18 a 20 , que incluyen una estación de monitoreo automática, una subred de muestreo por difusión pasiva en los 20 puntos, una subred de depósito de Partículas Sedimentables con 17 puntos y 3 puntos de monitoreo activo de $P M_{10}$ (Red de Monitoreo de Calidad del Aire, 2015).

Los puntos concebidos en el diseño de la red, su implementación y evolución hasta el 2014 en base a los Informes de Calidad de Aire del 2008 al 2014 (CUENCAIRE, 2009; CUENCAIRE, 2010; Red de Monitoreo de Calidad del Aire, 2011a; Red de Monitoreo de Calidad del Aire, 2012; Red de Monitoreo de Calidad del Aire, 2013a; Red de Monitoreo de Calidad del Aire, 2014; Red de Monitoreo de Calidad del Aire, 2015) se muestra en la Tabla 3. La ubicación espacial de los puntos de monitoreo se muestra en la Figura 6.

Cabe destacar que la escala de monitoreo de todos los puntos, acorde a la Tabla 2, es Vecinal, exceptuando el punto ICT cuyo monitoreo pasivo únicamente incluye Ozono y la Escala de Representatividad es Regional, los puntos LAR, BCB y VEG cuya representatividad es de microescala y los puntos MUN, EIE y CCA cuya escala a más de vecinal es urbana. 
Tabla 3. Diseño y Cambios de la Red de Monitoreo

\begin{tabular}{|c|c|c|c|c|c|c|c|c|}
\hline \multirow{2}{*}{$\begin{array}{l}\text { PUNTO } \\
\text { MAN }\end{array}$} & \multicolumn{2}{|c|}{ REFERENCIA } & \multirow{2}{*}{$\begin{array}{l}\text { DISEÑO } \\
\text { DE RED } \\
\mathrm{B}\end{array}$} & \multirow{2}{*}{$\begin{array}{l}\text { RED } \\
2008 \\
\text { B, PS }\end{array}$} & \multirow[t]{2}{*}{$\mathrm{DE}$} & \multicolumn{2}{|c|}{$\begin{array}{l}\text { CAMBIOS EN LA } \\
\text { RED } \\
\end{array}$} & \multirow{2}{*}{$\begin{array}{l}\text { RED ACTUAL } \\
\text { B, PS }\end{array}$} \\
\hline & D-3 & Machángara & & & & & & \\
\hline EIA & D-3 & $\begin{array}{l}\text { Escuela Ignacio Andra- } \\
\text { de }\end{array}$ & DP, PS & DP, PS & & & & DP, PS \\
\hline EHS & $C-2$ & $\begin{array}{l}\text { Escuela Héctor Sem- } \\
\text { pértegui }\end{array}$ & DP, PS & DP, PS & & & & DP, PS \\
\hline $\mathrm{CHT}$ & $\mathrm{C}-3$ & Colegio Herlinda Toral & DP, PS & DP, PS & & & & DP, PS \\
\hline TET & $\mathrm{C}-3$ & Terminal Terrestre & DP, PS & DP, PS & & & & DP, PS \\
\hline ECC & $C-3$ & $\begin{array}{l}\text { Escuela Carlos Crespi } \\
\text { II }\end{array}$ & $\mathrm{DP}$ & DP, PS & & & & DP, PS \\
\hline ODO & C- 4 & $\begin{array}{l}\text { Universidad de Cuen- } \\
\text { ca - Facultad de Odon- } \\
\text { tología }\end{array}$ & $\mathrm{DP}$ & DP, PS & & & & DP, PS \\
\hline EVI & B-4 & Escuela Velazco Ibarra & $\mathrm{DP}$ & DP, PS & & & & DP, PS \\
\hline MEA & B-4 & Mercado El Arenal & $\mathrm{DP}$ & DP, PS & & & & DP, PS \\
\hline BAL & B-3 & $\begin{array}{l}\text { Universidad de Cuen- } \\
\text { ca - Balzay CEA }\end{array}$ & DP, PS & DP, PS & & & & DP, PS \\
\hline CRB & A-5 & Colegio Rafael Borja & $\mathrm{DP}$ & DP, PS & & & & DP, PS \\
\hline VEG & $C-3$ & Calle Vega Muñoz & $\mathrm{DP}$ & $\mathrm{DP}$ & & & & $\mathrm{DP}$ \\
\hline CCA & $C-3$ & $\begin{array}{l}\text { Colegio Carlos Arizaga } \\
\text { Vega }\end{array}$ & $\begin{array}{l}\text { MA,DP, } \\
\text { PS }\end{array}$ & $\begin{array}{l}\text { MA, } \\
\text { PS }\end{array}$ & $\mathrm{DP}$ & & & MA, DP, PS \\
\hline MUN & C-4 & Municipio & $\begin{array}{l}\mathrm{AT}, \quad \mathrm{MA}, \\
\mathrm{DP}, \mathrm{PS}\end{array}$ & $\begin{array}{l}\text { MA, } \\
\text { PS }\end{array}$ & $\mathrm{DP}$, & $\begin{array}{l}\mathrm{AT}, \quad \mathrm{MA}, \\
\mathrm{DP}, \mathrm{PS}\end{array}$ & 2012 & $\begin{array}{l}\text { AT, MA,DP, } \\
\text { PS }\end{array}$ \\
\hline EIE & B-4 & $\begin{array}{l}\text { Escuela Ignacio Escan- } \\
\text { dón }\end{array}$ & $\begin{array}{l}\text { MA,DP, } \\
\text { PS }\end{array}$ & $\begin{array}{l}\text { MA, } \\
\text { PS }\end{array}$ & $\mathrm{DP}$ & & & MA, DP, PS \\
\hline $\mathrm{BCB}$ & $\mathrm{C}-4$ & Estación de Bomberos & $\mathrm{DP}$ & DP, PS & & & & DP, PS \\
\hline LAR & $\mathrm{C}-4$ & Calle Larga & $\mathrm{DP}$ & $\mathrm{DP}$ & & & & $\mathrm{DP}$ \\
\hline ICT & $C-5$ & Antenas de Ictocruz & DP, PS & $\mathrm{DP}$ & & & & $\mathrm{DP}$ \\
\hline CEB & B-3 & Cebollar & & & & DP, PS & 2011 & DP, PS \\
\hline MIS & A-4 & Misicata & & & & DP, PS & 2014 & DP, PS \\
\hline
\end{tabular}

AT Automática MA Monitoreo Activo DP Monitoreo por Difusión Pasiva PS Monitoreo de Partículas Sedimentables B Blanco de Fondo

\section{Conclusiones y Recomendacio- nes}

De conformidad con la información recopilada de las características urbanas y meteorológicas de Cuenca, y con la caracterización de la actual red de monitoreo de calidad del aire de Cuenca, se establece:

Acorde al tamaño y población de la ciudad, la instalación de una sola estación automática en el centro de urbe, cumple la recomendación a escala urbana y con los requerimientos mínimos de monitoreo. Sin embargo, es suficiente contar con dos monitores activos $P M_{10}$ a escala urbana, recomendándose que se conserven el punto MUN ubicado en el centro de la ciudad y el punto CCA cercano al parque industrial, no así el punto EIE ubicado al suroeste: la relocalización de este punto pudiera ser en el punto BCB o LAR en el centro de la ciudad, pero para medir concentraciones de micro-escala.

Los monitores automáticos de $\mathrm{CO}$ no se recomiendan utilizar a escala urbana, por lo tanto la 
Figura 6. Localización de los puntos de Monitoreo

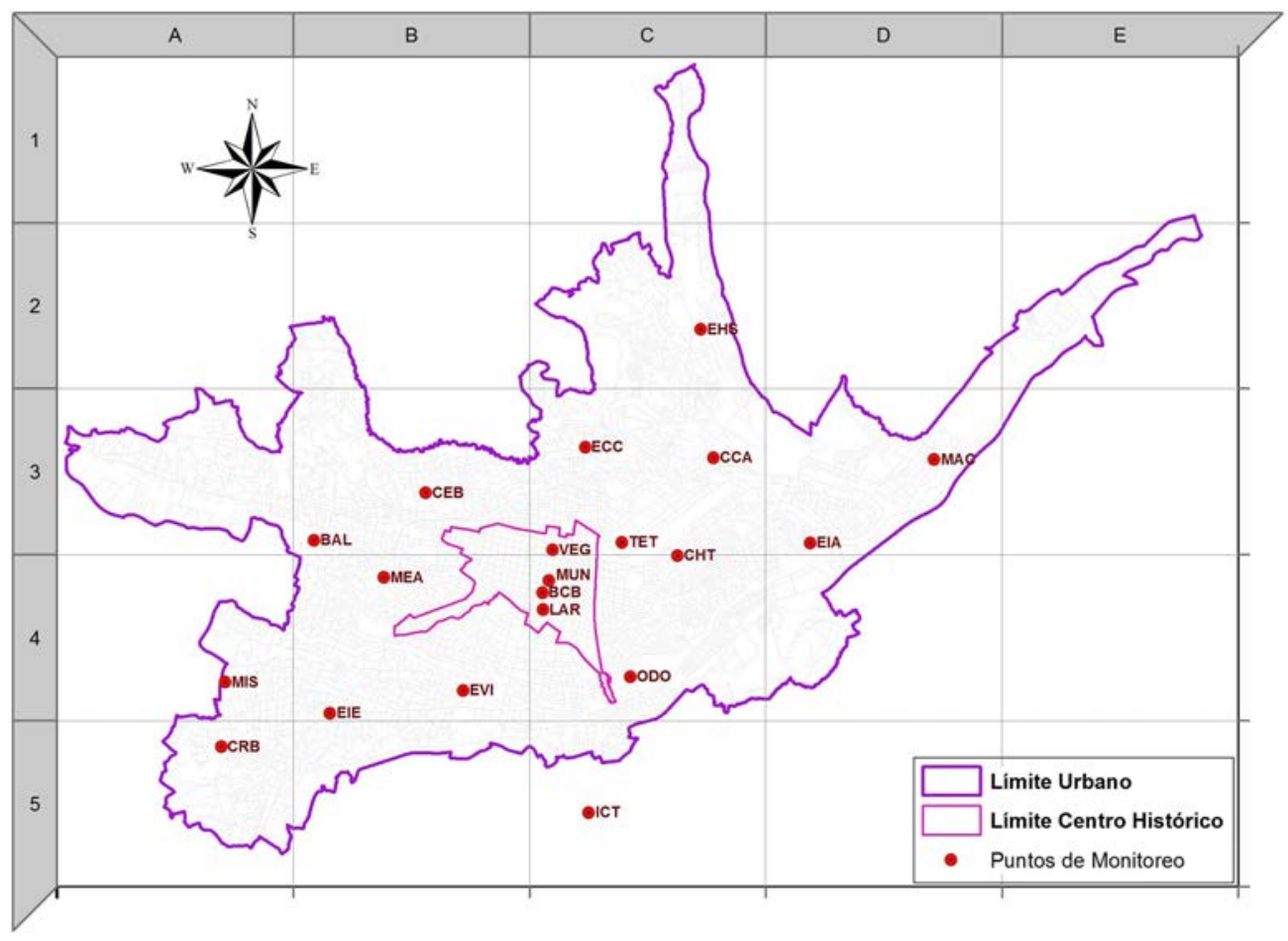

escala de representatividad de la concentración de CO en la estación MUN es de media escala o microescala.

La red de monitoreo a escala vecinal actual está conformada por 20 puntos, 13 están específicamente ubicados para este propósito y 3 concebidos en la red a escala urbana, en donde también se hace medición a escala vecinal. Esta red usa principalmente métodos de difusión pasiva, los cuales provén información en períodos largos de tiempo, ya sea entre 10 a 12 días para el caso de $\mathrm{NO}_{2}$ y $\mathrm{O}_{3}$, y 30 días para el $\mathrm{SO}_{2}$ y $P S$. Para la ciudad de Cuenca es adecuado el uso de estos métodos siempre y cuando se consideren como un soporte de la red a escala urbana. El empleo de los métodos pasivos ofrece información de gran calidad a un bajo costo. A mediano plazo, el número de puntos de monitoreo a escala vecinal pueden ser disminuidos, considerando que las recomendaciones dadas a escala vecinal establecen que la representación espacial es de hasta $4 \mathrm{~km}$ a la redonda. Se observa, acorde a la distribución espacial, que no se contempla medición a escala vecinal en un sector oeste y noroeste de la ciudad, recomendándose que se emplace un punto de acuerdo a la metodología establecida en este proyecto; ade- más, dos puntos de la red de escala vecinal -TET y CHT-, se encuentran muy próximos a menos de $1 \mathrm{~km}$ de distancia, por lo que el punto CHT debe ser reubicado más hacia el sureste, entre las posibilidades de reubicación están: Centro de Salud Pumapungo -800m-, Centro Comercial -Gran Aki 700m-, y el Centro Artesanal Gaspar Sangurima -570m-.

En la conformación de la actual red, el punto MAC (Blanco) es donde se colocan los monitores pasivos cerrados, los cuales no registran la contaminación del sector sino el comportamiento de los reactivos químicos con la variación de la temperatura diaria y del período, se recomienda por tanto colocar también monitores pasivos que nos permitan registrar los niveles de contaminantes en esta zona de la ciudad.

Se encuentra que el diseño contempla monitores automáticos de CO en los puntos MUN, EIE y CCA, sin embargo únicamente la estación automática ubicada en MUN está realizando mediciones. Se recomienda, por tanto que la estación CCA cuente con el monitoreo automático de $\mathrm{CO}$, por otra parte un monitor adicional se recomendaría para medir el efecto cañón en el punto BCB o LAR, y no es necesario contar con un monitor en el punto EIE, establecido en 
el diseño original.

El único punto a escala regional es ICT, de manera que para la determinación de la concentración de fondo fuera de Cuenca y el impacto de esta en la periferia, a más del punto propuesto se recomienda ubicar 5 puntos en la dirección suroeste cada $5 \mathrm{~km}$ de manera especial para medir el impacto del ozono troposférico generado por la ciudad. Esta medición se debe realizar en el período octubre-marzo que corresponde a los meses más cálidos del año.

El micro-emplazamiento de los monitores, donde se analizan las distancias de separación entre las vías de tráfico y los monitores, altura desde el suelo al analizador, distancia horizontal y vertical de las estructuras de apoyo al analizador, distancia de árboles $\mathrm{u}$ otros obstáculos hacia el analizador y espacio libre al ingreso cumplen los requisitos establecidos.

La operación y mantenimiento de la Red de Monitoreo de Calidad del Aire se ha venido efectuando de acuerdo a las recomendaciones dadas por la USEPA.

\section{Referencias}

CGA. Plan energético de Cuenca. 2007-2017. Technical report, Comisión de Gestión Ambiental. Municipio de Cuenca.

CUENCAIRE. 2009. Informe de la calidad del aire de Cuenca, año 2008. Technical report, GAD Municipal de Cuenca.

CUENCAIRE. 2010. Informe de la Calidad del Aire de Cuenca, año 2009. Technical report, Municipalidad de Cuenca.

EEA. 1999. Criteria for euroairnet. The eea air quality monitoring and information network. Technical Report 12, European Environmental Agency.

Fundación Natura, CUENCAIRE y Comisión de Gestión Ambiental. Municipio de Cuenca CGA. 2009. Inventario de emisiones atmosféricas del cantón Cuenca, año base 2007. Technical report.

GAD Municipal de Cuenca. 1998. Ordenanza que sanciona el plan de ordenamiento territorial del cantón Cuenca: determinaciones para el uso y ocupación del suelo urbano. Technical report.
GAD Municipal de Cuenca. 2013. Infraestructura de datos espaciales. Geovisor municipal.

Ibarra, B. 2007. Diseño de la red de monitoreo atmosférico del cantón Cuenca. Technical report, CUENCAIRE.

INAMHI. 2012. Anuario meteorológico 2010. Technical Report 50, Instituto Nacional de Meteorología e Hidrología.

INEC. 2010. VII Censo de Población y VI Vivienda CPV 2010. Technical report, Instituto Nacional de Estadística y Censos.

MAE. 2014. Texto Unificado de Legislación Secundaria. Technical report, Ministerio del Ambiente-Ecuador.

Red de Monitoreo de Calidad del Aire. 2011a. Informe de la calidad del aire de Cuenca, año 2010. Technical report, EMOV EP - GAD Municipal de Cuenca.

Red de Monitoreo de Calidad del Aire. 2011b. Inventario de emisiones atmosféricas del cantón Cuenca, año base 2009. Technical report, EMOV EP - GAD Municipal de Cuenca.

Red de Monitoreo de Calidad del Aire. 2012. Inventario de emisiones atmosféricas del cantón Cuenca, 2011. Technical report, EMOV EP GAD Municipal de Cuenca.

Red de Monitoreo de Calidad del Aire. 2013a. Informe de la calidad del aire de Cuenca, año 2012. Technical report, EMOV EP - GAD Municipal de Cuenca.

Red de Monitoreo de Calidad del Aire. 2013b. Inventario de emisiones atmosféricas del cantón Cuenca, año base 2011. Technical report, EMOV EP - GAD Municipal de Cuenca.

Red de Monitoreo de Calidad del Aire. 2014. Informe de la calidad del aire de Cuenca, año 2013. Technical report, EMOV EP - GAD Municipal de Cuenca.

Red de Monitoreo de Calidad del Aire. 2015. Informe de la calidad del aire de Cuenca, año 2014. Technical report, EMOV EP - GAD Municipal de Cuenca. 
US-EPA. 2007a. 40 c.f.r volume i. section 53. Ambient air monitoring reference and equivalent methods. Technical report, United States Environmental Protection Agency.

US-EPA. 2007b. 40 C.F.R. Volume I. Section 58. Ambient Air Quality Surveillance. Technical report, United States Environmental Protection Agency.

US-EPA. 2013. Quality Assurance Handbook for
Air Pollution Measurement Systems. Ambient Air Quality Monitoring Program, Volume II.

WHO. 1999. Monitoring ambient air quality for health impact assessment. WHO Regional Publications, Eurepean Series 85, World Health Organization.

WHO. 2006. Air Quality Guidelines. Global Update 2005. Particulate matter, ozone, nitrogen dioxide and sulfur dioxide. 
DOI:10.17163/lgr.n23.2016.04

\title{
ABSORCIÓN DE PLOMO DE SUELOS ALTAMENTE CONTAMINADOS EN ESPECIES VEGETATIVAS USADAS PARA CONSUMO ANIMAL Y HUMANO
}

\section{LEAD ABSORPTION IN HIGHLY CONTAMINATED SOIL OF VEGETATIVE SPECIES USED FOR ANIMAL AND HUMAN CONSUMPTION}

\author{
Elena Coyago ${ }^{1, *}$ y Sara Bonilla ${ }^{2}$
}

${ }^{1}$ Carrera de Ingeniería en Biotecnología, Universidad Politécnica Salesiana, Sede Quito, Campus El Girón, Av. 12 de Octubre, Telf. (005932) 3962800, Quito, Ecuador.

${ }^{2}$ Carrera de Ingeniería Ambiental, Universidad Politécnica Salesiana, Sede Quito, Campus Sur, Av. Moran Valverde y Rumichaca, Telf. (005932) 3962800, Quito, Ecuador.

*Autor para correspondencia: elena.coyago@hotmail.com, ecoyagoc@ups.edu.ec

Manuscrito recibido el 12 de diciembre de 2014. Aceptado, tras revisión, el 22 de junio de 2016

\section{Resumen}

El presente trabajo evaluó la capacidad de absorción de plomo de tres especies vegetativas: Amaranto Hybridus (amaranto), Beta Vulgaris (acelga) y Medicago sativa (alfalfa); las tres especies fueron germinadas en semilleros, usando tierra negra y tierra mezcla, y replantadas en suelos contaminados artificialmente con concentraciones de 2,5, 5 y $10 \%$ de plomo. Con la finalidad de determinar la cantidad absorbida en diferentes tiempos, la evolución de la absorción de plomo en las diferentes especies vegetativas fue medida utilizando la técnica de digestión ácida y cuantificada en un espectrofotómetro de absorción atómica a 0, 20, 30, 45, 60 y 90 días de exposición. La absorción de plomo se vio influenciada directamente por la biomasa generada. El amaranto presentó etapas de desintoxicación, mientras que la alfalfa y acelga presentaron una absorción continua, este factor involucra un problema potencial en seguridad alimentaria ya se evidencia una retención del contaminante en la estructura vegetativa, provocando la contaminación de animales y humanos por consumo directo en zumos o precocidos de estas plantas.

Palabras claves: contaminación alimentaria, Amaranto, Alfalfa, Acelga, plomo.

La Granja:Revista de Ciencias de la Vida 23(1) 2016:39-51.

(C)2016, Universidad Politécnica Salesiana, Ecuador. 


\begin{abstract}
This study evaluated the ability of absorbing lead in three vegetative species: Amaranthus hybridus (amaranth), Beta vulgaris (beet) and Medicago sativa (alfalfa); the three species were germinated in seeds with black soil and a soil mix, and were replanted in artificially contaminated soil at concentrations of $2.5,5$ and $10 \%$. In order to determine the amount of lead absorbed at different times, the evolution of lead absorption in different vegetative species were measured using the acid digestion technique and quantified by an atomic absorption spectrophotometry at $0,20,30$, 45, 60 and 90 days of exposure. The lead absorption was directly influenced by the generated biomass. Amaranth stages presented detoxification, while the beet and alfalfa showed a continuous absorption, this involves a potential problem in food safety as it retains the contaminant in the vegetative structure, causing contamination of animals and humans by direct consumption in juices or the precooked vegetal.
\end{abstract}

Keywords: food contamination, Amaranth, Beets, Alfalfa, lead.

Forma sugerida de citar: Coyago, E. y S. Bonilla. 2016. Absorción de plomo de suelos altamente contaminados en especies vegetativas usadas para consumo animal y humano. La Granja: Revista de Ciencias de la Vida. Vol. 23(1): 39-51. ISSN: 1390-3799. 


\section{Introducción}

El desarrollo industrial, la urbanización acelerada, la mala disposición de desechos, entre otros, incrementan los niveles de contaminación de suelo, aire y agua (Roca, A, 2009). El agua contaminada en muchas ocasiones es utilizada para regar cultivos, provocando la acumulación de contaminantes en el suelo, la vegetación y a su vez la inminente contaminación de animales y humanos que reciben el contaminante en forma preconcentrada (OMS, septiembre 2013; Krueger et al., 2013; Dueñas, J, 2014).

Uno de los mayores contaminantes son los metales pesados, los cuales son ampliamente utilizados en la agricultura, minería, fundición, galvanoplastia, refinado de oro, gasolina, explosivos, entre otros (Gupta et al., 2013; Infante et al., 2013).

Los metales pesados son elementos químicos que poseen peso atómico entre $63,55(\mathrm{Cu})$ y 200,59 $(\mathrm{Pb})$ y en concentraciones altas pueden ser tóxicos para el suelo, plantas y animales (Rodríguez et al., 2006a,b; Gunnar, N, 2012).

Asimismo, los metales pesados según su origen pueden clasificarse en: a) Geogénicos: cuando proceden de la roca madre en la que se formó del suelo (Diez et al., 2009) y b) Antropogénicos: cuando proceden de residuos peligrosos derivados de actividades industriales, agrícolas, mineras, residuos sólidos urbanos, entre otros (Falcó y Martí, 2012). Según su función biológica pueden dividirse en: a) Oligoelementos o micronutrientes: requeridos en pequeñas cantidades para que los organismos completen su ciclo vital (Benoit y Stephen, 2010) y b) Sin función biológica conocida: donde presentan la propiedad de acumularse en los organismos vivos y pueden resultar altamente tóxicos como $\mathrm{Cd}, \mathrm{Hg}, \mathrm{Pb}, \mathrm{Cu}$, Sb, Bi (Alcalá et al., 2009).

La acumulación de metales pesados en las plantas inhibe o activa algunos procesos enzimáticos que afectan la productividad (Mayank et al., 2011), dando como resultado una posible vía de entrada de estos metales en la cadena alimenticia.

Estudios realizados por (Adesodun et al., 2010; Agudelo et al., 2009; Babula et al., 2012; Chinmayee et al., 2012; De Souza et al., 2012), entre otros, señalan que los procesos de fitorremediación utilizan variedades de plantas que sirven para consumo humano y animal como el maíz (Zea mays) (Suthar et al., 2014), mostaza parda (Brassica juncea)(López y Torija, 2006), nabo (Brassica rapa) (Mateo, J, 2008), amaranto (Amaranthus hybridus) (Salas y Boradonenko,
2009; Peralta, 2009; Chinmayee et al., 2012), girasol (Helianthus annuus) (Flores, A, 2010), entre otras especies alimenticias.

Específicamente, el plomo es un metal carente de valor biológico, debido a su tamaño y carga puede sustituir al calcio acumulándose en los tejidos óseos (Qaisar et al., 2012; OMS, septiembre 2013), esta absorción dependerá principalmente del estado nutricional del individuo, siendo mayor cuando la dieta es pobre en calcio, hierro y proteínas (NOM, 2002).

Así, el aumento de poblaciones industrializadas y los procesos de contaminación asociados, se han convertido en una amenaza latente en la producción de alimentos de origen vegetal y animal, el deterioro inminente de la calidad de los mismos y un riesgo potencial para la salud de los humanos (Armas y Castro, 2009). Según varios estudios de suelos contaminados y plantas alimenticias en las inmediaciones de industrias que utilizaban plomo, se encontró que las concentraciones del metal en el suelo fueron alrededor de: 5906 a $171 \mathrm{mg} \mathrm{Pb} / \mathrm{kg}$ de suelo en Madrid (Cala y Kunimine, 2003), $24600 \mathrm{mg} \mathrm{Pb} / \mathrm{kg}$ de suelo en la India (Fakayode y Chianwa, 2002), 138 $\mathrm{mg} \mathrm{Pb} / \mathrm{kg}$ en hortalizas de la Habana, Cuba (Olivares et al., 2013), $51000 \mathrm{mg} \mathrm{Pb} / \mathrm{kg}$ de suelo en Canadá (Salin y Skinner, 1995), $37600 \mathrm{mg} \mathrm{Pb/kg} \mathrm{de}$ suelo en El Salvador (Herrera, K, 2009), 11113 mg $\mathrm{Pb} / \mathrm{kg}$ de suelo en la ciudad de Maracay (Carrasquero, A, 2006). En Ecuador, se ha detectado la presencia de concentraciones de plomo en diferentes cultivos: $8,70 \mathrm{mg} \mathrm{Pb} / \mathrm{kg}$ en cultivos de café (coffea arábiga) (Garzón, A, 2006; Betancourt, O, 2009), 0,24 a 5,36 ppm en suelos de cultivo para banano, cacao, café, palma y plátano (Félix et al., 2012). Así la Organización de las Naciones Unidas para la Agricultura y la Alimentación (FAO, 2010), presentó la preocupación frente al incremento de la contaminación alimentaria involucrando el control en "las materias primas utilizadas, la manipulación y todas las fases de elaboración, transporte, almacenamiento y venta de alimentos" (FAO, 2010).

Debido a estos requerimientos los organismos ecuatorianos han generado varias normas que ayudan a mantener un control de la contaminación en productos alimenticios, así se puede mencionar la norma NTE INEN 707:2010 (INEN, 2010), CPE INEN-CODEX CAC/RCP 56 (CPE, I, 2013; CODEX, 2014), entre otras; estas normas ayudan a buscar alternativas ambientalmente sustentables de regeneración de suelos que provoquen impactos positivos, 
beneficiando el consumo de productos saludables para los humanos y resguardando la seguridad alimentaria.

En vista de la importancia de la contaminación de especies vegetativas con plomo y la poca información existe a cerca del proceso de absorción, este estudio fue llevado a cabo con el objetivo de evaluar la cantidad de plomo absorbida por Amaranthus hybridus (amaranto), Beta vulgaris (acelga) y Medicago sativa (alfalfa) en diferentes tiempos.

\section{Materiales y métodos}

\subsection{Selección de especies vegetativas}

Previo a la experimentación, se realizó una investigación bibliográfica para seleccionar una muestra control y dos diferentes especies vegetativas alimentarias.

La mayoría de especies investigadas presentaron susceptibilidad en ausencia de agua, por tanto el amaranto fue seleccionado como muestra control dentro del estudio. La Figura 1 señala las semillas de las dos especies vegetativas que son ampliamente utilizadas como forraje, alimento para humanos, son ricas en nutrientes, están listas para la cosecha en uno o dos meses y además se desarrollan en climas fríos a templados; estos cultivos son de rebrote y de corta duración y presentan resistencia a plagas, sequías y condiciones ambientales.

Por tanto la muestra control fue el amaranto (Amaranthus hybridus) que es una especie usada en procesos de fitorremediación y una muestra de acelga (Beta vulgaris) y alfalfa (Medicago sativa), que fueron seleccionadas considerando los siguientes aspectos: a) Son usadas para consumo humano y animal b) Son utilizadas en los procesos de fitorremediación de plomo c) Son resistentes a las condiciones ambientales y d) Son resistentes a plagas.

Las semillas certificadas de las especies vegetales seleccionadas fueron adquiridas en el Instituto Nacional Autónomo de Investigaciones Agropecuarias (INIAP), estación Santa Catalina.

\subsection{Construcción de semilleros}

Los semilleros fueron construidos utilizando tierra negra sin tratamiento y una mezcla de tierra negra, cascajo y abono orgánico en proporciones 3:1:1 (tierra-mezcla), los cuales fueron sometidos a las mismas condiciones de temperatura y humedad; además albergaron un solo grupo de plantas a estudiar.

Los semilleros fueron construidos utilizando bolsas plásticas de color negro, necesarias para retener la humedad del suelo, provocar la germinación de la semilla y el crecimiento de la planta. Las bolsas estuvieron provistas de orificios necesarios para el drenaje del agua en exceso a una temperatura y humedad ambiental máxima promedio de $23^{\circ} \mathrm{C}$ y $90 \%$ y una mínima de $11^{\circ} \mathrm{C}$ y $41 \%$ respectivamente.

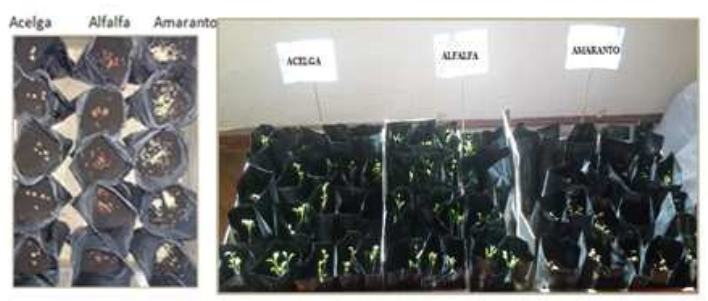

Figura 1. Semilleros

Cada semillero fue construido utilizando 40 bolsas con tres semillas para cada especie como se muestra en la Figura 1, las cuales se mantuvieron dentro del semillero por un lapso de 40 días y en cada uno de ellos se controló la tasa de germinación, crecimiento y mortalidad de las plántulas como se muestra en la Figura 2 y 3.

La adición de agua a los semilleros fue por aspersión, el cual aseguró la humectación uniforme del suelo. Se colocó en el suelo de los semilleros una sola dosis de fertilizante comercial, que ayudó a mantener el vigor de las plantas; luego de la germinación de las semillas, se dejó transcurrir 30 días hasta que las plántulas alcancen la madurez para el trasplante.

El análisis de $\mathrm{pH}$ en suelos no contaminados se determinó utilizando la norma AST D4972 (RECNAT, 2002; ASTM, 2014).

\subsection{Trasplante y cuantificación de plomo en especies vegetativas seleccionadas utili- zando la técnica de espectrofotometría de absorción atómica}

Las plantas germinadas en semilleros fueron trasplantadas en una matriz homogénea de suelos contaminados con plomo, en concentraciones de 2,5, 5 y $10 \%$, simulando altos episodios de contaminación. 


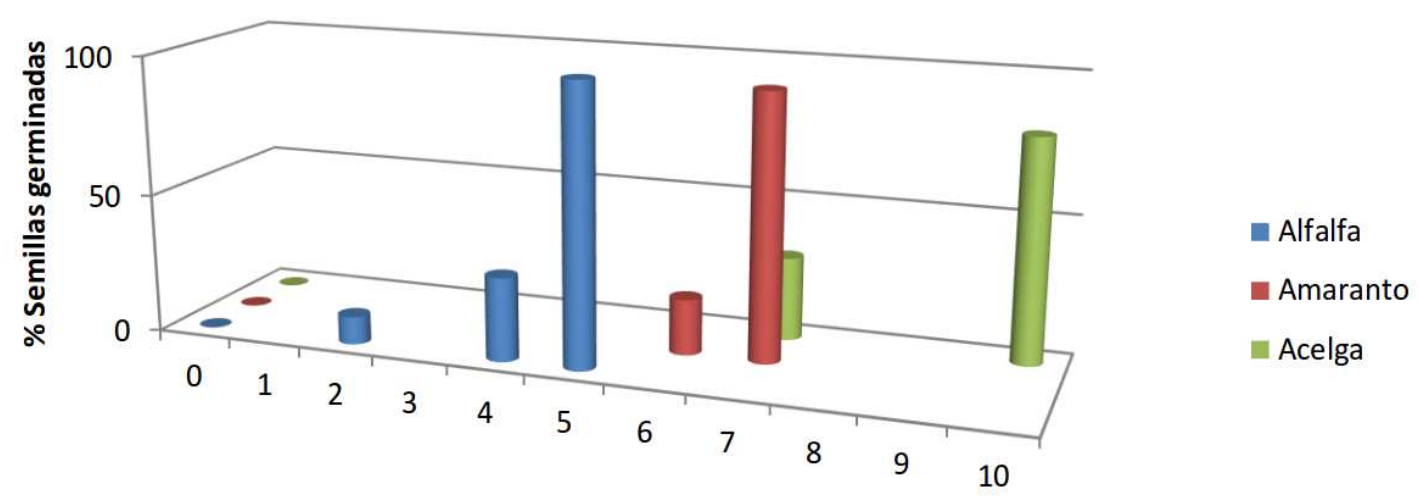

Figura 2. Porcentaje de germinación de semillas en tierra negra.

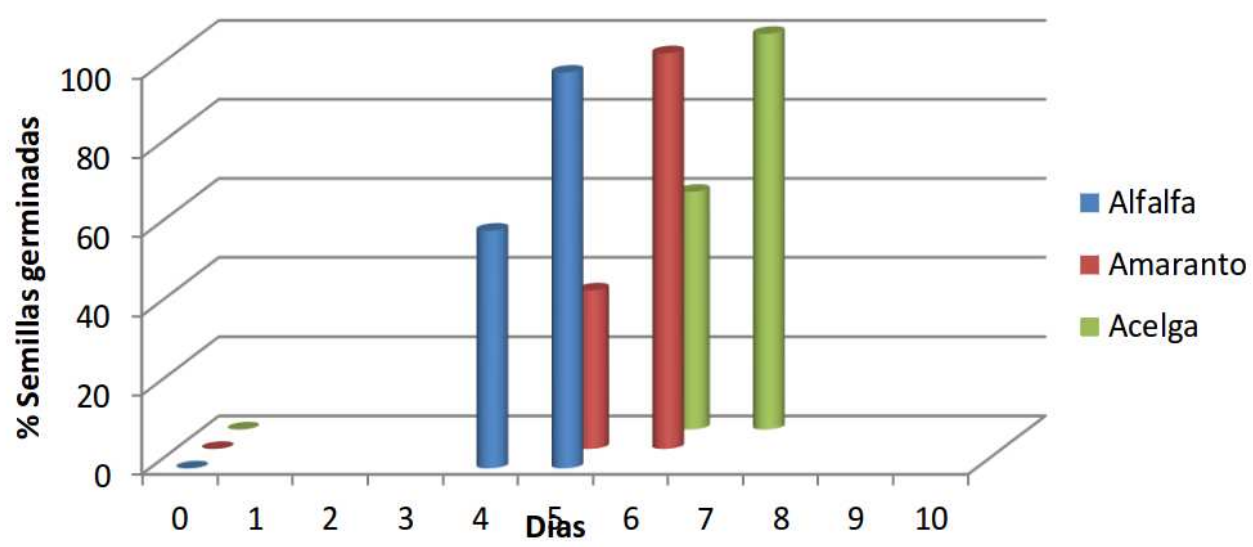

Figura 3. Porcentaje de germinación de semillas en tierra mezcla.

La cuantificación de plomo correspondió a plantas sin y con exposición de plomo y monitoreadas a 0, 20, 30, 45, 60 y 90 días, dicha cuantificación se llevó a cabo por triplicado. Las plantas seleccionadas para la cuantificación fueron extraídas del sustrato de forma aleatoria, lavadas para desprender exceso de tierra, secadas a temperatura ambiente, troceadas en su totalidad y almacenadas en congelación hasta el respectivo análisis.

Cada muestra fue sometida a un proceso de digestión ácida previa cuantificación utilizando la técnica de espectrofotometría de absorción atómica, empleando el método EPA 3010a, rev. 01, 1992; Standard Methods ed-21-2005, 3500 (EPA, 2005) con un límite de detección de 5 a $125 \mathrm{mg} / \mathrm{Kg}$. El proceso de digestión se realizó en un digestor marca Buchi
Scrubber Modelo B414, adicionando $50 \mathrm{~mL}$ de ácido nítrico Merck de pureza 69\% con 35 min de tiempo de digestión, filtrado y aforo a $50 \mathrm{~mL}$ con una solución de ácido nítrico al 3\% y posterior lectura en el espectrofotómetro de absorción atómica Perkin Elmer 3300 .

\section{Resultados y discusión}

\subsection{Germinación de semillas}

Los suelos utilizados para la germinación de semillas presentaron valores de $\mathrm{pH}$ de 7,1 para tierra negra y 7,5 para tierra-mezcla, tratándose de un suelo calificado como neutro y medianamente alcalino según lo expuesto por la norma ASTM D4972. 


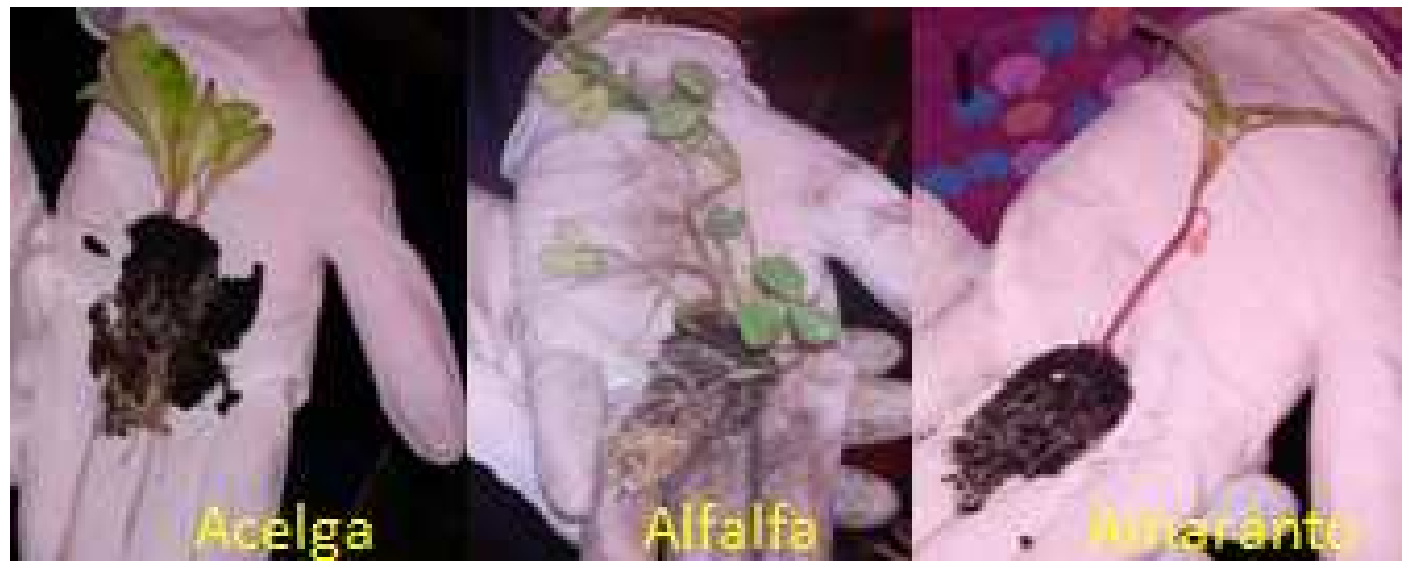

Figura 4. Plántulas germinadas en tierra negra, a las cuatro semanas.

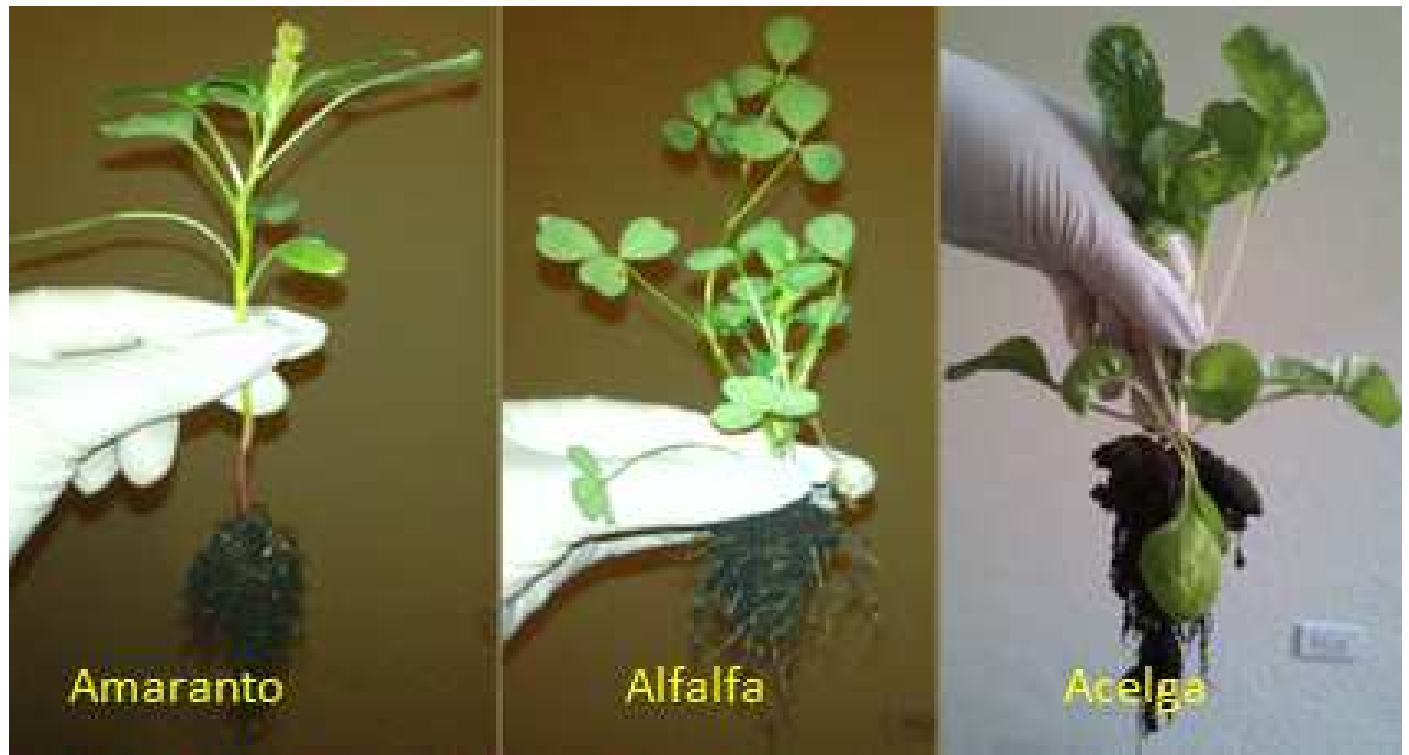

Figura 5. Plántulas germinadas en tierra-mezcla, a las cuatro semanas.

La germinación en tierra negra reportó valores superiores al $75 \%$ y tierra mezcla al $100 \%$, favoreciendo el desarrollo de las especies según lo expuesto por Torres et al., (2007), en el que se debe superar el $60 \%$ de germinación para que el desarrollo de las plantas sea óptimo; por otra parte los primeros brotes aparecieron a los 2, 5 y 7 días para alfalfa, amaranto y acelga respectivamente, mientras que para tierra mezcla aparecieron a los 4, 5 y 7 días, estos valores concuerdan con estudios de germinación realizados por (Botero, B, 2009; Torres et al., 2007; Botello, $\mathrm{N}, 2014)$.
Luego de haber transcurrido cuatro semanas, el follaje, grosor, sistema radicular y altura de las plantas germinadas en tierra mezcla fue mayor que las germinadas en tierra negra, con una altura promedio de 8 y $12 \mathrm{~cm}$ respectivamente como se observa en la Figura 4 y 5, este efecto se debió a la adición de abono orgánico contenido en tierra mezcla concordando con estudios realizados por (Guanopatín, M, 2012; Chamizo et al., 2009; Redín, L, 2009). 
Tabla 1. Proporciones de mezcla para suelos contaminados.

\begin{tabular}{cccccc}
\hline Ítem & $\begin{array}{c}\text { Concentración } \\
\mathrm{p} / \mathrm{p}\end{array}$ & $\begin{array}{c}\text { Masa Pb } \\
(\mathrm{g})\end{array}$ & $\begin{array}{c}\text { Masa tierra } \\
(\mathrm{g})\end{array}$ & $\begin{array}{c}\text { Masa tierra } \\
\text { contaminada } \\
(\mathrm{g})\end{array}$ & $\mathrm{pH}$ \\
\hline $\begin{array}{c}\text { Suelo } 2,5 \% \mathrm{~Pb} \\
(\mathrm{M} 1)\end{array}$ & 2,5 & 150 & 5850 & 6000 & $6,2_{a}$ \\
$\begin{array}{c}\text { Suelo } 5 \% \mathrm{~Pb} \\
(\mathrm{M} 2)\end{array}$ & 5 & 300 & 5700 & 6000 & $6,0_{a}$ \\
$\begin{array}{c}\text { Suelo } 10 \% \mathrm{~Pb} \\
(\mathrm{M} 3)\end{array}$ & 10 & 600 & 5400 & 6000 & $6,0_{a}$ \\
\hline
\end{tabular}

\subsection{Trasplante y cuantificación de plomo en especies vegetativas seleccionadas utili- zando la técnica de espectrofotometría de absorción atómica}

El sustrato contaminado con plomo en concentraciones de 2,5, 5 y $10 \%$ como se observa en la Figura 6 y Tabla 1, consistió de una mezcla de cenizas de plomo (reciclado de baterías automotrices) y tierra cancagua caracterizado por ser un suelo común en el norte y sur de Quito según lo expuesto por Jácome, (2011). El plomo y la cancagua fueron mezcladas hasta obtener un sustrato homogéneo, el mismo que fue colocado en macetas plásticas y el cual reportó valores de $\mathrm{pH}$ de 6 , que correspondió a suelos moderadamente ácidos según lo expuesto por ASTM, (2014) y NOM, (2002).

En la Figura 7 se muestra la evolución de absorción de Plomo en plantas de amaranto, el cual presentó un pico de absorción a los 20 días para especies con mayor biomasa o especies germinadas en tierra mezcla y posterior a esta fase empezó nuevamente la etapa de absorción de contaminante llegando a los 90 días a valores similares a los absorbidos a los 20 días; en especies con menor biomasa o especies germinadas en tierra negra, el efecto inicial de absorción hasta los 20 días se repitió, diferenciándose en la etapa de desorción la cual se prolongó hasta los 90 días, esto pudo deberse a que la capacidad de fotosíntesis en estas especies es menor debido a la baja biomasa existente, y las especies no logran recuperar el poder de absorción de contaminantes generando un proceso de protección como señala Agudelo, et al., (2009).

Las plantas germinadas en tierra mezcla presentaron mayor absorción de contaminante que las plantas germinadas en tierra negra, este efecto se debió a la cantidad de biomasa generada por cada especie, quedando comprobado lo expuesto por Agudelo, et al., (2009) y Mahdieh, et al., (2013), que señalan que la absorción de metales pesados en plantas depende de la biomasa que estas contengan, por tanto a mayor biomasa mayor es el porcentaje de absorción de contaminante.

Además se puede observar que mientras aumenta la concentración de contaminante la capacidad de absorción de plomo es mayor, llegando a valores de absorción de $500 \mathrm{mg} / \mathrm{Kg}$ de materia húmeda, por otra parte mientras se incrementa la concentración de contaminante el amaranto presenta dificultad para desintoxicarse, atrapando grandes cantidades de plomo en su estructura, por tanto los procesos de desintoxicación de las especies vegetativas se convierten en un beneficio para la seguridad alimentaria a expensas de provocar procesos no efectivos de descontaminación de suelos.

La alfalfa expuesta a diferentes concentraciones de contaminación por plomo como se muestra en la Figura 8, presentó un proceso de absorción paulatino llegando a los 60 días a valores de $1201 \mathrm{mg} / \mathrm{Kg}$ de materia húmeda en plantas germinadas en tierra mezcla; este efecto se repite en plantas de acelga como se muestra en la Figura 9, llegando a concentraciones de plomo absorbido de $529 \mathrm{mg} / \mathrm{Kg}$ de materia húmeda. La alfalfa y la acelga presentan una transición de absorción de plomo durante un periodo de tiempo y luego continuaron absorbiendo contaminante sin presentar desintoxicación como ocurrió en el amaranto, además se observó que las plantas germinadas en tierra negra presentaron un decaimiento de absorción de contaminante luego de llegar a un cierto nivel, mientras que las plantas de alfalfa no presentaron este decaimiento hasta los 90 días, este fenómeno sugiere que puede tratarse de 




Figura 6. Preparación de suelos contaminados con plomo.

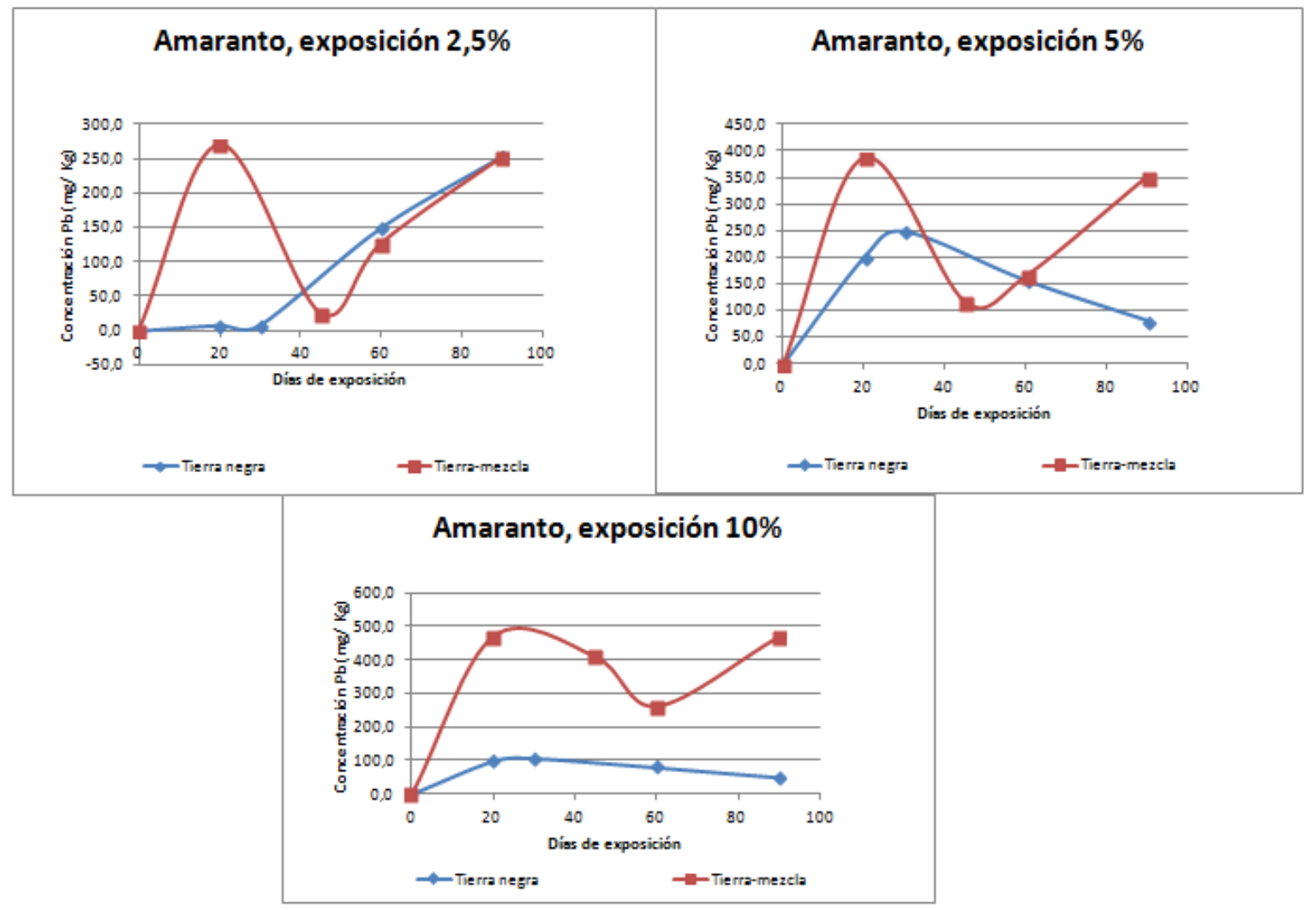

Figura 7. Plántulas germinadas en tierra-mezcla, a las cuatro semanas. 


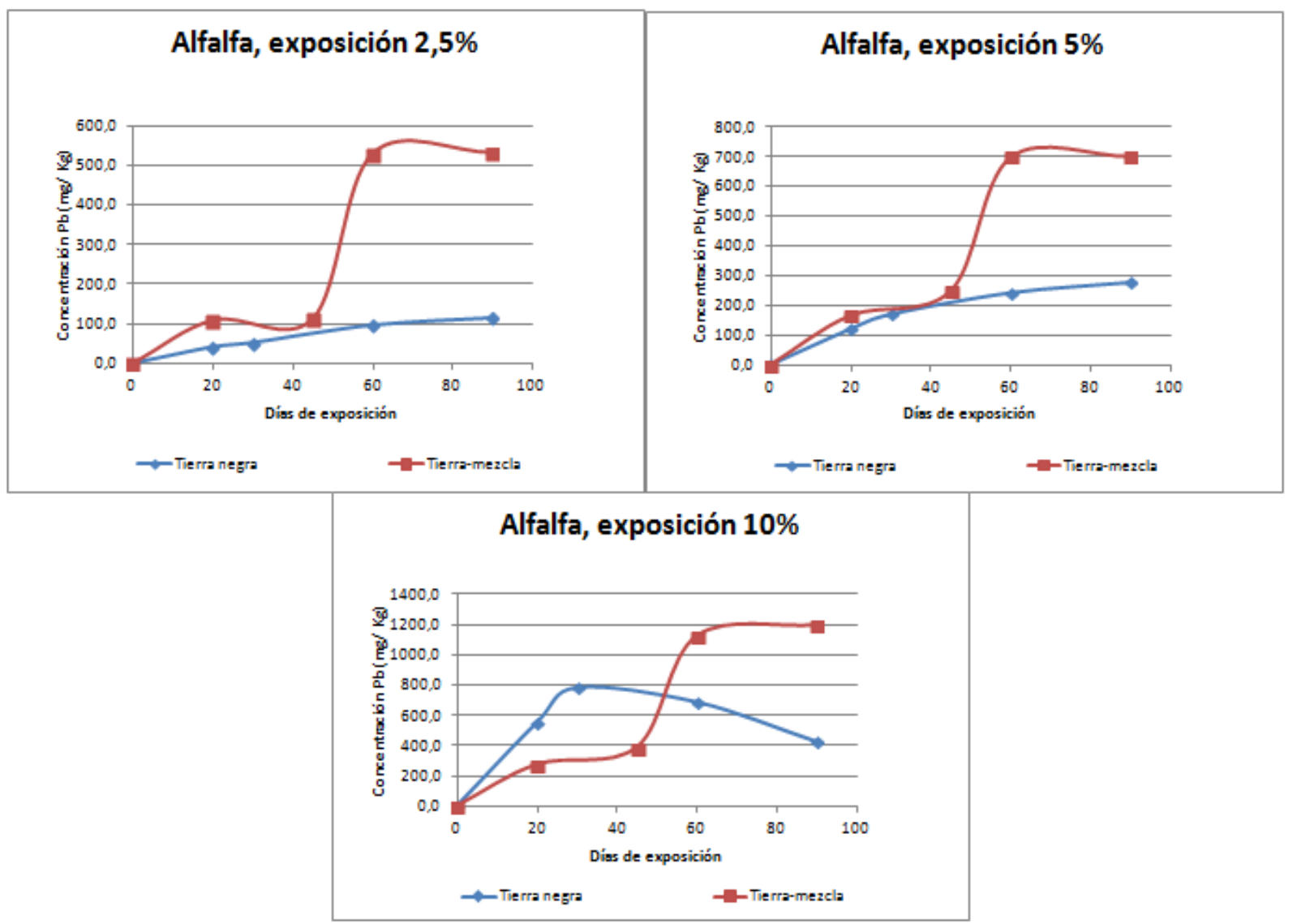

Figura 8. Plántulas germinadas en tierra-mezcla, a las cuatro semanas.

una planta hiper-acumuladora ya que el desarrollo de la planta no se ve afectada cuando incrementa el nivel de contaminante como señala Sarvajeet, et al., (2012) y Marrero, et al., (2012).

La diferencia en absorción de plomo en las especies vegetativas radica en la cantidad de biomasa generada durante la germinación, la cual hace que la planta mantenga el vigor durante el proceso de absorción y retención de plomo en la estructura vegetativa, por tanto a mayor cantidad foliar mayor cantidad de plomo absorbido según lo expuesto por Mahdieh, et al., (2013); este efecto generaría problemas de contaminación a los seres humanos y animales, ya que el metal pesado es atrapado por el tejido vegetal y permanece en la estructura sin presentar liberación del mismo debido a que el consumo habitual de estas especies en el caso de animales es de forma directa, mientras que para los humanos la ingesta es por medio de cocción en el caso del amaranto, germinados y sumos para la alfalfa y precocidos para la acelga, por tanto la incidencia y acumulación en los humanos es inminente.

La alfalfa al igual que el amaranto a medida que incrementó la concentración de contaminante presentó valores superiores de absorción, esto pudo deberse a que la estructura vegetativa y fibrosa de la planta facilitó la absorción, mientras que la acelga tiene estructura menos fibrosa dificultando el proceso tal como señala Zhou, et al., (2014) y Flores, et al., (2015); por otra parte la alfalfa y la acelga presentaron mayores valores de absorción debido a que son especies que están constantemente generando nuevos brotes, los cuales se encuentran absorbiendo continuamente el contaminante.

La Agencia Española de Seguridad Alimentaria y Nutrición (AESAN) en el año 2012, presentó un listado de productos que son susceptibles a la acumulación de metales pesados entre ellos se encontró la acelga, sugiriendo que para niños menores de 1 año se mantenga todos los controles del caso, ya que 


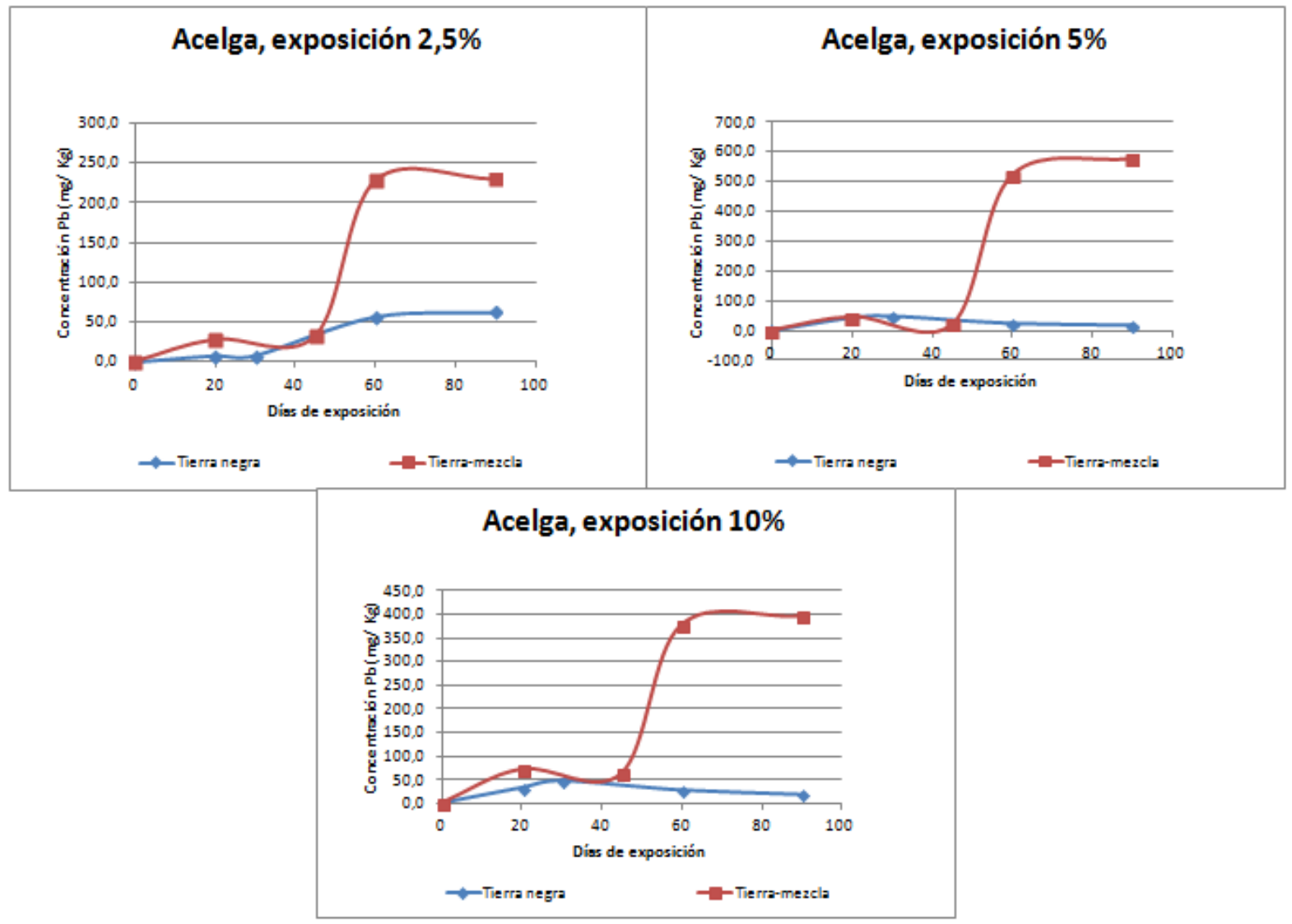

Figura 9. Plántulas germinadas en tierra-mezcla, a las cuatro semanas.

tres ingestas de acelga contaminada $(600 \mathrm{mg} \mathrm{Pb} / \mathrm{Kg}$ de acelga) en una dieta de $200 \mathrm{~g}$ serán suficiente para sobrepasar los $10 \mathrm{mg}$ de $\mathrm{Pb} / \mathrm{dL}$ de sangre establecido por la OMS. Por tanto es recomendable que previo a etapas de cultivos de especies vegetativas destinadas a consumo humano se realice análisis de metales pesados en los suelos de cultivo para evitar problemas de contaminación alimentaria.

\section{Conclusiones}

La especie Amaranthus hybridus (amaranto) presentó un proceso de desintoxicación de la planta, es decir liberación de plomo de la estructura vegetal, el cual nuevamente fue depositado en el suelo recontaminándolo, esto puede constituir un beneficio para la no contaminación de animales y humanos.

Medicago sativa (alfalfa) y Beta vulgaris (acelga) durante el tiempo de estudio (90 días) presentaron un proceso de absorción de plomo sin mostrar desintoxicación de la planta, esto sugiere que pueden tratarse de especies hiper-acumuladoras y potencialmente peligrosas para la seguridad alimentaria.

La adición de abono o nutrientes previo a la germinación de las especies, fue un factor determinante para la fitorremediación, ya que esto ayudó a que las plantas presenten abundante sistema radicular, un mayor crecimiento, frondosidad de la planta, mejores características al momento de su trasplante al suelo contaminado generando mayores concentraciones de absorción de plomo en plantas germinadas en tierra mezcla.

Finalmente, hay que mencionar que el proceso de fitorremediación es una técnica relativamente nueva y económicamente rentable, especialmente porque se puede trabajar con especies menores de ciclo corto y que pueden captar gran cantidad de metales pesados depurando el suelo, pero por otro lado la mala disposición de dichas especies podría 
provocar intoxicaciones severas y afectaciones a la seguridad alimentaria.

\section{Referencias}

Adesodun, J., M. Atayese, T. Abbaje, B. Osadiaye, O. Mafe y A. Soretire. 2010. Phytoremediation Potentials of Sunflowers (Tithonia diversifolia and Helianthus annuus) for Metals in Soils Contaminated with Zinc and Lead Nitrates. Water Air Sail Pollut. 7: 195-201.

Agudelo, L., K. Macías y A. Suárez. 2009. Fitorremediación: la alternativa para absorber metales pesados de los biosólidos. Red Revista Lasallista. 6: 57-60.

Alcalá, J., M. Sosa, M. Moreno, R. Juan, Q. C. y C. T. et al. 2009. Metales pesados en suelo urbano como un indicador de la calidad ambiental: Ciudad de Chihuahua, México. Argentina: B-Geobotánica y Fitogeografía IADIZA (CONICET). B: 53-69.

Armas, T. y D. Castro. 2009. Impacto de la contaminación ambiental sobre los cultivos: metales pesados. Ciencia y Tecnología de Alimentos. 17(7): 1-8. D. Instituto de Investigaciones para la Industria Alimentaria.

ASTM. 2014. Standard test method for $\mathrm{pH}$ of soils. ASTM D4972, 6.

Babula, P., V. Adam, L. Havel y R. Kisek. 2012. Cadmium Accumulation by Plants of Brassicaceae Family and Its Connection with Their Primary and Secondary Metabolism. En N. Anjun, I. Ahmad, E. Pereira, A. Duarte, S. Umar, \& N. Khan. The Plant Family Brassicaceae. Contribution Towards Phytoremediation. Moscú: Editorial Board: 71-98.

Benoit, V. y G. Stephen. 2010. Phytoremediation of chlorinated solvent plus. En A. AECOM Environment, In Situ Remediation of Chlorinated Solvent Plumes. Philadelphia: 1-8.

Betancourt, O. 2009. Minería y Contaminación en Ecuador. ACD Consulting. 1: 4.

Botello, N. 2014. Producción hidropónica de dos variedades de acelga (Beta vulgaris var. cicla) con tres soluciones nutritivas en el D-5 de la ciudad de El Alto. Universidad Mayor de San Andrés. 1: $1-44$.
Botero, B. 2009. Los germinados: Alimento y medicina natural. Germinados. 6: 1-8.

Cala, V. y Y. Kunimine. 2003. Distribución de plomo en suelos contaminados en el entorno de una planta de reciclaje de baterías ácidas. Revista Internacional de Contaminación Ambiental. 9: 109-115.

Carrasquero, A. 2006. Determinación de los niveles de contaminación con plomo en los suelos y polvo de las calles de la ciudad de Maracay. Agronomía Tropical. 16: 237-252.

Chamizo, A., R. Ferrera, M. Gonzáles y C. Ortiz. 2009. Inoculación de alfalfa con hongos micorrízicos arbusculares y rizobacterias en dos tipos de suelo. TerraLatinoamericana. 27(3,9): 197-205.

Chinmayee, D., B. Mahesh, S. Pradesh y I. Mini. 2012. The Assessment of Phytoremediation Potential of Invasive Weed Amaranthus Spinosus L. Appl. Biochem Biotechnol. 10: 1550-1559.

CODEX. 2014. Programa conjunto FAO/OMS sobre normas alimentarias. Organización de las Naciones Unidas para la agricultura y la alimentación. Comisión del Codex Alimentarius: 135.

CPE, I. 2013. Código de prácticas para la prevención y reducción de la presencia de plomo en los alimentos. (CAC/RCP 56-204, IDT). INEN. CPE INEN-CODEX CAC/RCP 56: 12.

De Souza, E., L. Guimaraes, E. Chaves, B. Ribeiro, E. DosSantos y E. DaCosta. 2012. Assessing the Tolerance of Castor Bean to $\mathrm{Cd}$ and $\mathrm{Pb}$ for Phytoremediation Purposes. Biol Trace Elem Res. 8: 93-100.

Diez, J., P. Kidd y C. Monterroso. 2009. Biodisponibilidad de metales en suelos y acumulación en plantas en el área de Trás-os-Montes (NE Portugal): influencia del material original. España: Sociedad española de la Ciencia del suelo. 17: 313328.

Dueñas, J. 2014. Propuesta de diseño en batch para remoción de plomo (III) desde solución acuosa, empleando un material adsorbente cubano. Revista estudiantil nacional de Ingeniería y arquitectura RENIA. 5: 40-44.

EPA. 2005. Acid digestion of aqueous samples and extracts for total metals for analysis by FLAA or 
ICP Spectroscopy . Standard methods ed-21. EPA 3010a: 5.

Fakayode, S. y P. Chianwa. 2002. Heavy metal contamination of soil, and bioaccumulation in Guinea grass (Panicum Maximun) around Ikeja Industrial Estate, Lagos, Nigeria. Environmental Geology. 6: 145-150.

Falcó, G. y J. Martí. 2012. Riesgo tóxico por metales presentes en alimentos. España.

FAO. 2010. Políticas de seguridad e inocuidad y calidad alimentaria en américa latina y el caribe. Chile: Organización de las Naciones Unidas para la Agricultura y la Alimentación.

Félix, I., F. Mite, M. Carrillo y M. Pino. 2012. Avances de Investigación del Proyecto Determinación de metales contaminantes en cultivos de exportación y su reprecusión sobre la calidad de los mismos. VII Congreso Ecuatoriano de la Ciencia del Suelo. 8 .

Flores, M., S. Hattab, S. Hattab, H. Boussetta, M. Banni y L. Hernández. 2015. Specific mechanisms of tolerance to copper and cadmiun are compromised by a limited concentration of glutathione in alfalfa plants. Plant Science. 233: 165173.

Flores, A. 2010. Influencia en seis híbridos de girasol (Helianthus annus), con aplicación de boro, su comportamiento agronómico y el rendimiento, en la granja experimental E.C.A.A. Quito: Pontificia Universidad Católica del Ecuador. Sede Ibarra.

Garzón, A. 2006. Informe Plomo y Cadmio en Ecuador. Quito: Ministerio de Ambiente de la República del Ecuador.

Guanopatín, M. 2012. Aplicación de Biol en el cultivo establecido de Alfalfa (Medicago sativa). Universidad Técnica de Ambato.

Gunnar, N. 2012. Metales: propiedades químicas y toxicidad. En: enciclopedia de la OIT. España: D-INSHT (Instituto Nacional de Seguridad e Higiene en el Trabajo).

Gupta, D., H. Huang y F. Corpas. 2013. Lead tolerance in plantas: strategies for phytoremediation. Environ Sci Pollut Res. 12: 2150-2161.
Herrera, K. 2009. Evaluación de la contaminación por plomo en suelos del cantón Sitio del Niño Municipio de San Juan Opico departamento de la Libertad. Universidad de El Salvador. Tesis Licenciatura: 129.

INEN. 2010. Preparados de inicio para la alimentación de lactantes. Norma Técnica Ecuatoriana NTE INEN 707:2010. INEN: 23.

Infante, C., D. Arco y E. Angulo. 2013. Removal of lead, mercury and nickel using the yeast Saccharomyces cerevisiae. Revista MVZ Córdoba. 10: 4141-4149.

Jácome, E. 2011. Perforaciones y estudios del suelo. Unidad de Metro Quito. 2.

Krueger, E., J. Darland, S. Goldyn, R. Swanson, R. Lehmann, S. Shepardson y et al. 2013. Water Leaching of Chelated $\mathrm{Pb}$ Complexes from PostPhytoremediation Biomass. Water Air Soil Pollut. 11: 1614-1618.

López, E. y E. Torija. 2006. Caracterización y tipificación de mostazas comerciales. Universidad Complutense de Madrid. página 304.

Mahdieh, M., M. Yazdani y S. Mahdieth. 2013. The high potential of Pelargonium roseum plant for phytoremediation of heavy metals. Environ Monit Assess. 5: 7877-7881.

Marrero, J., I. Amores y O. Coto. 2012. Fitorremediación, una tecnología que involucra a plantas y microorganismos en el saneamiento ambiental. REDALYC. ORG. Red de Revistas Científicas de América Latina, El Caribe, España y Portugal: 11.

Mateo, J. 2008. Prontuario de agricultura: cultivos agrícolas. España: Mundi-Prensa.

Mayank, V., D. Rohan, K. Devendra y P. Manoj. 2011. Bioassay as monitoring system for lead phytoremediation through Crinum asiaticum L. Environ Monit Assess. 9: 373-38.

NOM. 2002. Salud ambiental. Niveles de plomo en sangre y acciones como criterios para proteger la salud de la población expuesta no ocupacionalmente. Norma Oficial Mexicana. NOM-199SSA1-2000: 20.

Olivares, S., D. García, L. Lima, I. Saborit, A. Llizo y P. Pérez. 2013. Niveles de Cadmio, Plomo, Cobre y Zinc en Hortalizas cultivadas en una zona 
altamente urbanizada de la ciudad de la Habana, Cuba. Revista Internacional Contaminación Ambiental. 10: 285-294.

OMS. septiembre 2013. Intoxicación por plomo y salud. Organización Mundial de la Salud. Nota descriptiva $\mathrm{N}^{\circ} 379$. URL http://www.who.int/mediacentre/factsheets/ fs379/es/. Recuperado el 16 de Julio de 2014.

Peralta. 2009. Amaranto y Ataco preguntas y respuestas. Ecuador: Programa Nacional de Leguminosas y Granos Andinos. INIAP: 4.

Qaisar, M., R. Audil, A. Sehikh, A. Muhammad y B. Muhammad. 2012. Current Status of Toxic Metals Addition to Environment and Its Consequences. En N. Anjun, I. Ahmad, E. Pereira, A. Duarte, S. Umar, \& N. Khan, The plant famiy Brassicaceae. Contribution towards Phytoremediationl Moscú: Editorial Board: 35-65.

RECNAT. 2002. Norma Oficial Mexicana NOM021-SEMARNAT-2000 que establece las especificaciones de fertilidad, salinidad y clasificación de suelos, estudio, muestreo y análisis. Secretaría de Medio Ambiente y Recursos Naturales. página 85.

Redín, L. 2009. Caracterización física, química y nutricional de dos ecotipos de acelga (beta vulgaris L.) cultivados en el Ecuador como un aporte a la actualización de la norma INEN N ${ }^{\circ} 1749$ "Hortalizas frescas, acelga requisitos". Universidad Tecnológica Equinoccial. página 198.

Roca, A. 2009. Contaminación de suelos por metales pesados. Galicia: Centro de Investigaciones Agrarias de Mabegondo. INGACAL.

Rodríguez, J., R. Valdez, J. Lara, H. Rodríguez, R. Vásquez, R. Magallanes y et al. 2006a. Soil nitrogen fertilization effect on phytoextraction of
$\mathrm{Cd}$ and $\mathrm{Pb}$ by tobacco (Nicotiana tabacum) 1. Bioremediaton Journal. 10: 105-114.

Rodríguez, R., A. García y R. Rodríguez. 2006b. Los residuos minero-metalúrgicos en el medio ambiente. España: Instituto geológico y minero de España. Serie medio ambiente $\mathrm{N}^{\circ} 11$.

Salas, M. y A. Boradonenko. 2009. Insectos asociados al amaranto amaranthus hupocondriacus L. (amaranthaceae) en Irapuato, Guanajuato, México. Universidad de Guanajuato. 7: 50-55.

Salin, E. y C. Skinner. 1995. Determination of lead in soil surrounding a lead-acid battery manufacturer. Water Quality Research Journal of Canada. 30: 299-307.

Sarvajeet, G., A. Naser, A. Iqbal, P. Thangavel, G. Sridevi, A. Pacheco y et al. 2012. Metal Hyperaccumulation and Tolerance in Alyssum, Arabidopsis and Thlaspi: An Overview. En N. Anjum, I. Ahmad, E. Pereira, A. Duarte, S. Umar, \& N. Khan. The Plant Family Brassicaceae. Contribution Towards Phytoremediation. Moscú: Board: 99-137.

Suthar, V., K. Memon y M. Hassa. 2014. EDTA- enhanced phytoremediation of contaminated calcareous soils: heavy metal bioavailability, extractability, and uptake by maize and sesbania. Environ Monit Assess. 12: 3957-3968.

Torres, P., J. Silva y J. Escobar. 2007. Aplicación agrícola de lodos compostados de plantas de tratamiento de aguas residuales municipales. Livestock Research for Rural Development. 19: 12.

Zhou, P., F. Yang, X. Ren y B. H. Y. An. 2014. Phytotoxicity of aluminum on root growth and indole3-a acid accumulation and transport in alfalfa roots. Environmental and experimental botany. 104: 1-8. 
LA GRANJA:

REVISTA DE

CienCIAS DE LA VIDA

DOI:10.17163/lgr.n23.2016.05
Artículo científico / Scientific paper

CONTAMINACIÓN

\title{
EVALUACIÓN QUÍMICA Y MICROBIOLÓGICA DE LA PLAYA DE “LOS Esteros" EN LA CIUDAD DE MANTA
}

\author{
Chemical AND microbiological eVAluation of THE “Los Esteros" \\ BEACH IN THE MANTA CITY
}

\section{Carlos Enrique González Arteaga ${ }^{1, *}$ e Hilda Yajaira González Arteaga ${ }^{2}$}

${ }^{1}$ Pontificia Universidad Católica del Ecuador, Campus Chone. Dirección, Vía a Quito Km 111/2, Teléfono: (593) 099 482-280. Chone, Ecuador.

${ }^{2}$ Facultad de Medicina de la Universidad Laica Eloy Alfaro de Manabí. Dirección Av. Circunvalación, Manta, Ecuador.

*Autor para correspondencia: krloseng@hotmail.com

Manuscrito recibido el 20 de enero de 2015. Aceptado, tras revisión, el 10 de junio de 2016

\begin{abstract}
Resumen
Esta investigación analiza el estado ambiental de las playas de la parroquia "Los Esteros" de la ciudad de Manta. Estas playas en sus $1.2 \mathrm{~km}$ de extensión aproximada, presentan la cantidad de $\mathrm{DBO}_{5}, \mathrm{DQO}$, sólidos suspendidos así como coliformes totales, Escherichia coli entre otros factores. Los cuales inciden en las características de las aguas y sean consideradas poco aptas para usos recreativos de contacto primario. El análisis se lleva a cabo en el año 2014, utilizando las normas establecidas por el índice de calidad del agua y la comparación con los límites máximos permisibles para descargas a cuerpos marinos, establecidos en la Ley de Gestión Ambiental, del Ecuador.
\end{abstract}

Palabras claves: coliformes totales, límites máximos permisibles, playa Los Esteros, Manta.

\begin{abstract}
This research analyzes the environmental state of the "Los Esteros" beach in the city of Manta. In this beach, with $1.2 \mathrm{~km}$ length, were sudied the amounts of $\mathrm{DBO}_{5}, \mathrm{DQO}$, suspended solids and total coliforms; included Escherichia coli and other factors that affect the characteristics of the water and can considered unsuited for primary contact and recreation. The analysis was carried out in 2014, using the standards set by the water quality index and maximum permissible limits for discharges to marine bodies established by the Environmental Management Law of Ecuador.
\end{abstract}

Keywords: total coliforms, maximum permissible limits, Los Esteros beach, Manta.

Forma sugerida de citar: González, C. y H. González. 2016. Evaluación química y microbiológica de la playa de “Los Esteros" en la ciudad de Manta. La Granja: Revista de Ciencias de la Vida. Vol. 23(1): 52-59. ISSN impreso: 1390-3799. ISSN electrónico: 1390-8596. 


\section{Introducción}

En la parroquia "Los Esteros" el mayor problema son las descargas de aguas residuales, emisiones de humo y gas tóxico producido por actividades humanas e industriales aledañas que cada vez aumentan y con ello contribuyen a una mayor degradación de estas zonas no solo turísticas sino también ecológicas.

Además, existen bypass sanitarios, como por ejemplo el construido a la altura de la Calle 119 y Av. 101 (Ver Figura 1) y que lleva a que las aguas negras vayan directamente al mar, y otros bypass que se han construido en diferentes lugares a lo largo de esta playa y no solo afectan a la misma sino que se unen con los agentes contaminantes generados de la playa de Tarqui.

Es importante poder determinar el tipo de contaminación que se tiene sobre el área de estudio para tomar las medidas correctivas y preventivas, y aplicar la remediación pertinente, la misma que si bien es cierto será complicada, pero con resulta- dos notorios. Con estas medidas se debería también iniciar al mismo tiempo una cadena progresiva de campañas agresivas de concientización ambiental.

De esta manera, es evidente la importancia de realizar procedimientos de análisis cualitativos y cuantitativos que permitan determinar el tipo y la concentración del contaminante; además, de su fuente de generación. Para después dar respuesta al pregunta de por qué en los últimos años, según reportes del subcentro de salud de la parroquia Los Esteros, han surgido varias enfermedades dérmicas e intestinales en la población aledaña a esta playa sobre todo en la infantil (González, C., 2014).

La contaminación de la playa de la parroquia Los Esteros de la ciudad de Manta, es un problema que viene afectando tanto a la fauna marina como a los habitantes, turistas del sector y a los legendarios pescadores que iniciaron esta parroquia hace algunas décadas atrás. La situación empeora en la playa ubicada en la desembocadura del Río Muerto ya que es el medio que utilizan los industriales de la parroquia y algunos habitantes para descargar

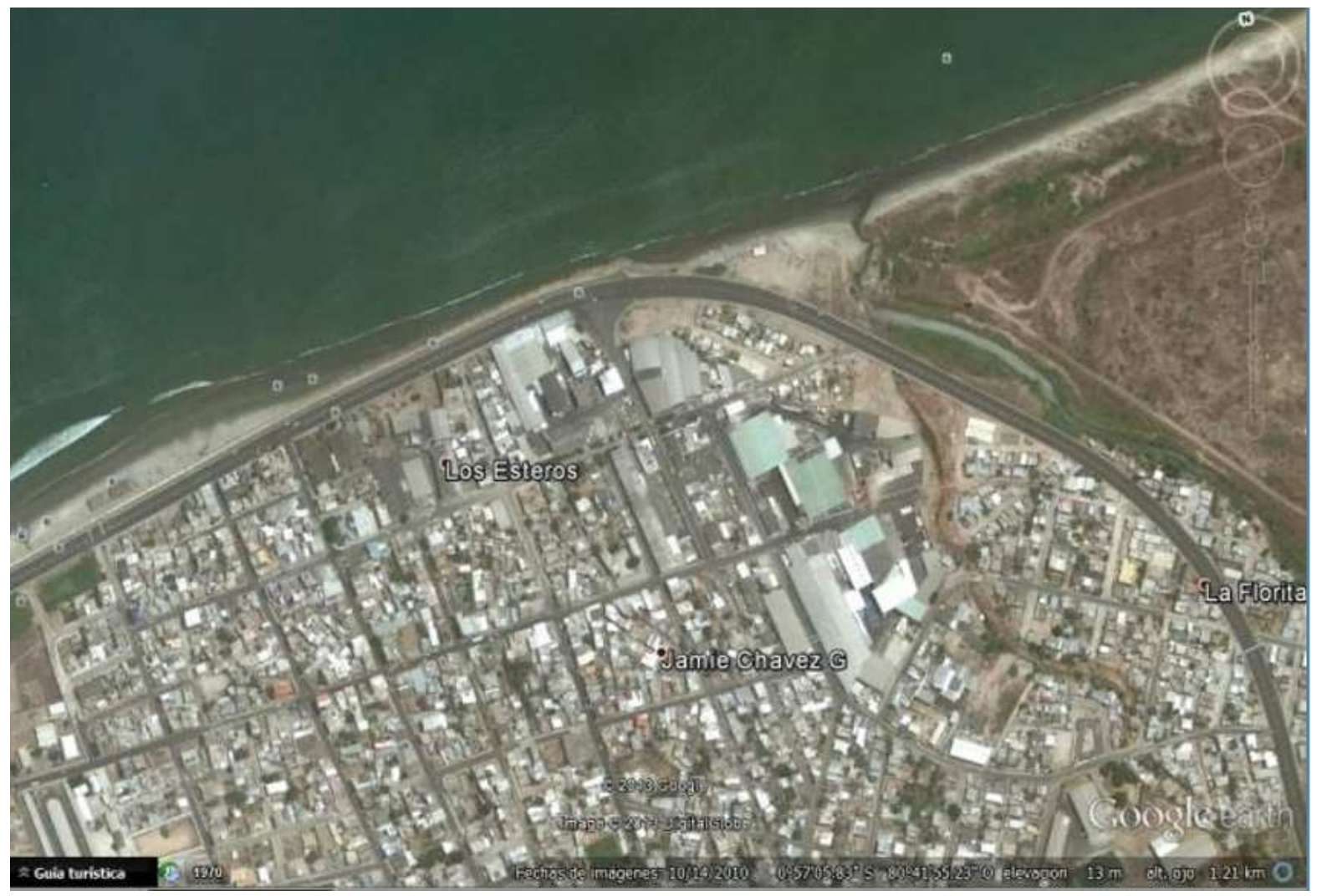

Figura 1. Playa “Los Esteros". Fuente: Google maps (2010) 
aguas residuales y que tienen destino final el mar. Inclusive la gente de la zona indica vernáculamente que es "el río Muerto que mató". Según las investigaciones realizadas por los autores de este artículo y por el Biólogo Jorge González (2014), esta playa registra los más altos índices y niveles de contaminación permitidos por la Ley de Gestión Ambiental. Puesto que existen altas dosis de grasas, aceites, enterobacterias, E. coli y hasta coliformes fecales. Pese a que los niveles han disminuido en los últimos años, aún hay conexiones clandestinas de fábricas y domicilios que van directo al río.

Las aguas no deben registrar niveles de contaminantes por encima de lo permitido, esto es en DBO100 mg/lt, y DQO $250 \mathrm{mg} / \mathrm{lt}$ así como 100 coliformes fecales por cada $100 \mathrm{mg} / \mathrm{lt}$ de sólidos suspendidos según la ley para la Prevención y Control de la Contaminación Ambiental del Ecuador (2008), al superar estas cantidades de residuos se convierten en aguas no aptas para la natación.

En el caso de esta playa como en muchos cuerpos de agua marino en el mundo, los vertidos llegan directamente al mar de la misma manera como salen de sus fuentes de origen, además de los contaminantes que se le suman en el trayecto que realizan (Daiefa et al., November 2014).

El agua de los mares y de los ríos ha sido utilizada tradicionalmente, como medio de evacuación de los desperdicios humanos y los ciclos biológicos del agua aseguran la reabsorción de dichos residuos orgánicos reciclables. Algunos de los productos vertidos, no son biodegradables y permanecen largo tiempo en el ambiente. Los elementos vivos que habitan en estas aguas, usualmente ingieren estos microorganismos o compuestos químicos y los llevan en la cadena trófica alimentaria de nuevo al ser humano. Específicamente en esta playa, se realizan labores de pesca y en el mismo sitio se comercializa pescado supuestamente fresco generando efectos negativos para la salud humana, aparte del daño ecológico en general. Efectos negativos que incluso ya se reflejan según el ministerio de salud a través del subcentro de salud de la parroquia donde se encuentra ubicada la playa en mención (González, C., 2014).

Hidrográficamente, el sitio de estudio se encuentra atravesado por tres extensos ríos invernales (Manta, Burro y Muerto), los que cruzan amplias zonas urbanas pobladas, y desembocan en el mar generando malos olores, color del agua con alteraciones, incrementándose los valores permitidos por la (Ministerio del Ambiente del Ecuador (MAE), 2008) en cuanto a DBO y DQO, variaciones en el $\mathrm{pH}$, entre otros. El mayor foco de contaminación de esta playa lo constituye el ya mencionado cauce del Río Muerto. Este río, por ser invernal, la mayor parte del año pasa seco, al menos así debería ser, incluso por eso su nombre, además de por la poca cantidad de vida marina que se encuentra en él. Sin embargo, al cruzar por zonas pobladas tales como "Mar y Cielo", "Divino Niño", "Urbanización Millenium" y la "Florita", los cauces del río han sido tomados como canales de descargas de aguas servidas, ya que una buena parte de la población circundante, ha construido canales o tuberías directas al cauce del río y de esta manera evacuan sus aguas negras y desechos sólidos, aun sabiendo que estos contaminan y los afectan directamente a ellos mismos.

Una parte de estas aguas servidas, al no existir flujo alguno de lluvias durante el verano, que las arrastren consigo hacia el mar como en el sector de las tres cruces, permanecen estancadas largos lapsos de tiempo, emanando fuertes olores y contaminando el ambiente, lo que lo convierte en un gran caldo de cultivo de insectos, roedores y agentes causantes de enfermedades que generalmente ponen en riesgo la salud de los mismos moradores del sector.

Así, la falta de una educación ambiental comunitaria en Salud Pública y el desconocimiento de los peligros que aquello representa para la propia salud de las personas que habitan en estos sectores, impide que se tome conciencia de las nefastas consecuencias y de las malas costumbres ciudadanas, lo cual se convierte en un verdadero peligro. A pesar de que se encuentra en construcción el plan maestro hidrosanitario y el mismo que casualmente cubre la mayoría de barrios que son atravesados por el río Muerto y cercanos a la playa en estudio (Empresa Pública de Aguas de Manta, 05 de 11 de 2014).

\section{Materiales y métodos}

El presente trabajo investigativo se realizó en los $1.2 \mathrm{~km}$ de playa que comprende el sector de la parroquia "Los Esteros" del cantón Manta. Los análisis realizados comprenden: Composición del agua de la playa, bromatología, parámetros microbiológicos, $\mathrm{pH}$ y temperatura.

Cada muestreo se realizó en tres puntos, El punto de Muestreo 1 se ubicó en la desembocadura del río Muerto, que es el lugar donde se une con la pla- 
ya de los Esteros, el punto de Muestreo 2, ubicó en la zona de mayor afluencia turística, y el punto de Muestreo 3 se ubicó al final de la playa de dicha parroquia y donde inicia la playa de la parroquia Tarqui.

En cada lugar de muestreo se realizaron tres repeticiones con un intervalo de 10 a 30 días correspondientes a los meses de octubre, noviembre y diciembre de 2014. Meses en los que se presenta un cambio de temporada de verano a invierno.Durante este periodo se realizó una medición diaria de $\mathrm{pH}$, temperatura, sólidos totales, DBO, DQO, E. Coli, Salmonella y Shiguella. Los análisis de agua se realizaron en las instalaciones de los Laboratorios de la Escuela Superior Politécnica Agropecuaria de Manabí MFL del cantón Bolívar.

Para la realización de estos análisis se utilizaron materiales de muestreo y de laboratorio como botellas de 500 cc, las cuales están provistas de una tapa de apertura remota a fin de no exponer al ambiente su interior una vez tomadas las muestras, para de esta forma, obtener mejores características naturales de del agua. Adicionalmente se utilizó un termómetro para verificar la temperatura de estas aguas y fundas plásticas para transportar las muestras de sedimentos. Así mismo se utilizaron materiales de laboratorio como pipetas, caja Petri, vasos de precipitación, balanzas, entre otros y los medios de culti- vo necesarios como agar, caldo selenito y otros.

\section{Resultados y discusión}

Se muestran los resultados de los análisis de $\mathrm{pH}$ en la playa de la parroquia Los Esteros en los tres puntos de muestreo en los meses de octubre, noviembre y diciembre del año 2014 que es donde se produce el cambio de temporada entre verano invierno. El $\mathrm{pH}$ se encuentra en rangos de 6 y 8 que son considerados altos.

En la Figura 3, se muestran los resultados de los análisis de DBO5 en la playa de "Los Esteros" en los meses de octubre, noviembre y diciembre. Los límites máximos permisibles son hasta $100 \mathrm{mg} / \mathrm{lt}$ y en el punto de Muestreo 1 sobrepasa este límite en todos los meses de estudio, mientras que en los meses restantes el resultado cumple con la norma.

A continuación se presentan los resultados de los análisis de DQO en la playa de "Los Esteros" en los meses que se realizó el muestreo. Se resalta que los datos de resultados que presentamos a continuación se hacen en $\mathrm{mg} / \mathrm{lt}$, y el límite máximo permisible que es de $250 \mathrm{mg} / \mathrm{lt}$ según la ley para la Prevención y Control de la Contaminación Ambiental del Ecuador 2008, sobre los índices de calidad del agua en la (Ministerio del Ambiente del Ecuador (MAE), 2008), libro VI.

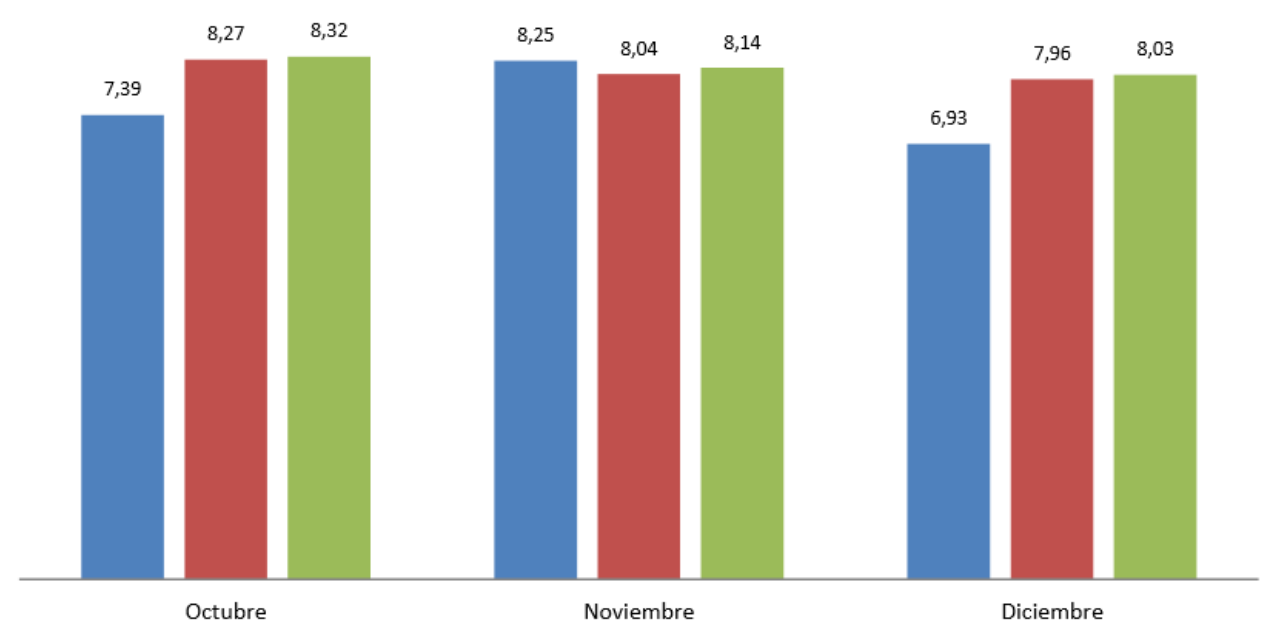

Figura 2. Resultados de análisis de $\mathrm{pH}$. El color azul representa el punto de Muestreo 1 ubicado en la desembocadura del río Muerto, que es el lugar donde se une con la playa de "Los Esteros", el color rojo el punto de Muestreo 2, que está ubicado en la zona de mayor afluencia turística, y el color verde. 


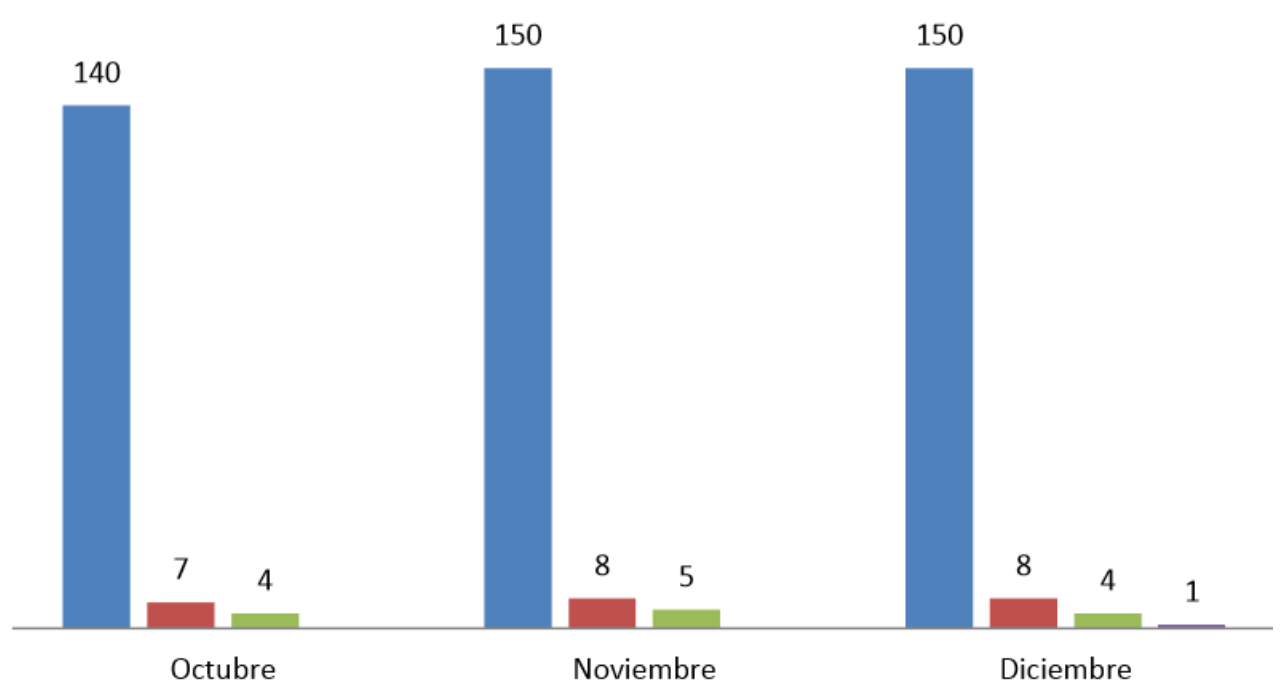

Figura 3. Análisis de $\mathrm{DBO}_{5}$ en $\mathrm{mg} / \mathrm{lt}$. El color azul representa el punto de Muestreo 1 ubicado en la desembocadura del río Muerto, que es el lugar donde se une con la playa de "Los Esteros", el color rojo el punto de Muestreo 2, que está ubicado en la zona de mayor afluencia turística, y el color verde el punto de Muestreo 3 ubicada al final de la playa de dicha parroquia y donde inicia la playa de la parroquia Tarqui.

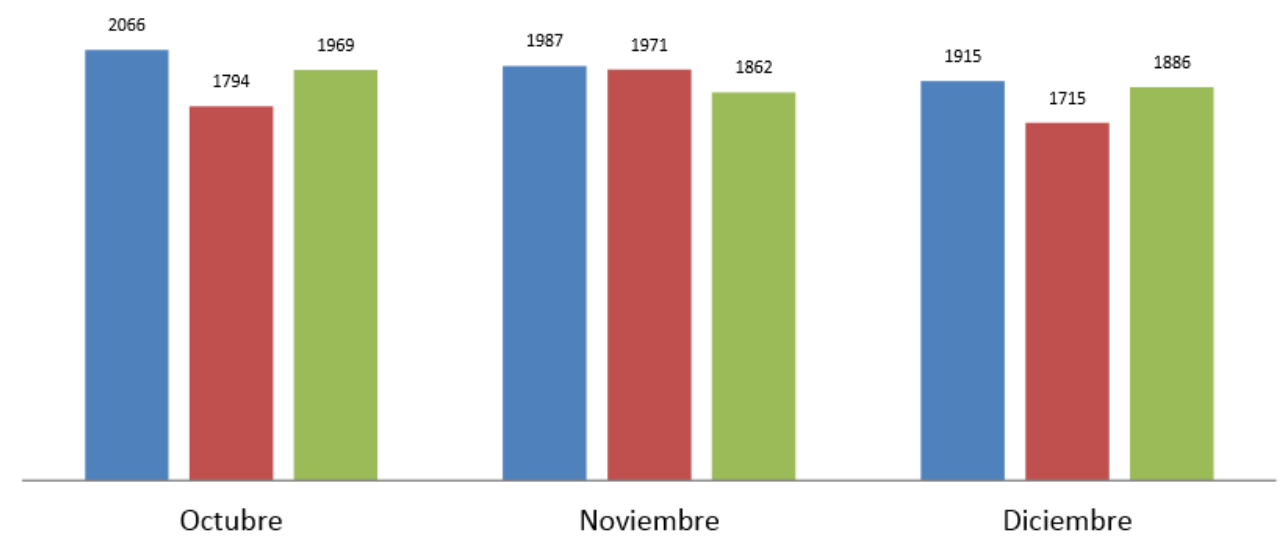

Figura 4. Resultados del análisis de DQO en ppm/lt. El color azul representa el punto de Muestreo 1 ubicado en la desembocadura del río Muerto, que es el lugar donde se une con la playa de "Los Esteros", el color rojo el punto de Muestreo 2, que está ubicado en la zona de mayor afluencia turística, y el color verde el punto de Muestreo 3 ubicada al final de la playa de dicha parroquia y donde inicia la playa de la parroquia Tarqui.

En la Figura 4, se muestran los resultados de sólidos totales encontrados en los diferentes puntos de muestreo de la playa en estudio. Sabiendo que en este parámetro es indeseable que existan sólidos en un cuerpo de agua marino con fines recreativos.

Se aprecia la existencia de una elevada presencia de sólidos totales, siendo el límite máximo permisible de 100 ppm/lt y en los tres meses de muestreo se registraron niveles de entre 1715 y 2055 ppm/lt, asimismo ocurre con los valores de sólidos suspendidos (Figura 5) lo cual demuestra que estas aguas están altamente contaminadas y sobrepasan los parámetros de los índices de calidad.

Así como se realizaron análisis químicos, también se presentan análisis microbiológicos para determinar la presencia de agentes causantes de en- 
fermedades a los habitantes de sectores aledaños, tanto a la playa como al río Muerto por la relación directa y contaminante que se genera en ellos. En el Figura a continuación, se presentan los resultados de los análisis de coliformes fecales, donde se determina la presencia en exceso, y he aquí la respuesta confirmativa a tantos casos registrados en el área de salud en el año anterior a la presente investigación.

En cuanto a Salmonella y Shiguella se tuvieron resultados positivos en el punto de Muestreo 1, es decir en la desembocadura del río hacia la playa ; es decir, que existe presencia de ambos, mientras que en los puntos 2 y 3 no se determinó presencia de los mismos. En cuanto a Coliformes totales en el punto de Muestreo 1, en los tres meses se detectó mediante los análisis de laboratorio que eran incontables pero no por la inexistencia de los mismos sino más bien por la presencia excesiva de los mismos, ya que en el conteo en laboratorio fue imposible determinar un número exacto o aproximado por la elevada cantidad que existe.

En Figura 7 se presentan los datos obtenidos de esta investigación; en el año 2012 según los reportes obtenidos en el subcentro de salud de la parroquia "Los Esteros" que se encuentra ubicado a 500 metros aproximadamente del cauce del río Muerto y a $1 \mathrm{~km}$ aproximado de distancia de la playa en estudio, existieron varias enfermedades reportadas aquel año, y la mayoría de las enfermedades que se relacionan con la contaminación de estos cuerpos marinos se dieron en personas que habitan en el sector del cauce del río Muerto y que muchas veces las viviendas donde ellos habitan, contribuyen a dicha contaminación tanto con los residuos líquidos como residuos sólidos domiciliarios.

En cuanto a enfermedades del tipo Infección respiratoria aguda se presentó aquel año un total de 2244 casos de personas infectadas de la parroquia "Los Esteros" y el mayor índice de casos ocurrió en niños de entre 1-4 años de edad, mientras que parasitosis se dio en su mayoría en niños de 5-14 años de edad donde se tuvieron 395 casos solo en este rango de edad, mientras que de forma general se tuvieron 791 casos. En cuanto a la dermatitis se presentaron 126 casos y de estos la mayor parte fue entre niños de menos de un año hasta personas de entre 15 a 49 años, donde se presentaron 121 casos.

\section{Conclusiones}

Los resultados demuestran que la playa está contaminada tanto en sus características químicas como microbiológicas. Esta playa no debería ser considerada apta para fines recreativos, ya que sobrepasa los límites máximos de contaminación permisibles en la legislación ambiental ecuatoriana, sobretodo en el cauce del Río Muerto.

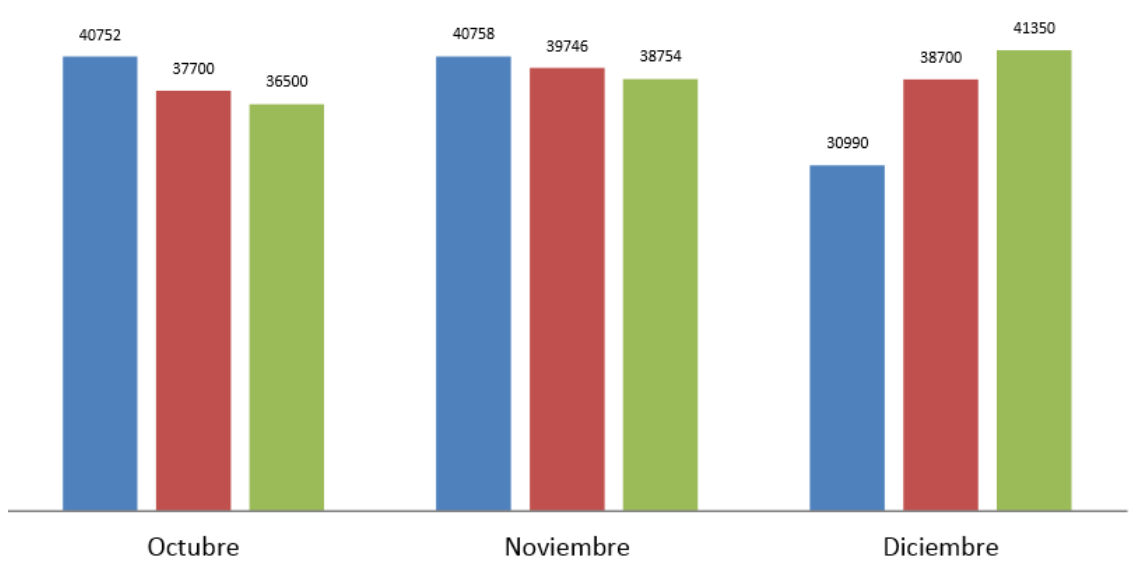

Figura 5. Resultados de análisis de sólidos suspendidos en ppm/lt. El color azul representa el punto de Muestreo 1 ubicado en la desembocadura del río Muerto, que es el lugar donde se une con la playa de "Los Esteros", el color rojo el punto de Muestreo 2, que está ubicado en la zona de mayor afluencia turística, y el color verde el punto de Muestreo 3 ubicada al final de la playa de dicha parroquia y donde inicia la playa de la parroquia Tarqui. 


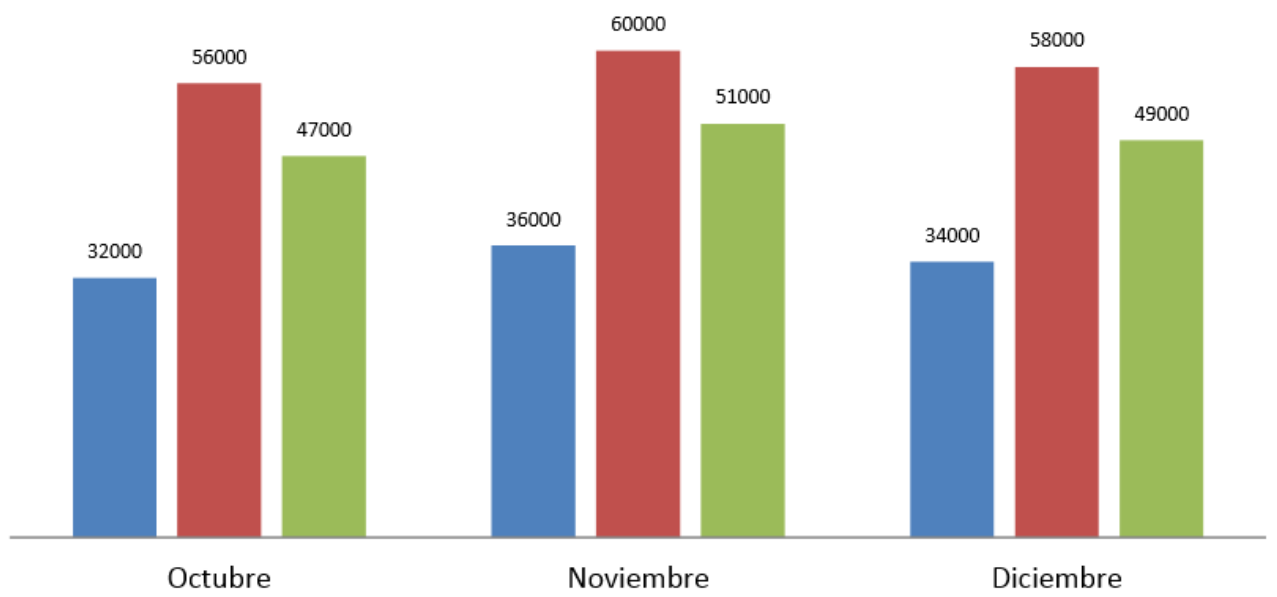

Figura 6. Resultados de análisis de Coliformes fecales. El color azul representa el punto de Muestreo 1 ubicado en la desembocadura del río Muerto, que es el lugar donde se une con la playa de "Los Esteros", el color rojo el punto de Muestreo 2, que está ubicado en la zona de mayor afluencia turística, y el color verde el punto de Muestreo 3 ubicada al final de la playa de dicha parroquia y donde inicia la playa de la parroquia Tarqui.

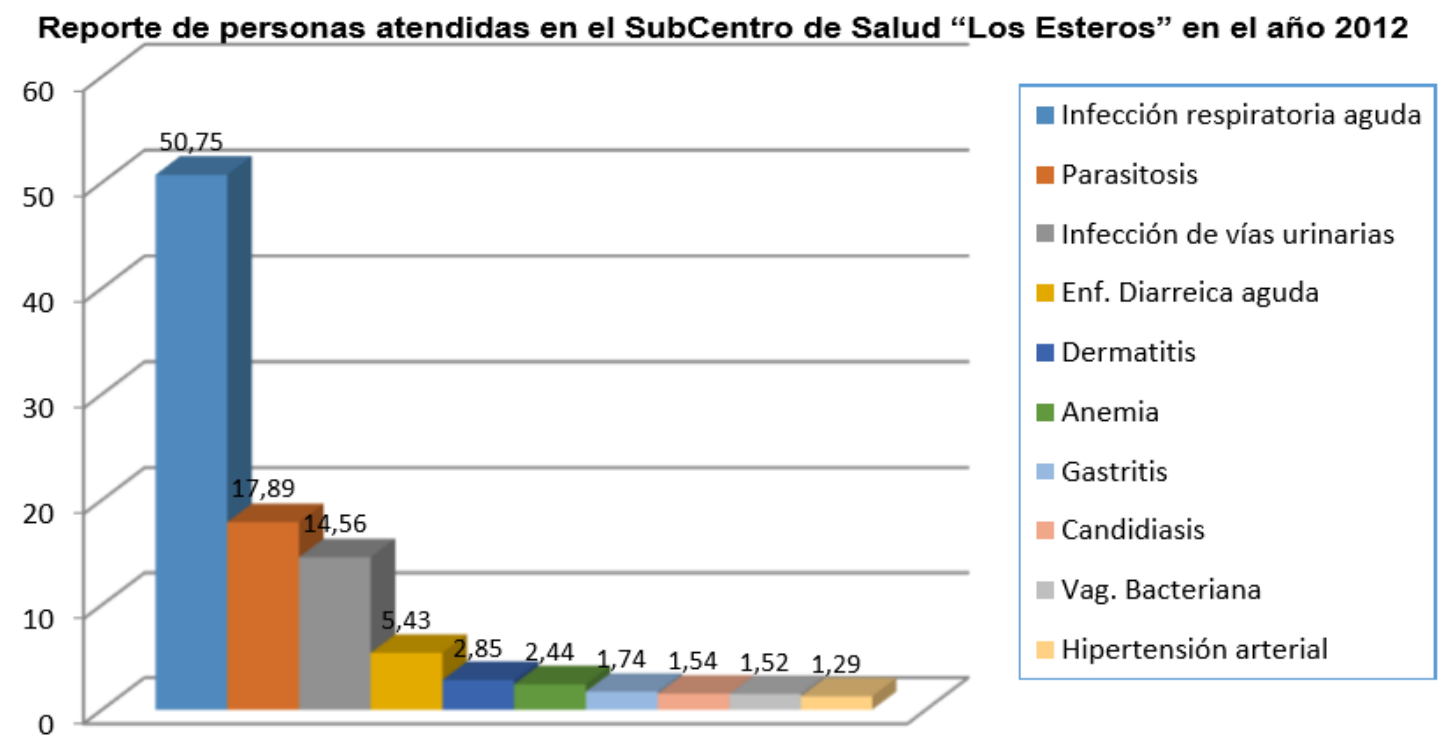

Figura 7. Principales causas de Morbilidad durante el año 2012 SCS Los Esteros-Manta.

Se concluye que esta playa necesita una intervención inmediata con el fin de concretar su recuperación. Se deben eliminar todos los aspectos y agentes que ocasionan contaminación tanto de origen industrial como por actividades propias de la vivienda.

\section{Referencias}

Centro de Salud Los Esteros. 2013. Archivos y estadísticas. Área de salud. \# 4.

Comisión Nacional del Agua. 1999. Índice de Cali- 
dad del Agua. Gerencia de Saneamiento y Calidad del Agua. Recuadro iii: 2.2.2.

Daiefa, Z., A. Borjab, L. Joulamic, M. Azzia, A. Fahdea y H. Bazairid. November 2014. Assessing benthic ecological status of urban sandy beaches (Northeast Atlantic, Morocco) using M-AMBI. Ecological Indicators. 46: 586-595.

Empresa Pública de Aguas de Manta. 05 de 11 de 2014. Lagunas de oxidación de Manta. Manta, Manabí, Ecuador.

González, C. 2014. Estudio sobre causas y niveles de contaminación de la playa de la parroquia Los Esteros, cantón Manta, periodo julio-diciembre 2013. Universidad Laica Eloy Alfaro de Manabí. Manta, Ecuador: Proyecto de titulación.
Ley De Gestión Ambiental. 2008. De la gestión ambiental local y nacional. Artículos. 30, 37, 38,40, 43.

L.P.P.C.C.A.E. 2008. Límites de Descarga a un cuerpo de Agua Marina. Ecuador.

Ministerio del Ambiente del Ecuador (MAE). 2008. Texto unificado de legislación secundaria TULSMA. 4.

Ramos X. (Entrevistador). 08 de septiembre de 2007. Contaminadas playas Los Esteros y Tarqui. Diario El Universo.

Ruiz, F. 05 de 11 de 2014. Las aguas residuales de Manta. Entrevista. 
DOI:10.17163/lgr.n23.2016.06

\title{
APROVECHAMIENTO ENERGÉTICO DE RESIDUOS PLÁSTICOS OBTENIENDO COMBUSTIBLES LÍQUIDOS POR MEDIO DE PIRÓLISIS
}

\author{
ENERGY USE GETTING PLASTIC WASTE LIQUID FUELS BYPYROLYSIS \\ Myriam Mancheno*, Servio Astudillo, Pablo Arévalo, Inés Malo, Tania \\ Naranjo, Johana Espinoza
}

Universidad Politécnica Salesiana, Campus El Vecino, Calle Vieja 12-30 y Elia Liut, Cuenca, Ecuador

*Autor para correspondencia: mmancheno@ups.edu.ec

Manuscrito recibido el 21 de enero de 2015. Aceptado, tras revisión, el 24 de junio de 2015

\begin{abstract}
Resumen
Este estudio da a conocer una forma eficiente de gestionar los residuos plásticos obteniendo combustibles a través del proceso de pirólisis de poetilentereftalato, polietileno de alta densidad y poliestireno, residuos plásticos de mayor generación dentro de la Universidad Politécnica Salesiana; en la investigación se determinó que el residuo que mayor porcentaje de fracción líquida produce es el poliestireno. Sin embargo, de acuerdo a los análisis el de mejor calidad es el polietileno de alta densidad considerado como crudo mediano. De acuerdo a los análisis de cromatografía, se muestra que las fracciones líquidas del proceso de pirólisis de residuos plásticos contienen sustancias que forman parte de los combustibles y petróleos, lo que confirma la obtención de combustibles líquidos de características semejantes a los tradicionales y que se pueden usar para generar energía en motores de combustión.
\end{abstract}

Palabras claves: pirólisis, residuos plásticos, combustibles líquidos, poliestireno, polietileno.

\begin{abstract}
This study, found an efficient way to manage plastic wastes obtaining fuels; by pyrolysis process at poetilentereftalato, high density polyethylene, polystyrene and high generation plastic wastes at the Universidad PolitÃ (C) cnica Salesiana; in the investigation was determined that the highest percentage of liquid fraction residue was achieved by polystyrene. However, according to analyzes the best quality was the high density polyethylene considered medium crude. According to chromatographic analysis, this research demonstrates that the liquid fractions of pyrolysis of plastic wastes contain substances that are part of fuels and oils, which confirms the existence of liquid fuels with similar characteristics to traditional ones and can be used in combustion engines.
\end{abstract}

Keywords: pyrolysis, plastic waste, liquid fuels, polystyrene, polyethylene.

Forma sugerida de citar: Mancheno, M., et al. 2016. Aprovechamiento energético de residuos plásticos obteniendo combustibles líquidos por medio de pirólisis. La Granja: Revista de Ciencias de la Vida. Vol. 23(1): 60-67. ISSN impreso: 1390-3799. ISSN electrónico: 1390-8596. 


\section{Introducción}

Los plásticos han reemplazado a otros materiales tradicionales como los metales, cerámicas y maderas, en muchas de sus aplicaciones (Salinas y Vásquez, 2010) es por ello que la producción de plásticos a nivel mundial ha aumentado una media de un $10 \%$ anual (Almeida, N, 2006). En Ecuador en el año 2002 se producían 336 ton/día de residuos plásticos de origen doméstico, industrial y agroindustrial, mientras que en Cuenca se genera alrededor del $22 \%$ por año de plásticos, del total de materiales reciclables. Dando lugar a una problemática ambiental que tiene dos variantes: La explotación de un recurso natural no renovable y problemas de disposición y tratamiento de residuos (MAVDT2, 2008).

En busca de una solución a este problema medio ambiental se han planteado varias técnicas para el tratamiento de residuos plásticos, entre ellas, reciclado mecánico del cual se obtienen materias primas secundarias con propiedades físicas y químicas idénticas a las del material original (Aracil, I, Julio de 2008; Espinoza, E, 2009), aprovechamiento energético en donde el plástico es usado como combustible debido a su elevado poder calorífico, aquí se pueden aprovechar todo tipo de plásticos incluso aquellos que presentan deterioro o suciedad (Aracil, I, Julio de 2008), y reciclado químico que incluye despolimerización, gasificación y pirólisis, en donde se descomponen los plásticos usados en componentes más sencillos como son los monómeros de partida, gas de síntesis o hidrocarburos (Espinoza, E, 2009).

La pirólisis es el proceso de descomposición térmica en ausencia de oxígeno, con temperaturas comprendidas entre $400^{\circ}$ y $1000^{\circ} \mathrm{C}$, obteniendo una fracción gaseosa, líquida y sólida aprovechables (Aracil, I, Julio de 2008). Este es un proceso se ha utilizado desde hace mucho tiempo atrás, es así que en la década de los 80, se desarrolló en Japón, pirólisis de residuos sólidos urbanos para la producción de electricidad. (Helt y col., 1984 citado por (Conesa, J. A, 1996)). En España, mediante este proceso, se comprobó que a mayor temperatura, se da la formación de compuestos más estables térmicamente (Aracil, I, Julio de 2008). De igual manera, en Colombia, al pirolizar los residuos sólidos municipales se obtuvieron productos con alto poder calorífico (Gamarra, 2006). En Ecuador, en los experimentos realizados por (Proaño y Crespo, 2009), usando polietileno de alta densidad, se obtiene diésel, kerosene y gasolina contenida en la fracción líquida.

\section{Materiales y métodos}

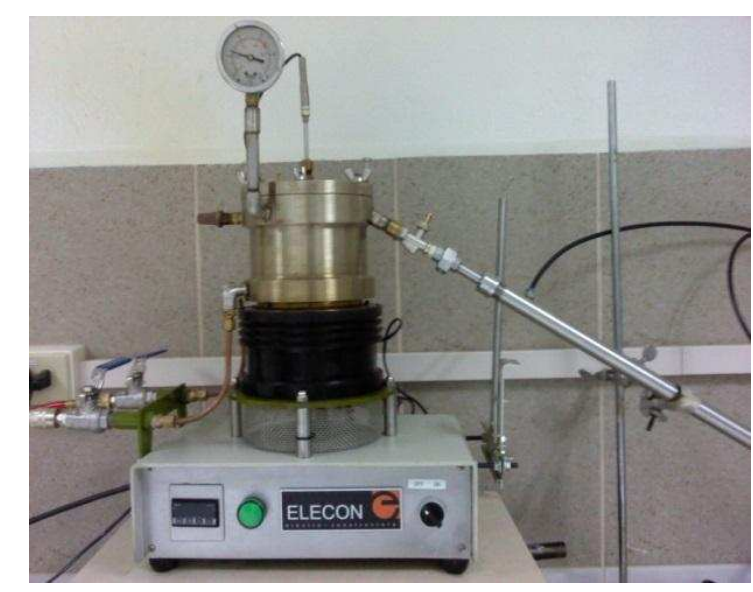

Figura 1. Reactor de Pirólisis utilizado en esta investigación

\subsection{Materiales}

Para la realización de este proyecto de investigación se utilizó: polietileno de alta densidad, poliestireno y polietilentereftalato provenientes de la Universidad Politécnica Salesiana previamente lavados, secados y triturados. Además se usó un catalizador de zeolita que, previo a su uso, pasó por el analizador de humedad para determinar el porcentaje de la misma y por una mufla para su desecación.

El reactor de pirólisis fue el tipo semi-batch, de 1 litro de capacidad, con calentamiento eléctrico (niquelina), marca UPS, termocupla, sistema de control térmico, manómetro con capacidad de 1 bar, con entradas para gas (N2) y aire (cámara de enfriamiento), salida de productos, válvula de paso. El sistema se muestra en la Figura 1.

Para los análisis físicos de la fracción líquida obtenida se utilizaron: termómetro, picnómetro de $5 \mathrm{ml}$, viscosímetro de Oswalt, balanza analítica, calentador con agitador, congelador, equipo de destilación.

Además, como complemento a los análisis realizados se usa un cromatógrafo, con un estandar que contiene acenafteno, acenaftileno, antraceno, benz (a) antraceno, benz (b) fluoranteno, benzo (k) fluoranteno, benzo (a) pireno, benzo $(\mathrm{g}, \mathrm{h}, \mathrm{i})$ perileno, criseno, fluoranteno, fluoreno, naftaleno, in- 
deno $(1,2,3-\mathrm{c}, \mathrm{d})$ pireno, fenantreno, pireno que son las sustancias que se analizarán en la muestra, se trabaja con solvente de acetonitrilo $(100 \mathrm{ml})$, con un detector tipo GC/ FID, una columna DB-5,30m, un diametro interior de $0,25 \mathrm{~mm}$, un volumen de inyección de 1 ul a $320^{\circ} \mathrm{C}$ y flujo de $1 \mathrm{ml} / \mathrm{min}$. La corrida inicia con una temperatura de $110^{\circ} \mathrm{C}$ por $5 \mathrm{~min}$ y finaliza con una temperatura de $320^{\circ} \mathrm{C}$ por $8 \mathrm{~min}$, teniendo una gradiente de $5^{\circ} \mathrm{C} / \mathrm{min}$.

Finalmente, para el análisis estadístico de los resultados se utilizó el software MINITAB.

\subsection{Métodos}

\subsubsection{Clasificación de residuos plásticos}

Para determinar los plásticos producidos en mayor cantidad se procedió a clasificar los residuos plásticos en base a la NTE INEN 2634:2012 "Disposición de desechos plásticos post-consumo, Requisitos" (INEN, NTE INEN 2634:2012 Disposición de desechos plásticos post-consumo, Requisitos., 2012). Para el pre-tratamiento de los residuos plásticos, antes de su ingreso al reactor, se procede a su lavado, secado y triturado.

\subsubsection{Ensayos para la determinación de las variables del proceso}

Las variables que se manejaron fueron la temperatura, el tiempo de residencia y los tipos de residuos plásticos, las cuales se modifican de acuerdo al ensayo que se realice. La presión que es regulada por la válvula de paso se establece como constante, y se trabaja con empaque de teflón para evitar la fuga de los gases generados durante el proceso, asegurando que permanezcan el tiempo adecuado dentro del reactor.

Al iniciar la evacuación de los gases, estos psaron por los erlenmeyer refrigerados de $250 \mathrm{ml}$, convirtiéndose en producto líquido; mientras que los no condensables, fueron enviados al erlenmeyer de $1000 \mathrm{ml}$ para medir su volumen. Al finalizar el proceso, se pesó nuevamente los erlenmeyer de $250 \mathrm{ml}$ que contienían el producto líquido para determinar por diferencia de pesos la cantidad de líquido recolectado, y se midió el volumen de agua desalojado que representa la cantidad de gases no condensables producidos.

Para determinar la temperatura de trabajo, se realizaron pruebas a $220{ }^{\circ} \mathrm{C}$ de temperatura, con tiempos de residencia de 10, 15, 20 y 30 minutos, a 9
PSI de presión, utilizando $15 \mathrm{~g}$ de polietileno de alta densidad. Se realizaron ensayos para determinar las condiciones más óptimas, tomando como variable el tiempo de residencia, estableciéndose valores de: 30,60 y 120 minutos, a una temperatura de $400^{\circ} \mathrm{C}$, con Polietileno de Alta Densidad y Presión constante (9 PSI).

Para la valoración de la pirólisis con diferentes tipos de plásticos, se utilizaron tres tipos de plástico: polietileno de alta densidad, polietilen tereftalato y poliestireno; trabajando a una temperatura de $400^{\circ} \mathrm{C}$, tiempo de residencia de 30 minutos definido en la prueba anterior y a presión constante de 9 PSI.

\subsubsection{Análisis de la fracción liquida obtenida}

De las fracciones líquidas resultantes de la pirólisis de polietileno de alta densidad (PEAD) y poliestireno (PS), se procede a realizar las siguientes pruebas físicas: color y olor en base a la percepción del observador. Densidad basada en la norma venezolana COVENIN 2052-93 "Productos Derivados del Petróleo. Determinación de la Densidad y la Densidad Relativa de Líquidos por Medio del Picnómetro Bingham". Viscosidad en base a la NTE INEN 810:1986 "Productos de Petróleo. Determinación de la Viscosidad Cinemática y Dinámica en Líquidos Transparentes y Opacos" (INEN, NTE INEN 810:1986 ). Punto de Inflamación en base a la NTE INEN 808:1986 "Productos de Petróleo". Determinación de los "Puntos de Inflamación y Combustión en Vaso Abierto Cleveland" (INEN, NTE INEN $808: 1986,1986)$ y Punto de Congelación basado en las normas internacionales ASTM, D 2386-06 "Standard Test Method for Freezing Point of Aviation Fuels" (ASTM, 2012). Dichas pruebas no se pueden realizar con Polietilen Tereftalato (PET), debido a la mínima cantidad de fracción liquida generada.

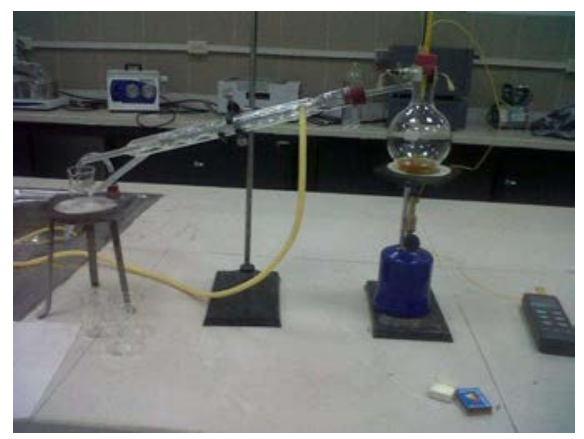

Figura 2. Sistema de destilación utilizado en esta investigación 


\subsubsection{Análisis de la fracción liquida utilizando el cromatógrafo de gases}

Previo al análisis en el cromatógrafo de gases, se destiló la fracción líquida, proceso que fue necesario realizar para evitar la contaminación de la $\mathrm{CO}^{-}$ lumna cromatográfica, tanto del polietileno de alta densidad como del poliestireno para separar las distintas fracciones que serán analizadas rigiéndose en la NTE INEN 926:1982 "Productos de Petróleo. Ensayos de Destilación" (INEN, NTE INEN 926:1982, 1982). El sistema de destilación se muestra en la Figura 2.

En el cromatógrafo de gases, se procedió a diluir las muestras con acetonitrilo de las diferentes fracciones destiladas, para disminuir su concentración, se prepararon 5 viales: un vial de acetonitrilo para la limpieza de la columna, y en los 4 respectivos viales las fracciones obtenidas de los líquidos pirolíticos.

\section{Resultados y discusión}

\subsection{Clasificacion de residuos plásticos}

La clasificación de los plásticos se la realizó en el repositorio de residuos sólidos de la Universidad Politécnica Salesiana por un tiempo aproximado de tres meses, posteriormente se procede al pesaje y valoración con el fin de establecer que el residuo plástico de mayor generación dentro de la UPS es el polietilentereftalato, seguido del poliestireno y en tercer lugar el polietileno de alta densidad.

\subsection{Proceso de pirólisis a temperaturas me- nores de $300{ }^{\circ} \mathrm{C}$}

Coincidiendo con los análisis realizados por Proaño y Crespo (2009), a temperaturas menores a $300^{\circ} \mathrm{C}$ se obtiene la acumulación de un producto sólido resinoso, que representa la cantidad de residuo plástico que no ha sido pirolizado totalmente, razón por la cual no se trabaja con temperaturas inferiores para evitar los bajos rendimientos de combustible líquido.

\subsection{Determinación del tiempo de residencia más óptimo}

En el análisis estadístico de la fracción líquida de pirólisis a 30, 60 y 120 minutos de tiempo de residencia, se obtiene un valor de p mayor a 0.05 , demostrando que no existe diferencia significativa entre ellos, lo mismo que se evidencia en el traslape de cajas mostrado en la Figura 3, con lo que se confirma que la variable tiempo no produce resultados diferentes.

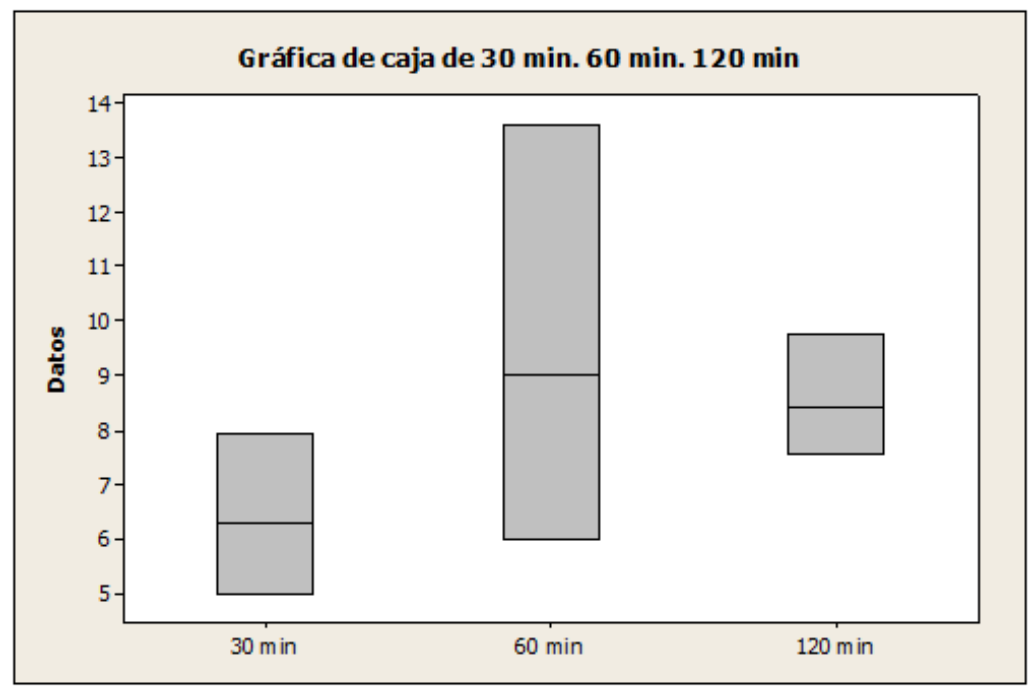

Figura 3. Gráfico de cajas de los tiempos de residencia a 30, 60 y 120 minutos 


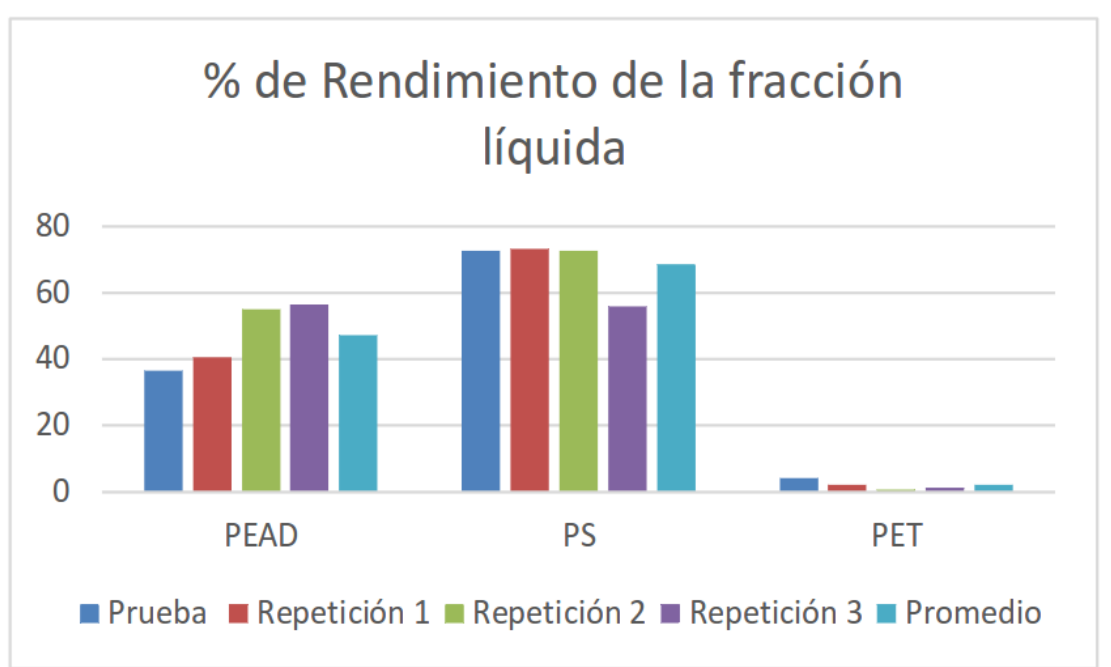

Figura 4. Rendimiento de fracción líquida de los diferentes tipos de plástico. Donde PEAD es polietileno de alta densidad, PS Poliestireno y PET Polietilen Tereftalato

En los ensayos realizados por Proaño y Crespo (2009) se recomienda tiempos de residencia de 60 y 120 minutos como los más óptimos, sin embargo, para este estudio se toma un tiempo de residencia de 30 minutos debido a que no existe una diferencia significativa de producción de fracción líquida en los diferentes tiempos planteados. Además considerando que, con ello se disminuye el consumo de energía eléctrica así como el tiempo empleado en el desarrollo de cada prueba.

\subsection{Valoración de la pirólisis con diferentes tipos de plásticos}

Una vez realizadas las pruebas con las condiciones adecuadas de temperatura, tiempo de residencia y presión, se obtuvo un rendimiento promedio del poliestireno PS de $68.55 \%$ como el de mayor porcentaje; seguido del polietileno de alta densidad PEAD con $47.18 \%$ y por último el PET (Polietilen Tereftalato) con $2.13 \%$. Como se muestra en la Figura 4.

De acuerdo a los análisis ANOVA existe una diferencia significativa en el volumen de fracción líquida obtenido en la pirólisis de PEAD, PS y PET; ratificando con el análisis de Tukey presentado en la ilustración 6, que la cantidad de PS es mayor tanto al PET como al PEAD, siendo el PS el residuo plástico que mayor cantidad de fracción líquida genera.

Por lo tanto, el PS constituye el residuo plástico de mayor generación de fracción líquida y que puede ser usada como combustible o materias primas según (PT. Williams y EA. Williams, 1998) citado por (García, 2005; Chattopadhyay et al., 2008; Regnier et al., 1997) citado por ( Lee y Cheon, 2009). Sin embargo, del PET se obtiene mayor cantidad de fracción sólida, siendo de importancia para la producción de carbón activado de acuerdo a los estudios realizados por (Almazán, 2006); además, de acuerdo con lo citado por (Cunliffe et al, 2013) y (Kaminsky, 1993) la fracción gaseosa puede ser utilizada para la generación de energía para el mismo y otros procesos.

\subsection{Análisis de la fracción líquida}

Para realizar el análisis del olor de la fracción líquida de PEAD y PS se tomó cada fracción y se percibió el desprendimiento de un olor irritante característico de la gasolina, diésel u otros derivados del petróleo. En cuanto al color, el primero es de color amarillo mientras que el segundo presenta un color oscuro tendiente a negro.

La gravedad API es un valor internacional estandarizado por el American Petroleum Institute, para determinar la calidad de los hidrocarburos; así como se muestra en la Tabla 1, la fracción líquida de PEAD al tener una gravedad API de 27.435, se ubica dentro de un crudo mediano; y el PS con una gravedad API de 19.160, se considera un crudo pesado. 


\begin{tabular}{ll}
\hline Hidrocarburos & Gravedad ${ }^{\mathrm{o}} \mathrm{API}$ \\
\hline Crudo Liviano & $>\mathrm{a} 31.1$ \\
Crudo Mediano & $22.3-31.1$ \\
Crudo Pesado (P) & $10.0-22.3$ \\
Crudo Extrapesado (XP) & $<$ a 10 \\
Fracción de PEAD & 27.435 \\
Fracción de PS & 19.160 \\
\hline
\end{tabular}

Tabla 1. Comparación de la gravedad API (Docsetools, 2014)

\section{VISCOSIDAD}

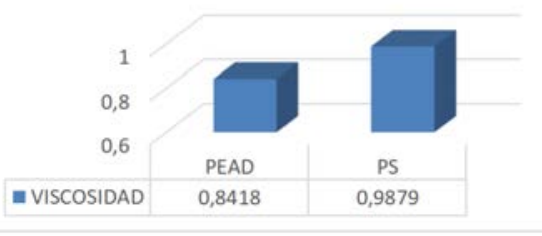

Figura 5. Viscosidad de PEAD y PS

La viscosidad aumenta cuando disminuye la densidad API, es decir, cuanto más pesado es un crudo mayor viscosidad presentará. Y esto se evidencia claramente en los resultados obtenidos de la viscosidad (Figura 5), así, el crudo resultante de la pirólisis de residuos de polietileno de alta densidad (PEAD) tiene una viscosidad de $0.8418 \mathrm{cSt}$, con una densidad ${ }^{\circ}$ API de 27.4352, mientras que el crudo obtenido de la pirólisis de residuos de poliestireno (PS) tiene una viscosidad de 0.9879 y una densidad ${ }^{\circ}$ API de 19.1601; entonces el poliestireno es más pesado que el polietileno de alta densidad y por tanto más viscoso.

Como se puede observar en la Tabla 2, la fracción líquida de PEAD puede ser almacenada a una temperatura menor a $34.86{ }^{\circ} \mathrm{C}$, para evitar su inflamación, y mayor a $-1.41^{\circ} \mathrm{C}$ para impedir su congelación; de igual manera el PS debe mantenerse a una temperatura menor a $43.08^{\circ} \mathrm{C}$ y mayor a $-6.9^{\circ} \mathrm{C}$. Es- tos resultados están directamente relacionados con los ${ }^{\circ} \mathrm{API}$, en donde, mientras mayor sea la densidad API de la muestra menor será la temperatura del punto de inflamación y mayor la de congelación, tal como se muestra en la Tabla 2.

\begin{tabular}{ccc}
\hline Hidrocarburo & $\begin{array}{c}\text { Pto. de Inflamación } \\
\left({ }^{\circ} \mathrm{C}\right)\end{array}$ & $\begin{array}{c}\text { Pto. de Congelación } \\
\left({ }^{\circ} \mathrm{C}\right)\end{array}$ \\
\hline PEAD & 34.86 & -1.41 \\
PS & 43.08 & -6.9 \\
\hline
\end{tabular}

Tabla 2. Punto de inflamación y congelación de PEAD y PS

\subsection{Cromatografía de gases}

De la destilación de PEAD y PS, se obtuvieron tres fracciones las mismas que están en función del cambio de temperatura, la primera de $0-140^{\circ} \mathrm{C}$, la segunda de $140-170{ }^{\circ} \mathrm{C}$ y la tercera corresponde a la fracción no destilada. Esto se evidencia en los resultados presentados en la Tabla 3 en donde, el porcentaje de destilación del PS es mayor al del PEAD, quedando menor cantidad de fracción pesada de PS sin destilar.

Una vez realizado el análisis en el cromatógrafo de gases se establece que, la muestra que presenta mayor cantidad de compuestos aromáticos es la obtenida por destilación de Poliestireno a $165^{\circ} \mathrm{C}$ y la de menor cantidad es la muestra de Polietileno de Alta Densidad obtenida a $140^{\circ} \mathrm{C}$. Los datos obtenidos se presentan en las tabla 4.

\section{Conclusiones}

Luego de nuestro estudio se determinó que los residuos plásticos de mayor generación dentro de la Universidad politécnica Salesiana corresponden al Polietilen Tereftalano PET con un $33.72 \%$, seguido por Poliestireno PS con un $19.82 \%$ y Polietileno de Alta Densidad PEAD con un $17.62 \%$.

\begin{tabular}{cccccc} 
& FRACCIÓN 1 & FRACCIÓN 2 & F1 +F2 & \% DE DESTILADO & FRACCIÓN 3 \\
\hline PEAD (ml) & 3.63 .65 & 7.25 & 48.33 & 3.62 & \\
PS $(\mathrm{ml})$ & 6.54 & 3.08 & 9.62 & 64.13 & 1.85 \\
\hline
\end{tabular}

Tabla 3. Fracciones de la destilación de PEAD y PS 


\begin{tabular}{lllll} 
& \multicolumn{4}{c}{ Cantidad } \\
\cline { 2 - 5 } Sustancia & PS a $140^{\circ} \mathrm{C}$ & PS a $165^{\circ} \mathrm{C}$ & PEAD a $140^{\circ} \mathrm{C}$ & PEAD a $170^{\circ} \mathrm{C}$ \\
\hline Fluoranteno & 8.374 & 43.784 & 0 & 1.009 \\
Benzo (b) fluoranteno & 0.372 & 0.925 & 0 & 6.782 \\
Benzo (k) fluoranteno & 2.188 & 1.717 & 2.229 & 1.128 \\
Benzo (a) pireno & 0.227 & 0.208 & 0 & 0.992 \\
Indeno (1, 2, 3-c, d) pireno & 0.660 & 1.974 & 1.448 & 0.559 \\
Benzo (ghi) perileno & 0.816 & 1.208 & 1.715 & 4.531 \\
\hline TOTAL & 12.637 & 49.815 & 5.392 & 15.001 \\
\hline
\end{tabular}

Tabla 4. Sustancias contenidas en las fracciones de PS y PEAD

Se determinó que la temperatura óptima para el desarrollo del proceso de pirólisis de residuos plásticos es $400{ }^{\circ} \mathrm{C}$, debido a que a temperaturas menores a $300^{\circ} \mathrm{C}$ el proceso de pirólisis no se desarrolla en su totalidad.

Posterior a los ensayos se concluye que los tiempos de residencia no influyen de forma significativa en el rendimiento de fracción líquida.

De acuerdo a los referentes bibliográficos, el proceso de pirólisis de residuos plásticos, genera tres fracciones que pueden ser usados en procesos secundarios; como se demuestra en este estudio la fracción líquida puede emplearse para la producción de energía.

El Poliestireno PS es el residuo plástico que mediante el proceso de pirólisis a $400^{\circ} \mathrm{C}$, presión constante y tiempo de residencia de 30 minutos, presenta mayor rendimiento de fracción líquida con el $68.55 \%$.

Según los ensayos realizados se determinó que el Polietilentereftalato PET, no favorece la producción de fracción líquida, generando una mayor cantidad de fracción sólida, que de acuerdo a la información bibliográfica, puede ser aprovechada como carbón activado.

De los análisis de propiedades físicas se establece, que la fracción líquida obtenida del Polietileno de Alta Densidad PEAD es un crudo mediano, mientras que la del Poliestireno PS se considera un crudo pesado.

Utilizando la técnica de cromatografía de gases se determinó que las fracciones obtenidas de la pirólisis de residuos plásticos de Polietileno de Alta Densidad y Poliestireno contienen Hidrocarburos Aromáticos Policícliclos (HAPs), que forman parte de los combustibles y petróleos.

\section{Referencias}

Almazán, M. 2006. Carbones activos a partir de residuos de politereftalato de etileno (PET). Granada: Editorial de la Universidad de Granada.

Almeida, N. 2006. Ensayos preliminares de pirólisis de residuos sólidos municipales para obtención de biocombustibles. Bogotá.

Aracil, I. Julio de 2008. Formación de Contaminantes y Estudio Cinético en la Pirólisis y Combustión de Plásticos (PE, PVC y PCP). Tesis Doctoral. Alicante: Universidad de Alicante.

ASTM. 2012. Standard Test Method for Freezing Point of Aviation Fuels. ASTM D 2386-06.

Botello, F., F. Avalos y E. Camporredondo. 2010. Pirólisis del polietileno en presencia y ausencia de catalizadores arcillosos. Prospect.

Conesa, J. A. 1996. Estudio de la Pirólisis de residuos plásticos de polietileno y neumáticos usados. Alicante: Universidad de Alicante.

Cunliffe, A., N. Jones y P. T. Williams. 2013. Pyrolysis of composite plastic waste. Environmental Technology.

Docsetools. 2015. http://docsetools.com/articulosutiles/article_110782.html.

Espinoza, E. 2009. Modelo de Gestión de Residuos Plásticos. Mensoza-Argentina: II Simposio Iberoamericano de Ingeniería de Residuos.

INEN. 1982. Ensayos de Destilación. Ecuador. Productos de Petróleo. NTE INEN 926:1982. 
INEN. 1986a. Determinación de la Viscosidad Cinemática y Dinámica en Líquidos Transparentes y Opacos. Ecuador. Productos de Petróleo. NTE 810:1986.

INEN. 1986b. Determinación de los Puntos de Inflamación y Combustión en Vaso Abierto de Cleveland. Ecuador. Productos de Petróleo. NTE INEN 808:1986.

INEN. 2012. Disposición de desechos plásticos post-consumo, requisitos. ecuador. NTE INEN 2634:2012.

Kaminsky, W. 1993. Recycling of polymers by pyrolysis. Journal de Physique IV.

Lee, K. y O. S. Cheon. 2009. Kinetics of the thermal degradation of wax materials obtained from pyrolysis of mixed waste plastics. Cheonan.
MAVDT2. 2008. Construcción de Criterios Técnicos para el Aprovechamiento y Valorización de Residuos Sólidos Orgánicos don Alta Tasa de Biodegradación, Plasticos, Vidrio, Papel y Cartón. Bogotá.

Parres, F. 2005. Investigación de las variables limitantes en la recuperación de residuos de poliestireno procedentes del sector envase. Valencia.

Proaño, O. y S. Crespo. 2009. Obtención de combustibles a partir de residuos plásticos. Revista Politécnica. 1: 137-144.

Salinas, J. y R. Vásquez. 2010. Diseño y construcción de un sistema de combustión para caracterización térmica de desechos plásticos utilizados como combustible alternativo. Sangolquí-Ecuador: Escuela Politécnica del Ejército. 


\title{
RECOMENDACIONES PARA LA CARACTERIZACIÓN Y CUANTIFICACIÓN DE RESIDUOS SÓLIDOS UNIVERSITARIOS. CASO DE ESTUdIO: UNIVERSIDAD POLITÉCNICA SALESIANA, CAMPUS SUR, QUITO
}

\author{
RECOMMENDATIONS ON CHARACTERIZATION AND QUANTIFICATION OF \\ UNIVERSITY SOLID WASTE. CASE STUDY: UNIVERSIDAD POLITÉCNICA \\ SALESIANA, SOUTH CAMPUS, QUITO
}

Elena Coyago ${ }^{1, *}$, Katty Gonzales ${ }^{2}$, Edgar Heredia ${ }^{2}$ y Renato Sánchez ${ }^{2, * *}$

${ }^{1}$ Carrera de Ingeniería en Biotecnología de los Recursos Naturales, Universidad Politécnica Salesiana, Sede Quito, Campus Girón. Av. 12 de Octubre, Telf. (593 2) 3962800, Quito, Ecuador.

${ }^{2}$ Grupo de Investigación en Ciencias Ambientales GRICAM, Centro de Investigación en Modelamiento Ambiental CIMA-UPS, Carrera de Ingeniería Ambiental, Universidad Politécnica Salesiana, Sede Quito, Campus Sur, Av. Morán Valverde y Rumichaca, Telf. (593 2) 3962800, Quito, Ecuador.

Autor para correspondencia: ecoyagoc@ups.edu.ec*,elena.coyago@hotmail.com*,rsanchez@ups.edu.ec**

Manuscrito recibido el 5 de abril de 2016. Aceptado, tras revisión el 29 de junio de 2016

\begin{abstract}
Resumen
El presente trabajo, estudió la generación y cuantificación de residuos sólidos en diferentes áreas dentro de la Universidad Politécnica Salesiana, Sede Quito, Campus sur (UPS-QS), en los años 2012-2013 y la producción per cápita de residuos sólidos generados (PPC). Los residuos sólidos producidos en las áreas académica, administrativa, externa, cafetería, biblioteca y copiadora, fueron caracterizadas según la fuente generadora, determinando la composición para cada categoría como: papel, vidrio, metal, plástico, orgánico, inorgánico y residuos peligrosos; además del contenido de humedad y análisis químico de CNPK (carbono, nitrógeno, fósforo y potasio), contenido de humedad, densidad y granulometría. La caracterización reportó que en la UPS-QS un 51,07\% de residuos orgánicos, 22,17\% de plásticos, $16,45 \%$ papel, $7,05 \%$ de vidrio y metales, $3,12 \%$ de restos inorgánicos, $0,14 \%$ de residuos especiales como aparatos electrónicos y $0,01 \%$ de residuos peligrosos como pilas. Con una densidad promedio de $79,7 \mathrm{Kg} / \mathrm{m}^{3}$ y una granulometría menor a 203,2 mm para el $99 \%$ de plásticos. La caracterización de residuos permitió calcular la PPC de la población universitaria usuaria de las instalaciones con un valor promedio de $0,3 \mathrm{~kg} / \mathrm{hab}$.día.
\end{abstract}

Palabras claves: residuos sólidos, generación, caracterización, cuantificación, Universidad Politécnica Salesiana. 


\begin{abstract}
This paper studied the generation and quantification of solid waste in different areas within the Universidad PolitÃ@cnica Salesiana, South Camp in Quito, in the years 2012-2013 and per capita production of solid waste. Were analyzed the academic, administrative, external, cafeteria, library and copier areas were characterized by the generating source, determining the composition of each category such as paper, glass, metal, plastic, organic, inorganic and hazardous waste; besides the respective chemical analysis CNPK (carbon, nitrogen, phosphorus and potassium), moisture content, density and granulometry. The characterization reported $51.07 \%$ of organic waste, plastic $22.17 \%$, $16.45 \%$ paper, $7.05 \%$ glass and metals, $3.12 \%$ inorganic residues, $0.14 \%$ of special waste such as electronics and $0.01 \%$ of hazardous waste such as batteries, with an average density of $79.7 \mathrm{~kg} / \mathrm{m}^{3}$ and a smaller particle size to $203.2 \mathrm{~mm}$ for the $99 \%$ plastics. The per capita production of solid waste (PPC) had an average value of $0.3 \mathrm{~kg} / \mathrm{hab}$.day.

Keywords: solid waste, generation, characterization, quantification, Universidad Politécnica Salesiana.

Forma sugerida de citar: Coyago, E., et al. 2016. Recomendaciones para la caracterización y cuantificación de residuos sólidos universitarios. Caso de estudio: Universidad Politécnica Salesiana, campus sur, Quito. La Granja: Revista de Ciencias de la Vida. Vol. 23(1): 68-79. ISSN impreso: 1390-3799. ISSN electrónico: 1390-8596.
\end{abstract}




\section{Introducción}

La época en que vivimos contempla el crecimiento acelerado de la población, evolución de la tecnología, sustitución de la mano de obra por procesos industrializados, generando ambientes modernistas que tienen como contraparte la insostenibilidad de los recursos naturales del planeta y como actor principal al ser humano (Frers, 2009).

Algunos centros universitarios no se encuentran alejados de los cambios que ha sufrido la sociedad y en su gran mayoría se caracterizan por ser instituciones que realizan docencia, investigación y extensión; interactuando con estudiantes, docentes, personal administrativo, de servicio y con la colectividad en general; esta relación diaria genera transformación de insumos, diferentes materiales de descarte y residuos sólidos que durante mucho tiempo fueron retirados de los lugares de origen y depositados en lugares no controlados para no causar alteraciones en la salud de la población (Hester y Harrison, 2002).

El origen de los residuos puede ser natural o antropogénico y están influenciados por la localización geográfica, estación del año, frecuencia de recolección, operaciones de recuperación, reciclaje, legislación y características actitudinales de la población (Robles y Rodríguez, 2010).

Mientras que, los residuos generados se pueden clasificar según el estado, tipo de manejo, origen, composición y efectos (Fernández, 2012; Díaz y Janon, 2010; Bautista, 1998; Cantoni, 2010).

Por lo tanto, el incremento de los residuos sólidos en cada localidad ha provocado la rápida saturación de rellenos sanitarios, convirtiéndose en un problema de contaminación que se contrapone a la legislación ecuatoriana referente al buen vivir de los individuos. La municipalidad de Quito sin estar ajena a los problemas ambientales existentes, ha visto la necesidad de crear diferentes ordenanzas que contribuyen al mejoramiento del ambiente e involucran la gestión integral de residuos dentro de cada organización (Ordenanza 332, 2010).

La gestión integral de residuos incluye las etapas de control en la generación, almacenamiento, recolección, transferencia, transporte, tratamiento y disposición final (Lianette et al., 2009), incluyendo el seguimiento administrativo de forma que armonice con los principios de salud pública, ingeniería, economía, estética, conservación y otras consideraciones ambientales que responden a las expectati- vas de la opinión pública (Brion, 2010; Quito Verde, 2012).

El desarrollo de un sistema de gestión integral de residuos involucra la caracterización y cuantificación de residuos generados dentro de un área determinada (Bernache, 2009); es así que, el presente proyecto tiene por objetivo proveer recomendaciones y determinar la cantidad, composición y calidad de residuos sólidos generados al interior de la Universidad con miras a cumplir la ordenanza $\mathrm{Mu}-$ nicipal 332 "Ordenanza metropolitana de gestión integral de residuos sólidos del distrito metropolitano de Quito" y la ordenanza 213, Capítulo I: De la gestión de los residuos sólidos urbanos, domésticos, comerciales, industriales y biológicos potencialmente infecciosos.

\section{Métodos}

La investigación incluyó las etapas de levantamiento de línea base, planificación, cuantificación y caracterización de residuos sólidos conforme establece la norma ASTM, D5231-92, 2008 “Método de Ensayo Estándar para la Determinación de la Composición de Residuos Sólidos Municipales sin Procesar"; para el efecto se calculó el número de muestras e individuos a estudiar según establece (Runfola y Gallardo,2009).

\subsection{Parámetros iniciales de cuantifica- ción y caracterización de residuos}

\subsubsection{Línea base}

La UPS-QS se encuentra en una zona urbana, el suelo ha sido alterado por la acción antrópica debido al incremento de las actividades comerciales, industriales, educativas y residenciales como se muestra en la Figura 1, provocando cambios marcados en el medio biótico, convirtiéndose en una zona urbana con las comodidades y servicios básicos característicos para satisfacer las necesidades y demandas de sus habitantes; por esta razón no cuenta con vegetación y fauna propia del sector; con las consideraciones señaladas el análisis de la zona de estudio incluyó la definición del área de influencia directa e indirecta utilizando el programa ARGIS y la interrelación de la investigación con las variables socio-ambientales influyentes como: medio físico, clima, medio biótico y socioeconómico; dichos parámetros fueron obtenidos de fuentes bibliográficas, 
datos históricos y registros oficiales proporcionados por las autoridades instituciones y gubernamentales (Romero, 2012).

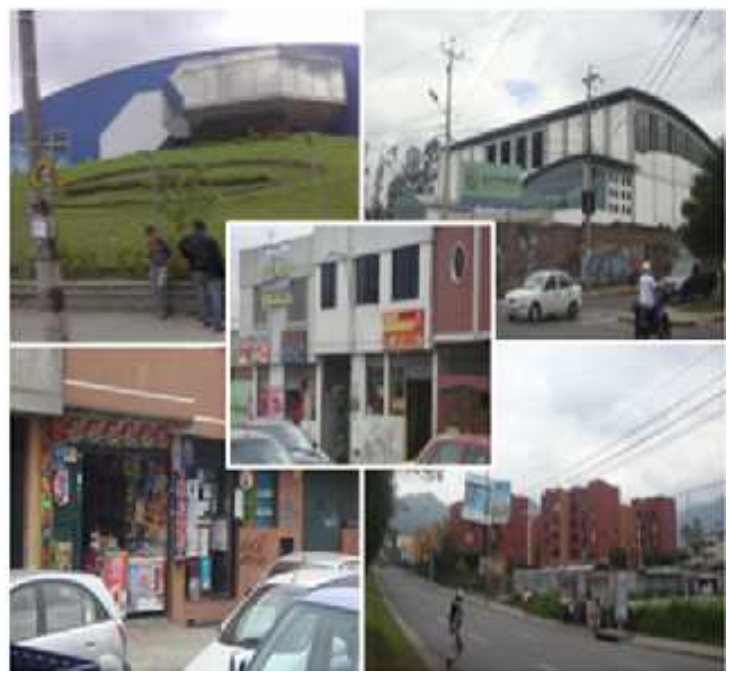

Figura 1. Actividades comerciales, industriales, educativas y residenciales del sector

\subsubsection{Planificación}

Incluyó el desarrollo de las siguientes actividades: a) la determinación de fuentes de generación de residuos domiciliarios (área académica, área administrativa, cafetería, centro de copiado, biblioteca, áreas libres) y especiales (laboratorios); b) determinación de número de individuos a muestrear utilizando la fórmula estadística Ec. 1 para poblaciones menores a 10000 habitantes, poblaciones finitas y muestreo simple aleatorio (Férnandez y Virtudes, 2005), peso de muestra Ec. 2, y número de muestreos Ec. 3, c) definición de lugar de trabajo, d) adquisición de materiales, insumos y equipos c) Formación previa al proceso de cuantificación y caracterización de residuos y d) Cronograma de caracterización.

$$
n=\frac{N}{1+\frac{e^{2}(N-1)}{z^{2} \cdot p q}}
$$

Donde:

$n=$ Tamaño de la muestra de individuos.

$N=$ Tamaño conocido de la Población individuos.

$z=$ Nivel de confianza $95 \%$ valor estándar $(z=1,96)$.

$e=$ margen de error valor estándar $(5 \% \mathrm{e}=0,05)$.

$p q=0,25$.

El muestreo de individuos se convierte en un sistema complejo debido a la movilidad de los mis- mos, existiendo la necesidad de transformar los individuos en $\mathrm{Kg}$ de residuos generados según estable (Velasco,2003;Taype,2009), en la Ec. 2.

$$
M=n \cdot P P C
$$

Donde:

$M=$ Tamaño de muestra.

$P P C=$ Producción per cápita de residuos .

El número de muestras seleccionadas se calculó utilizando la Ec. 3.

$$
M_{c}=\frac{M}{100}
$$

Donde:

$M c=$ Número de muestras a caracterizar.

$100=$ Tamaño de muestra recomendado por norma $(100 \mathrm{~kg})$.

El proceso de cuantificación y caracterización de residuos es un proceso de alto riesgo para los diferentes individuos que interactúan, por tal motivo la capacitación se convierte en una herramienta importante de prevención de riesgos, esta herramienta incluyó: a) Uso adecuado de ropa de trabajo y equipo de protección personal como mascarillas, gorra, gafas y guantes de seguridad b) Capacitación en buenas prácticas de trabajo como: no comer e ingerir bebidas, no fumar, no estar bajo la influencia de bebidas alcohólicas o estupefacientes durante la jornada de trabajo c) Restricción de participación de mujeres embarazadas debido al peligro que representa el proceso d) Notificación al supervisor de campo de cualquier lesión ocasionada durante la jornada de trabajo e) Identificación de servicios médicos más cercanos antes de iniciar el trabajo y f) Capacitación en primeros auxilios básicos.

Además se consideró que el cronograma de ejecución en un programa de caracterización debe ser ejecutado en fechas alejadas de festividades, feriados o cualquier evento que altere el normal desenvolvimiento de las actividades debido a que cambia el comportamiento de la muestra en estudio.

\subsection{Caracterización y cuantificación de residuos sólidos comunes}

Los residuos sólidos comunes se cuantificaron siguiendo el protocolo que se menciona a continuación: 


\begin{tabular}{ll}
\hline \multicolumn{1}{c}{ Sub-categoría } & \multicolumn{1}{c}{ Descripción } \\
\hline Papel mezclado & $\begin{array}{l}\text { Papel de oficina, papel de computadora, revistas, papel satinado, papel } \\
\text { encerado, y otro papel no definido dentro de las categorías de papel de } \\
\text { periódico y cartón ondulado } \\
\text { Corrugado, medio corrugado, cajas de cartón, bolsas de papel }\end{array}$ \\
Periódico & Todos los plásticos \\
Residico & Ramas de desechos de jardín, hojas, hierba y otros materiales vegetales \\
Residuos de comida & Todos los residuos de comida excepto huesos \\
Madera & Productos de madera, pallets, muebles \\
Otros & Textiles, caucho, cuero y otros materiales incinerables no incluidos en la \\
Combustibles & categoría anterior. \\
Ferrosos & Hierro, acero, latas y latas bimetálicas \\
Aluminio & Aluminio, latas de aluminio y láminas de aluminio \\
Vidrio & Todos los vidrios \\
Otros inorgánicos / & Roca, arena, tierra, cerámica, yeso, metales no ferrosos que no sean de \\
No combustibles & aluminio, metales (cobre, latón, etc.) y huesos. \\
\hline
\end{tabular}

Tabla 1. Categorización de residuos según la norma ASTM D 5231-92 (2008)

a) Delimitación y adecuación del lugar de trabajo.

b) Recolección y etiquetado de residuos generados y la respectiva clasificación según fuente generadora.

c) Pesaje de residuos generados por tres ocasiones consecutivas según establece CEPIS, (2005).

d) Determinación de la PPC de la población universitaria mediante la Ec.4.

$\operatorname{PCC}_{(\text {Residuos Sólidos })}=\frac{\text { Cantidad de Residuos Generados }}{\text { Población }}$

e) Selección de una muestra para cuantificar características físico-químicas de los residuos, la misma que será enviada para el respectivo análisis en un laboratorio acreditado por el Servicio de Acreditación Ecuatoriana (SAE).

f) Cuantificación de la densidad total de residuos como se muestra en la ecuación 5 (Taype,2009).

$$
\text { Densidad }=\frac{\text { Masa de los residuos muestreados }(\mathrm{Kg})}{\text { Volumen del recipiente de muestreo }}
$$

g) Caracterización de residuos según la Tabla 1, correspondiente a la norma ASTM D5231-92 (2008).

h) Tamizado de residuos.

\subsection{Cuantificación de residuos sólidos especiales}

Los residuos sólidos especiales se incluyeron dentro de un protocolo de levantamiento de información para cada laboratorio; este inventario se realizó con el fin de proporcionar información de la vida útil de cada uno de los insumos y la conversión en residuos especiales.

\section{Resultados y discusión}

\subsection{Parámetros iniciales de cuantifica- ción y caracterización de residuos}

La Universidad Politécnica Salesiana campus Sur (UPS-QS) se encuentra ubicada en la Provincia de Pichincha, cantón Quito, parroquia Chillogallo, administración zonal Quitumbe, entre la avenida Morán Valverde y la calle Rumichaca; está situada en una zona comercial de alta afluencia de tráfico e individuos cuya biótica corresponden a especies introducidas resistentes al desarrollo demográfico, tomando en cuenta las características e influencia de las actividades involucradas dentro y fuera de la UPS-QS sobre la investigación a realizarse, se establecieron puntos externos de referencia como entes limitantes del área de influencia así: al norte parada de buses en la Av. Morán Valverde, sur hospital 


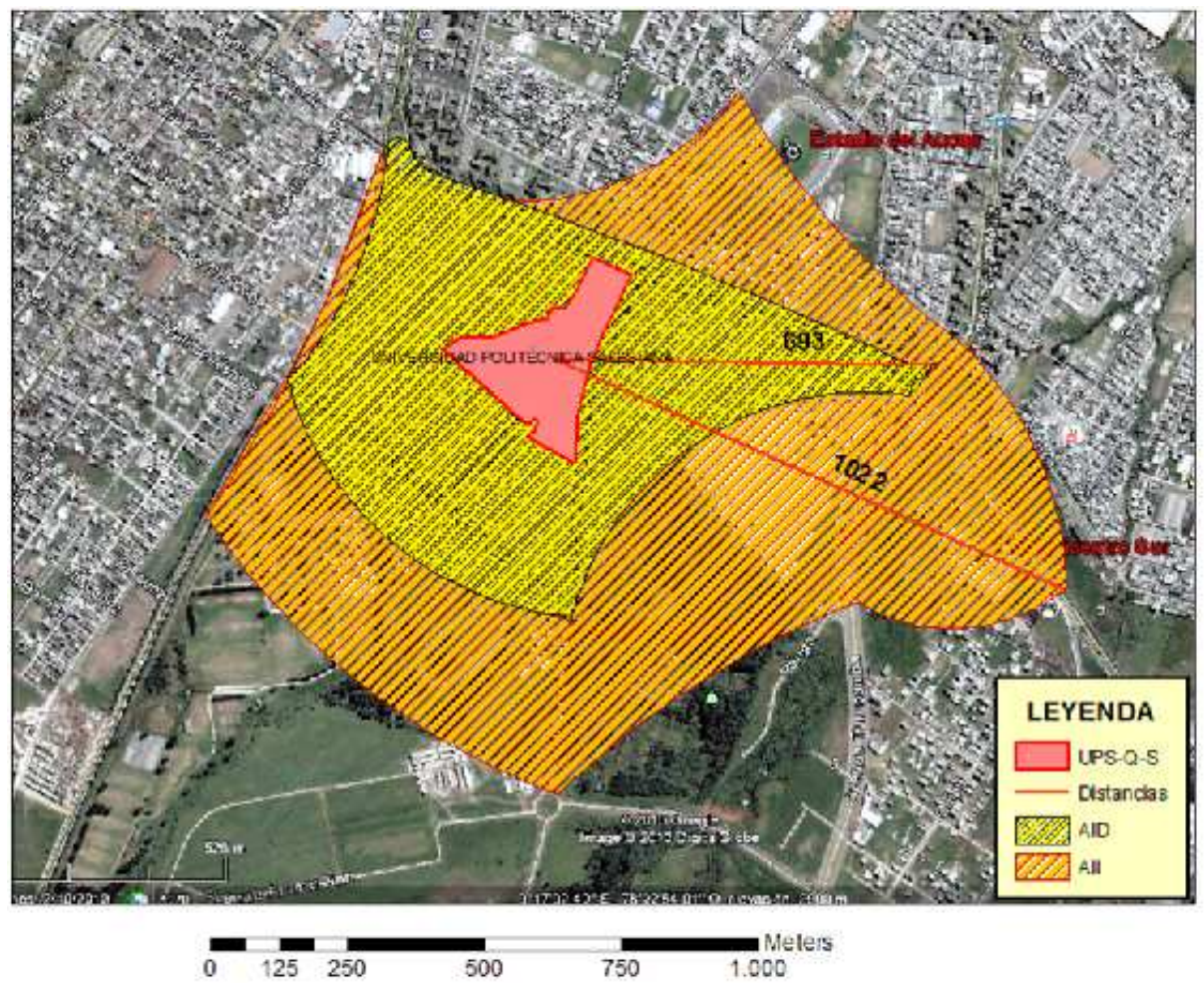

Figura 2. Definición de área de influencia directa (AID) e indirecta (AII) de la UPS-QS

\begin{tabular}{lccc}
\hline Fuente & $\begin{array}{l}\mathrm{N}^{\circ} \text { de individuos a } \\
\text { muestrear }(\mathrm{n})\end{array}$ & $\begin{array}{l}\mathrm{Kg} \text { de muestra } \\
\text { muestrear }(\mathrm{M})\end{array}$ & $\begin{array}{l}\mathrm{N}^{\circ} \text { de muestras por } \\
\text { día a muestrear }(\mathrm{Mc})\end{array}$ \\
\hline Personal administrativo & 144 & 86,7 & 1 \\
Estudiantes & 348 & 208,5 & 2 \\
\hline Total & 350 & 209,7 & 2 \\
\hline
\end{tabular}

Tabla 2. Cálculo de número de muestras a caracterizar

Padre Carollo, este parada de trolebús y oeste parada corredor oriental, lograron un polígono con superficie irregular como se muestra en la Figura 2, cuya distancia desde el centro hasta el lugar más alejado reportó valores de $693 \mathrm{~m}$ y $1022 \mathrm{~m}$ para el área de influencia directa e indirecta respectivamente.

El área de estudio estuvo influenciada por valores de temperatura media de alrededor de $14^{\circ} \mathrm{C}$ con precipitaciones entre 28 a $261 \mathrm{~mm}$ de agua mensuales, velocidad de viento de $1,97 \mathrm{~m} / \mathrm{s}$ y una humedad relativa de $66 \%$, según datos promedios reportados por la Red de Monitorero Ambiental- Estación El Camal de la Secretaría del Ambiente (2013) y es- tación IZOBAMBA (M003) del INAMI para el año 2013.

La UPS-QS por tratarse de una institución educativa está conformada por docentes, personal administrativo, estudiantes, personal de limpieza y guardias de seguridad con un total de 3884 individuos para el año 2012 y con un incremento semestral del 29\% según el informe de gestión reportado por Romero (2012); por tanto aplicando la ecuación [1] se determinó un tamaño de muestra de 144 personas administrativas y 348 estudiantes que representarían al total de la población, tal como se muestra en la Tabla 2; además aplicando la ecuación [2] y considerando un PPC estimado para Quito de 0,6; 
se determinó que se requiere de 2 muestras diarias para realizar la caracterización.

\subsection{Caracterización y cuantificación de residuos sólidos comunes}

Una vez definida el área de trabajo se procedió a impermeabilizar la misma para evitar contaminación del suelo, posteriormente se dividió, delimitó y organizó el área de trabajo como se muestra en la Figura 3.a, consecuentemente se realizó la cuantificación de residuos generados previamente clasificados en bolsas de colores (Figura 3.b) previo al uso estricto de equipo de protección (Figura 3.c).

El proceso de cuantificación diaria promedio de residuos sólidos comunes en la UPS-QS reportó un valor total de $96,9 \mathrm{Kg}$ /día, correspondiendo a 80,2 $\mathrm{Kg}$ /día de residuos sólidos comunes y 16,7 kg/día de residuos de poda. Como se observa en la Figura 4, el área que genera mayor cantidad de residuos sólidos comunes es la cafetería, esta área se caracteriza por ser el sitio de confluencia de todos los individuos que interactúan dentro de la institución, por tanto su generación de residuos fue mayoritaria.

a

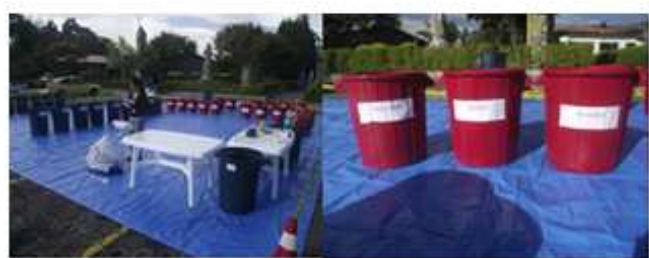

b

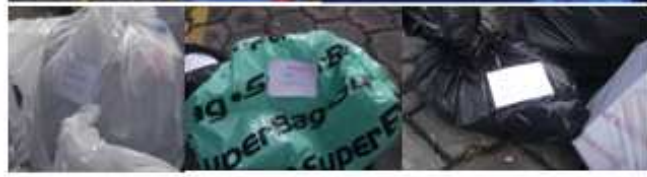

C

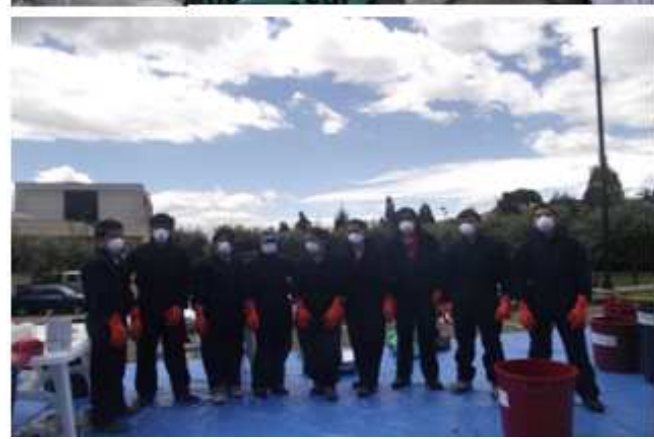

Figura 3. Adecuación del área y equipo de trabajo
La cuantificación promedio de residuos sólidos comunes permitió determinar la producción per cápita para la UPS-QS con un valor promedio de 0,3 $\mathrm{Kg}$ / (habitante día) y una densidad promedio de 80 $\mathrm{Kg} / \mathrm{m}^{3}$ como se muestra en las Figuras 4 y 6 .



Figura 4. Generación promedio diaria por fuente de generación.

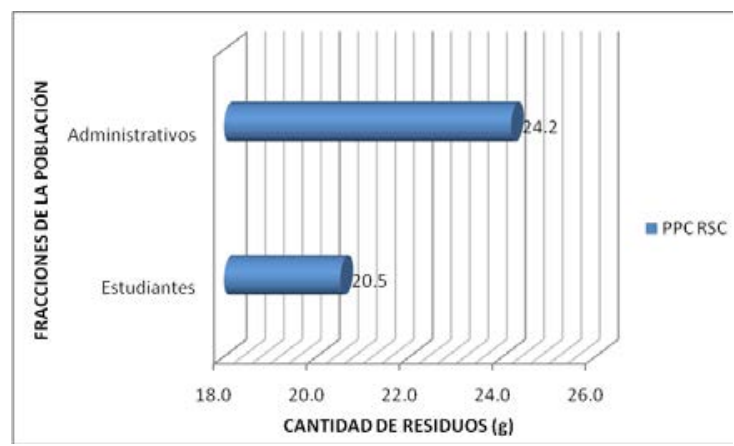

Figura 5. PPC de residuos sólidos comunes por fracciones de población de la UPS-QS.

El análisis químico de los residuos sólidos comunes presentaron diferencias significativas para cada uno de los parámetros analizados como se señala en la Tabla 3; además se puede observar que el contenido de agua supera el $50 \%$ que conlleva a concluir que el mayor porcentaje dentro de la composición de los residuos corresponde a materia orgánica y hecho corroborado por los altos porcentajes de nitrógeno y potasio existentes en dichas muestras analizadas; sin embargo, la cantidades obtenidas de estos macro nutrientes no son suficientes para usar los residuos orgánicos como abono con un tratamiento previo de compostaje. 


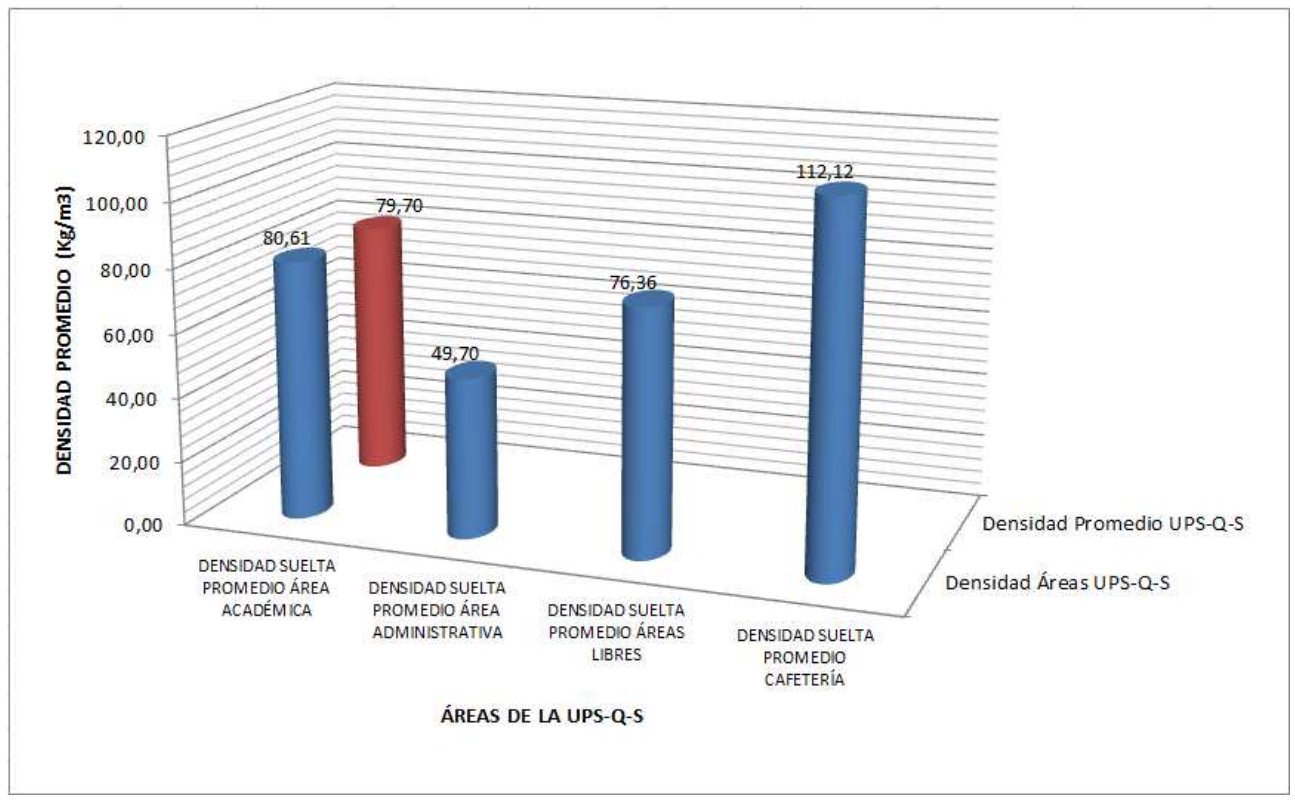

Figura 6. Densidad típica de los residuos sólidos UPS-QS.

\begin{tabular}{ccccc}
\hline Parámetro & Área Académica & Área de cafetería & Aéreas libres & Método \\
\hline Humedad $(\%)$ & $66,03 \mathrm{a}$ & $72,33 \mathrm{~b}$ & $69,32 \mathrm{c}$ & MAL-13/AOAC 925.10 \\
Cenizas $(\%)$ & $1,56 \mathrm{a}$ & $1,45 \mathrm{~b}$ & $1,72 \mathrm{c}$ & MAL-02/AOAC 923.03 \\
Fósforo $(\mathrm{mg} / 100 \mathrm{~g})$ & 0,00 & 296,11 & 0,00 & MAL-24 \\
Nitrógeno $(\%)$ & $0,38 \mathrm{a}$ & $0,46 \mathrm{~b}$ & - & MAL-04/AOAC 981.10 \\
Potasio $(\mathrm{mg} / \mathrm{Kg})$ & $4834,00 \mathrm{a}$ & $5026,00 \mathrm{~b}$ & $1721,00 \mathrm{c}$ & DIGESTIÓN Y ABSORCIÓN ATÓMICA \\
\hline
\end{tabular}

Tabla 3. Parámetros químicos de residuos sólidos comunes

La caracterización de residuos clasificados por sub-categorías Figura 7 y Tabla 4, señalan que el área académica presenta los mayores valores tanto en el total como en cada una de las sub-categorías.

La composición total de residuos sólidos comunes por sub-categoría generados por la comunidad universitaria Figura 8, muestra que la fracción orgánica es la más abundante dentro de los residuos y dentro de ella un $46.47 \%$ corresponde a desperdicios de comida, seguido por la fracción plástica que alcanza un $21.22 \%$ y $15.87 \%$ papel; estos datos coinciden con la realidad nacional e internacional en la que los residuos orgánicos, plástico y papel corresponden a los rubros más importante de residuos generados según lo expone (Frers,2009).

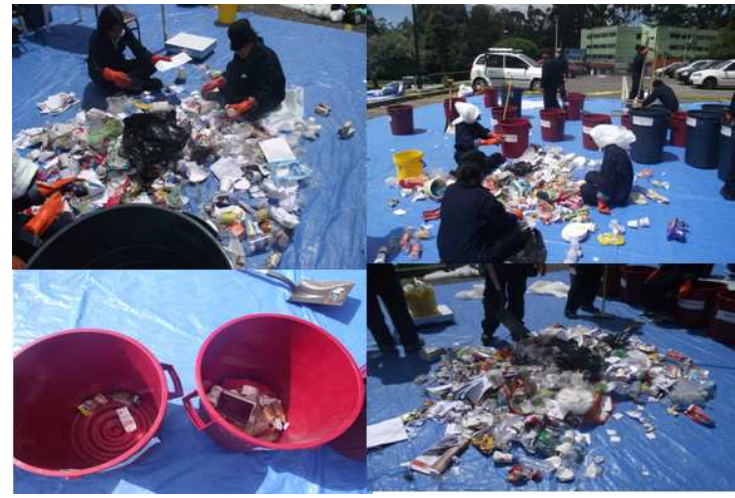

Figura 7. Proceso de separación de residuos por subcategoría. 


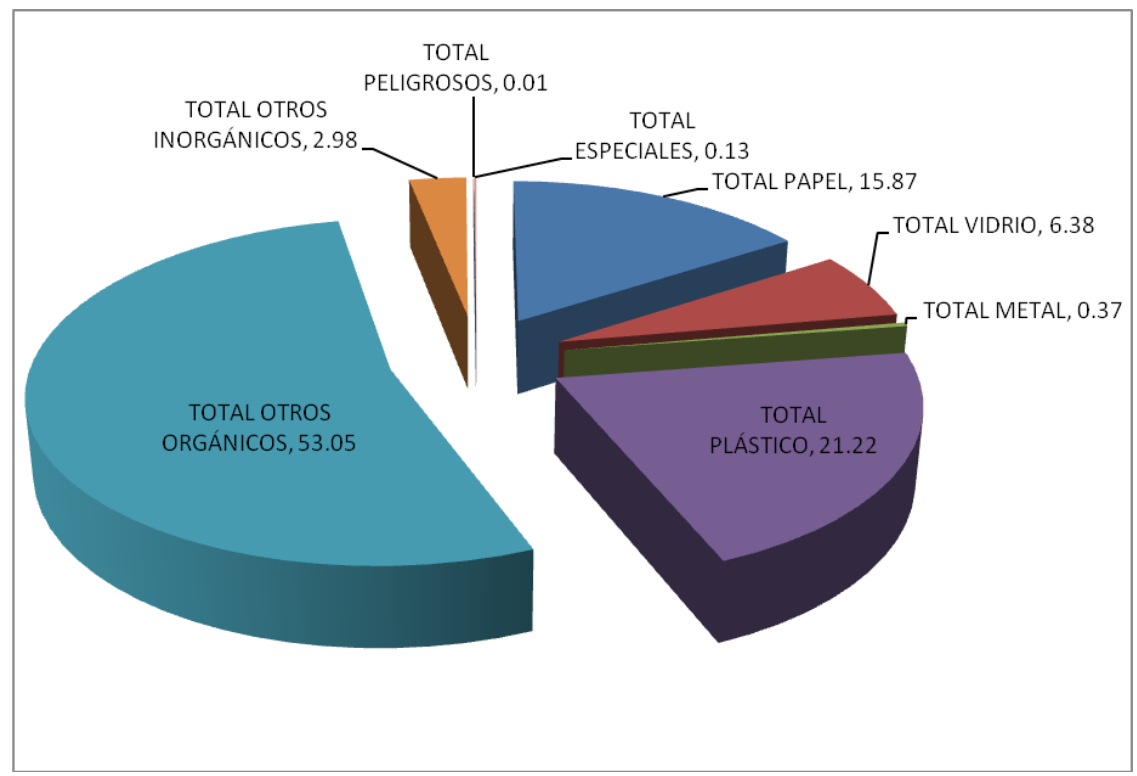

Figura 8. Composición típica general de los residuos sólidos comunes generados por todas las áreas de la UPS-Q-S presentados en porcentajes.

\begin{tabular}{lccccc}
\hline Total Sub-categoría (Kg/día) & Académica & Administrativa & Abiertas & Cafetería & Copiadora \\
\hline Papel & 5,06 & 0,98 & 1,04 & 1,90 & 0,58 \\
Vidrio & 3,24 & 0,31 & 0,16 & 1,18 & \\
Metal & 0,12 & 0,05 & 0,05 & 0,08 & \\
Plástico & 8,34 & 1,54 & 1,98 & 4,60 & \\
Otros orgánicos & 3,60 & 0,58 & 1,96 & 3,69 & \\
Otros inorgánicos & 1,90 & 0,08 & 0,06 & 0,34 & \\
Peligrosos & 0,00 & 0,00 & 0,00 & 0,00 & \\
\hline Total & $22,26 \mathrm{a}$ & $3,54 \mathrm{~b}$ & $5,27 \mathrm{c}$ & $11,79 \mathrm{~d}$ & $0,58 \mathrm{e}$ \\
\hline
\end{tabular}

Tabla 4. Sub-categoría de residuos generados por área en la UPS.

\begin{tabular}{cccccc}
\hline Tamaño de poro & \multicolumn{5}{c}{ Porcentaje pasante } \\
\cline { 2 - 6 } (pulgadas) & PlásticoCartón & Papel & vidrio & Orgánico \\
\hline 8 & 99,52 & 77,64 & 100 & 100 & 100 \\
4 & 87,43 & 71,84 & 56,21 & 100 & 95,27 \\
2 & 15,89 & 8,33 & 28,27 & 0 & 79,51 \\
1 & 14,88 & 1,75 & 11,47 & 0 & 44,3 \\
Fondo & 0 & 0 & 0 & 0 & 0 \\
\hline
\end{tabular}

Tabla 5. Porcentaje de residuos pasantes vs tamaño de poro.

Una vez clasificados los residuos se procedió a determinar la granulometría con la ayuda de tamices de madera y alambre galvanizado malla $8,4,2$ y 1 pulgada de abertura construida para dicho fin como se muestra en la Figura 8 y cuyos resultados se encuentran tabulados en la Tabla 5. 


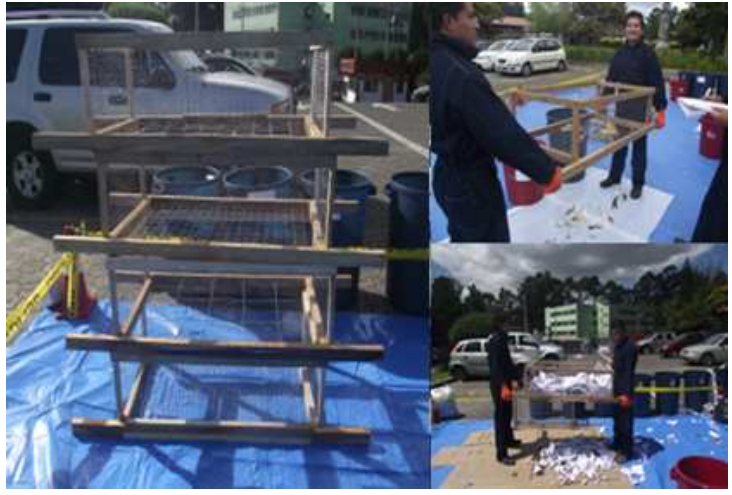

Figura 9. Tamices utilizados para caracterización de residuos sólidos.

\subsection{Cuantificación de residuos sólidos especiales}

El inventario de los diferentes laboratorios que trabajan con productos químicos reportó un total de $151 \mathrm{Kg}$ de químicos de los cuales el $100 \%$ son utilizados en soluciones las cuales son desechadas como residuos líquidos de carácter especial.

El laboratorio de suelos debido a la actividad específica que realiza genera $17600 \mathrm{Kg} /$ mes de material de desalojo propio de los análisis realizados, cuyos residuos son desechados como material de escombro y depositados en escombreras asignadas por el Municipio Metropolitano de Quito para dicho fin.

Los laboratorios de cómputo se convierten en generados permanentes de residuos especiales debido a la obsolescencia inmediata que presenta el cambio continuo de tecnología, incrementando las bodegas de almacenamiento hasta su disposición final, así se evidenció un total de 909 equipos obsoletos que cumplieron su vida útil; los ítems que frecuentemente requieren reemplazo continuo son: monitores, teclados, fuentes de poder y mouse que correspondieron al $65 \%$ de los ítems computacionales desechados.

\section{Conclusiones y recomendacio- nes}

La generación de residuos sólidos comunes de la UPS-QS siguió el estándar característico de producción de residuos del Distrito Metropolitano de Quito, reportando mayores cantidades para plástico, papel y residuos orgánicos, por tal motivo una adecuada segregación de residuos en la fuente ayudaría a disminuir la cantidad total de residuos que se envía al relleno sanitario El Inga.

El PPC de 0,3 Kg/(habitante día) reportado para la UPS-QS fue inferior al PPC de 0,6 reportado para la ciudad de Quito, esto se debe a que los individuos que interactuaron dentro de la institución son considerados como población flotante, y por tanto presentan tiempos de permanencia inferiores, haciendo que el valor de PPC también sea inferior.

La cantidad de residuos generados en un establecimiento universitario pequeño como el del presente estudio no requiere la separación en la fuente de más de dos tipos distintos, ya que la cantidad generada de residuos es muy pequeña como se puede observar en la Tabla 4. La separación en muchos tipos de residuos disminuye la eficiencia del sistema por un rechazo del generador a tener que colocar y conocer varios contenedores. Así también existe un rechazo del gestor a tener que disponer por separado residuos que como en el caso del metal no llega a medio kilogramo diario. Por tanto se recomienda la disposición en dos contenedores, uno para residuos reciclables y otro de residuos no reciclables cuyo destino final será el relleno sanitario. Los residuos reciclables pueden ser entregados a gestores, evitando que estos tengan que realizar una separación manual como se lo realiza actualmente.

Además, no se debe realizar contenerización separada de residuos en la fuente cuando no se dispone de una correcta gestión diferenciada de los mismos. Cuando se colocan contenedores diferenciados en sitios públicos y estos no reciben la adecuada gestión diferenciada, se crea en la población un rechazo a separar sus residuos en la fuente, lo cual merma la ejecución de planes de gestión de residuos inegrales y correctamente realizados.

Existe un $46,47 \%$ de basura orgánica que no cumple con las cantidades y relaciones de macronutrientes para ser considerada como abono. Por esta razón, no se recomienda un sistema de compostaje, ya que su producto final solo serviría como un acondicionador de suelos, y su cantidad generada no compensa para una inversión en espacio y mantenimiento. La basura orgánica se dispondrá como basura no reciclable y su destino final será el relleno sanitario de la ciudad.

Por otro lado, el estudio de granulometría de residuos ayudará a diseñar contenedores que permitan albergan cantidades de residuos determinados, 
facilitando a los gestores ambientales el desalojo de los mismos y a la UPS-QS la liberación de gran parte de residuos reutilizables y el cumplimiento de la Ordenanza Municipal 332, Ordenanza metropolitana de gestión integral de residuos sólidos del Distrito Metropolitano de Quito.

Los residuos sólidos especiales generados en la UPS-QS no son considerados potencialmente peligrosos ya que en su totalidad son desechados como residuos líquidos bajo protocolos de neutralización de soluciones.

Finalmente, el proceso de caracterización de residuos se convierte en un programa crítico dentro de las diferentes organizaciones ya que debe ser estructurado desde el inicio con etapas de planificación, levantamiento de línea base, capacitación de personal y la ejecución del proyecto, recomendándose seguir los protocolos establecidos para obtener exitosos procesos de caracterización que servirán para implantar sistemas integrales de tratamiento de residuos.

\section{Agradecimientos}

Este estudio fue financiado por la III convocatoria abierta de proyectos de investigación de la Universidad Politécnica Salesiana año 2012-2013.

\section{Referencias}

ASTM. 2008. Standard test method for determination of the composition of unprocessed Municipal solid waste. ASTM. D5231-92: 6.

Bautista, C. 1998. Residuos guía técnico-jurídica. Madrid: Mundi-Prensa Libros.

Bernache, G. 2009. Cuando la basua nos alcance: el impacto de la degradación ambiental. México: CIESAS- Centro de Investigaciones y Estudios Superiores en Antropología Social.

Brion, R. 2010. Disposición final de residuos sólidos urbanos. Argentina: ANI-Academia Nacional de Ingeniería.

Cantoni, N. 2010. Reciclado una solución al problema de la basura. Buenos Aires: Albatros Saci.
CEPIS. 2005. Procedimientos Estadísticos para los Estudios de Caracterización de Residuos Sólidos. Lima.

Díaz, L. y C. Janon. 2010. Reciclaje y tratamiento biológico de los residuos sólidos municipales. Quito.

Fernández, A. y M. Virtudes. 2005. Muestreo estadístico. España: Septem Ediciones.

Fernández, R. 2012. Principales obligaciones medioambientales para la pequeña y mediana empresa. Alicante: Club Universitario.

Frers, C. 2009. Los problemas de la basura y una posible solución. El Cid Editor. apuntes: 7.

Hester, R. y R. Harrison. 2002. Environmental and Health Impact of Solid Waste Management Activities. New York: The Royal Society of Chemistry. Issues in environmental science and technology, No.18.

INAMHI. 2013. Anuario Meteorológico 2009 $\mathrm{N}^{\circ}$ 49. http:/ / www.inamhi.gob.ec/index.php /clima/anuarios-meteorologicos/204anuario-meteoro logico-2009.

Lianette, M., G. Del Pozo y R. González. 2009. Gestión de residuos sólidos: un tema de vital importancia para la gestión ambiental empresarial. En: memorias del taller por el Día Mundial del Medio Ambiente. Cuba: Editorial Universitaria.

Ordenanza 213. 2010. Ordenanza sustituta del título V, "Del Medio Ambiente". Libro segundo, del código municipal para el Distrito Metropolitano de Quito. Quito: Concejo Metropolitano de Quito. página 165.

Ordenanza 332. 2010. Ordenanza metropolitana de gestión integral de residuos sólidos del distrito metropolitano de Quito. En C. M. Quito, Ordenanza Metropolitana No. 0332. Quito: Concejo Metropolitano de Quito. página 134.

Quito Verde. 2012. I Cumbre Nacional de Alcaldes-10 Acciones de Quito frente al Cambio Climático. Quito: Ilustre Municipio de Quito. 
Robles, D. y E. Rodríguez. 2010. Caracterización físico y química de los residuos sólidos granulares del barrio de calles y avenidas en la localidad de Usaquén de la ciudad de Bogotá. Bogotá: Universidad Distrital Francisco José de Caldas Facultad Tecnológica Ingeniería Civil.

Romero, A. 2012. Informe trianual de la sede Quito. Periodo junio 2009-junio 2012. Quito: Universidad Politécnica Salesiana.

Runfola, J. y A. Gallardo. 2009. Análisis comparativo de los diferentes métodos de caracteriza- ción de residuos urbanos para su recolección selecitiva en comunidades urbanas.

Secretaría de Ambiente del Distrito Metropolitano de Quito. 2013. Informe Anual 2012 de Calidad de Aire. Quito.

Taype, G. 2009. Caracterización de los residuos sólidos en Castilla Piura, Perú. Universidad Nacional de Piura, 8.

Velasco, V. 2003. Muestreo y tamaño de la muestra. Una guía práctica para personal de salud que realiza investigación. Argentina: Editorial El Cid. 


\section{NORMAS PARA LA PREPARACIÓN DE MANUSCRITOS}

LA GRANJA (pISSN: 1390-3799, eISSN: 13908596) es una revista internacional, física y electrónica, bilingüe, y de frecuencia semestral dedicada a la publicación de artículos científicos originales previa aceptación y revisión por pares académicos o árbitros científicos (peer review).

\section{Política económica}

Todos los artículos son publicados para poder acceder a su contenido de manera abierta sin restricciones de contenido o económicas. La revista es publicada por Abya-Yala, de Quito, Ecuador.

\section{Copyright}

Los autores son los titulares de los derechos de todos los artículos en La Granja, no obstante los autores han concedido a terceros, de antemano y a perpetuidad, el derecho a usar, reproducir o difundir el artículo, previa citación de la originalidad del mismo artículo

Para que un artículo pueda ser sometido al proceso de Revisión por Pares, se deben cumplir los siguientes pasos y lineamientos:

\section{Originalidad}

1. Al ingresar un manuscrito a La Granja: Revista de Ciencias de la Vida, el sistema exige que el autor confirme que el material entregado es inédito y original, que no ha sido publicado anteriormente en forma impresa o electrónica y que no se presentará a ningún otro medio antes de conocer la decisión de esta revista.

\section{Envío electrónico por OJS}

2. Enviar el manuscrito en forma electrónica a través del sistema OJS (Open Journal System) de la página de La Revista de Ciencias de la Vida: La Granja $\langle$ http://revistas.ups.edu.ec/index.php/granja $\rangle$, previo registro y junto con la CARTA DE PRESENTACIÓN (adjunta en el mismo enlace) que debe incluir el tipo de artículo que se quiere someter a revisión: artículo científico, revisión bibliográfica o punto de vista. Las comunicaciones breves se reservan para hallazgos sobresalientes y se publicarán en un tiempo mucho menor al de los artículos regulares. De la mísma manera, se deben responder las siguientes preguntas del manuscrito:

- ¿Qué preguntas o hipótesis aborda su trabajo?

- ¿Es su trabajo claramente importante y novedoso? ¿Por qué?

- ¿Cómo contribuye su trabajo a la comprensión y avances de la ciencia?

- ¿Su estudio es relevante para científicos de otros países?

\section{Requerimientos técnicos}

3. Los artículos pueden estar escritos sobre Microsoft Word (.doc o .docx) o LATEX(.tex).

4. Cuando presente el artículo, usted no debe intentar diseñar el manuscrito, no justifique el documento, o centre los títulos, ni utilice el formato de doble columna. El único formato requerido es que los nombres en latín de los organismos deben estar en itálicas.

5. Las fotos, ilustraciones únicamente se presentan como figuras, y éstas, al igual que las tablas, deben estar numeradas secuencialmente incluyendo una descripción al pie explicativa para cada una, así como estar referidas en el texto. Las ecuaciones a las cuales se haga referencia en el artículo también deberán estar numeradas.

6. Use doble enter al final de cada párrafo, título o encabezamiento. No use enter en ningún otro lugar, deje al programa procesador de palabras romper las líneas en otros lugares. 


\section{Componentes del manuscrito}

7. Título: debe ser corto, conciso y reflejar el contenido del artículo. Escribirlo en mayúsculas y minúsculas, centrado; si contiene nombres científicos de taxa, destacarlos con cursivas, sin el autor del taxón. Debe estar escrito en inglés y español.

8. Nombre de los autores y filiación: El nombre del (los) autor(es) deberá escribirse completo, en mayúsculas y minúsculas, alineados al centro. Todo autor debe indicar su filiación institucional con superíndices indicando su dirección de contacto, y correo electrónico.

Adicionalmente se debe incluir qué autor sera el responsable del manuscrito o autor por correspondencia.

9. Resumen: Este párrafo debe informar al lector sobre la hipótesis que buscó responder través de su investigación, la metodología o diseño experimental utilizado, los principales resultados y conclusiones (en no más de 250 palabras). Debe estar escrito en inglés (Abstract) y en español.

10. Palabras clave: Las palabras clave serán de tres a seis y representarán los principales temas del artículo, deberán ser colocadas al final del resumen, en minúsculas, separadas entre sí por comas. Deberán incluirse tanto en español, como en inglés (Key words).

- Introducción

- Materiales y métodos (incluyendo área de estudio )

- Resultados

- Discusión

- Agradecimientos

- Referencias

11. Los Resultados y la Discusión pueden presentarse en algunos casos combinados.

12. Los agradecimientos deberán estar solamente en un párrafo al final del artículo y ser cortos.

13. La sección de Referencias debe incluir todas publicaciones referidas en el texto. No se debe incluir reportes no publicados $u$ otro tipo de información que no es posible obtener.
Las tesis deben citarse únicamente cuando estén disponibles para consulta en una biblioteca. En el texto las referencias deben seguir el sistema nombre-fecha en orden cronológico por ejemplo: Whitmore (1984), Van der Maarel et al.,(1987), Olsen y Balslev (1990), Laegaard (1992). Dos o más referencias citadas en el mismo sitio del texto deben ser arregladas cronológicamente y no alfabéticamente, por ejemplo: Acosta Solís (1982,1992), Estrella $(1983,1986,1989,1991,1995)$.

14. La sección de Referencias deberá incluirse en un archivo aparte sobre LTEXproporcionando un archivo de información bibliográfica (.bib); o si el artículo está escrito sobre Microsoft Word u otro procesador de texto, añadir una tabla en Microsoft Excel (.xls o .xlsx) y utilizer el Sistema Admimstracuón de Fuentes. De esta manera, el formato de la revista para las referencias se coloca automáticamente, tal como se muestra en algunos ejemplos a continuación:

\section{Referencias}

Granados, R. y M. Villaverde. 2002. Microbiología, tomo II. Parafino S.A., segunda edición, pág. 13.

Merino, A. 2010. Métodos topológicos para teoría cuántica. En: Cuarto encuentro de Física. Escuela Politécnica Nacional.

Noriega, P., P. Coba, J. Naikiai y J. Abad. 2011. Extracción, pruebas de estabilidad y análisis químico preliminar de la fracción colorante obtenida a partir del exocarpo del fruto Renealmia alpinia. La Granja, 13(1): 13-20.

Ramírez, R. 2000. Autocritícalidad de los incendios forestales. Tesis Doctoral, Universidad Nacional de Estudios a Distancia.

UICN. 2007. Lista Rápida para plantas de la UICN. Programa de Especies. Gland, Suiza, URL 〈 http.//www.iucnsis.org〉, consulta: 10 de abril de 2008. 
15. Numerar las figuras secuencialmente con números arábigos $(1,2,3, \ldots)$ en el orden en que deben aparecer en el texto. Numerar las tablas secuencialmente con números arábigos $(1,2,3, \ldots)$ en el orden en que deben aparecer en el texto. Cuando escriba los títulos de figuras y los encabezamientos de tablas, asegúrese de que cada una de las figuras y tablas sean autocomprensibles, por ejemplo: sin tener que regresar a leer el texto de nuevo.

\section{Preparación de las figuras}

16. Las figuras pueden ser dibujos lineales, mapas, o fotografías de medios tonos en blanco y negro o a color en resolución de 300 dpi.

17. Diseñe las figuras para que se ajusten eventualmente al tamaño final de la revista 19,2 $\times$ $26,2 \mathrm{~cm}$. Asegúrese de que las inscripciones o detalles, así como las líneas, tengan tamaños y grosores adecuados de tal manera que no queden ilegibles cuando sean reducidos a su tamaño final (números, letras y símbolos deben ser reducidos al menos a 2,5 mm de altura después que las ilustraciones han sido reducidas para ajustarse a la página impresa). Idealmente, las ilustraciones lineales deben ser preparadas a aproximadamente a un cuarto de su tamaño final de publicación, ejemplo: 4,7 × 6,5 $\mathrm{cm}$.

18. Diferentes elementos en la misma figura deben ser deletreados a, b, c, d, etcétera.

19. Las fotografías deben gravarse con alto contraste y en alta resolución. Recuerde que las fotografías frecuentemente pierden contraste en el proceso de impresión.

20. El texto en las figuras y mapas debe escribirse con letras fácilmente legibles, por ejemplo con el tipo Arial.

21. Si las figuras han sido previamente usadas, es la responsabilidad del autor el obtener el per- miso correspondiente para evitar problemas posteriores relacionados con los derechos de autor.

\section{Procedimiento editorial}

22. Cuando el manuscrito ha sido recibido por el editor pasa por dos procesos de selección. El primero se lleva a cabo dentro de un Consejo Editorial Interno que determinará la pertinencia y solvencia científica del manuscrito.

23. Si el manuscrito es aprobado, pasará al segundo proceso dentro del Consejo Editorial Externo, el cual está conformado por expertos de instituciones extranjeras, con reconocimiento internacional.

24. Si el artículo no es aceptado, será devuelto al autor.

25. Si el artículo es aceptado para publicación, el editor combinará los comentarios de los revisores con sus propios comentarios editoriales y regresarán el manuscrito al autor principal para su revisión final. El autor debe entonces realizar las correcciones y cambios necesarios. Usualmente el tiempo dado para cambios no será mayor a dos semanas.

26. La editorial hará las correcciones necesarias al manuscrito. En este punto, si es necesario, una segunda prueba de impresión puede ser enviada al autor corresponsal, pero usualmente esto no ocurrirá.

27. Los editores combinarán todos los manuscritos de acuerdo al tema en el volumen de la revista.

28. La velocidad de publicación del volumen de la revista depende de la calidad de colaboración entre los autores de los manuscritos, los revisores, la imprenta, y los editores. Cada vez que uno de los autores toma más tiempo del necesario para contestar a un requerimiento, el proceso entero será afectado. 


\section{GUIDELINES FOR PAPER SUBMISSION}

LA GRANJA (pISSN: 1390-3799, eISSN: 1390-8596) is a biannual, bilingual, print and digital international magazine of original scientific articles with previous acceptance and review by scientific or academic peers.

\section{Economic policy}

All articles are published without any content or economic restrictions, both on the review and publication processes. The magazine is published by the Editorial Abya-Yala, in Quito, Ecuador.

\section{Copyright}

The authors are the rights holders of all the articles in La Granja, however they have conceded, perpetually and beforehand, the right for a third party to use, reproduce, and disseminate their article with prior quotation of the originality of the said article. Creative Commons License: BY, NC, SA.

\section{Editorial procedure}

For an article to be subject of the peer review process, the following steps and guidelines should be followed:

\section{Originality}

1. When submitting a manuscript in La Granja: Revista de Ciencias de la Vida, the systems requires that the author confirms that the text presented is original and unpublished and that it will not be submitted to another medium before a decision has been made by this magazine.

\section{Digital submission through OJS}

2. Send the manuscript in digital form through the OJS (Open Journal System) of the Magazine's web site (http://revistas.ups.edu.ec/index.php /granja/user/register) with prior REGISTRATION, under the author's profile with his or hers PRESENTATION LETER (attached in the same link) which has to include the type of article intended for review: scientific article, bibliographical review or opinion piece.

\section{Technical requirements of the manuscript}

3. The articles can be written on Microsoft Word (.doc o .docx) or LateX (.tex).

4. When presenting the article, you should not try to design it, justify the document, or centering the titles, nor use the double column format. The only required format is that the names of the organisms in Latin should be in italic.

5. Pictures, illustrations and graphs are only presented as figures, and these, like the tables, must be sequentially numerated including a explicative foot note for each one, as well as being referred to the text. The equations referred in the text should also be numerated.

6. Use double 'enter' at the end of each paragraph, title or headline. Don't use 'enter' in any other place and allow the Word processing program break the lines in other places.

\section{Manuscript components}

7. Title: must be short, concise and reflect the contents of the article. It is necessary to write it in upper case and lower case and centered. If it contains taxa scientific names, they should be highlighted in cursive without the taxon's author. It must be written in English as well as Spanish.

8. Name of the authors and affiliation: The complete name of the author(s) should be written in upper case and lower case and centered. Every author should indicate their institutional affiliations, its contact address and email with superscripts. Additionally, it must be included with an asterisk $\left(^{*}\right)$ that the author will be responsible for the manuscript or author by correspondence. 
9. Abstract. This paragraph should inform the reader about the hypothesis that you sought to answer through your research, the methodology or used experiment design, the main results and conclusions (in no more than 250 words). It must be written both in English and Spanish.

10. Key words. The key words would be between three and six and should represent the main themes of the article. They should be located at the end of the abstract, in lower case and separated by commas. They must be written both in English and Spanish.

11. Introduction. The introduction is the presentation letter of the article. Even though there are many types of introductions, many authors usually present, in this section, the theoretical framework, the formulation of the main question, hypothesis, the objective of the study and the background of the work, amongst others. In this section and in the others it is necessary to include the respective references.

12. Materials and method. This part should be written with enough detail to ensure the reproducibility of the investigation. This usually includes: area of study, sample size, experimental and statistical design, laboratory equipment and computer programs used, among others.

13. Results and discussion. In this section should be included quantitative and qualitative information that will support the final conclusions. Generally, this includes tables, figures or maps, with their respective analysis and discussion.

14. Conclusions. It is the closure of the article, it answers to the work objectives as well as the showed results. This section can be also called Conclusions and discussion, if the discussion in the section has not taken place.

15. The acknowledgement section should only be a short paragraph at the end of the article.

16. The 'References' section should include the publications referred to in the text. Unpublished reports or other types of inaccessible information should not be included. The thesis should only be quoted when they are available in a library. In the text, the references should follow the system 'name - date' in chronological order. For example: Whitmore (1984), Van der Maarel et al., (1987), Olsen y Balslev (1990), Laegaard (1992). Two or more references quoted in the same place of the text should be chronologically arranged rather than alphabetically, for example: Acosta Solís (1982, 1992), Estrella $(1983,1986,1989,1991,1995)$. The quotation format of the magazine is the Chicago.

17. The references section can be included in a different file on LATEX, providing a bibliographical information fila (.bib); if the article was written in Microsoft Word, the source manager of the program can be used or allocate every datum of the references in separate Excel cells.

\section{Reference examples}

Granados, R. y M. Villaverde. 2002. Microbiología, tomo II. Parafino S.A., segunda edición, pág. 13.

Merino, A. 2010. Métodos topológicos para teoría cuántica. En: Cuarto encuentro de Física. Escuela Politécnica Nacional.

Noriega, P., P. Coba, J. Naikiai y J. Abad. 2011. Extracción, pruebas de estabilidad y análisis químico preliminar de la fracción colorante obtenida a partir del exocarpo del fruto Renealmia alpinia. La Granja, 13(1): 13-20.

Ramírez, R. 2000. Autocritícalidad de los incendios forestales. Tesis Doctoral, Universidad Nacional de Estudios a Distancia.

UICN. 2007. Lista Rápida para plantas de la UICN. Programa de Especies. Gland, Suiza, URL 〈 http.//www.iucnsis.org〉, consulta: 10 de abril de 2008.

\section{Figure preparation}

18. The figures can be lineal drawings, maps or pictures in shades of black and white, or in color at a 300 dpi resolution, meaning that the si- 
ze of the figure should be big, appropriate for a publication in quality format.

19. Design the figures so they adjust eventually to the final size of the magazine $19,2 \times 26,2$ $\mathrm{cm}$. Make sure that the inscriptions or details, as well as the lines, have adequate sizes and thickness so they are not rendered unreadable when they are reduced to their final size (Numbers, letters and symbols should be reduced at least $2.5 \mathrm{~mm}$ in height after the illustrations have been reduced to fit the printed page) Ideally, the lineal illustrations should be prepared in approximately one quarter of the final size of the publication, example: $7 \times 6,5 \mathrm{~cm}$.

20. Different elements on the same figure should be marked a, b, c, d, and etcetera.

21. Photographs should be rendered in high contrast and high resolution. Remember that frequently photographs loose contrast during the printing process.

22. If the figures have been previously used, is the author's responsibility to obtain the proper permissions to avoid any trouble regarding copyright.

\section{Editorial procedure}

23. Once the manuscript has been received by the editor through the OJS, it goes through two processes of selection: the first occurs within our internal Editorial Board, which will determinate the scientific pertinence and solvency of the text.
24. If the manuscript is approved, it will go through the second process within the external Editorial Board, which will be composed of experts from external institutions, with international recognition.

25. If the article is not accepted, it would be returned to the author, including the verdict.

26. If the article is accepted for publication, the editor will combine the commentaries and remarks from the reviewers with his or her own and will return the text to the main author for the final review. Then the author should perform the necessary corrections and changes. Usually, the time given to make these changes would not be greater than two weeks.

27. Once the article is approved, the editorial will do the necessary style corrections. At this point, if necessary, a second print test can be send to the correspondent author, however this usually will not occur.

28. The editor will combine all the manuscripts in accordance with the theme of the volume of the magazine.

29. The speed of the publication of the volume of the magazine depends on the quality of the collaboration among the authors of the manuscripts, the reviewers, the print and the editors. Each time one of the authors takes more time than necessary to meet a requirement, the entire process is affected. 


\title{
UNIVERSIDAD POLITÉCNICA SALESIANA DEL ECUADOR
}

\author{
Javier Herrán Gómez, sdb \\ RECTOR \\ (CUniversidad Politécnica Salesiana del Ecuador, 2016 \\ Turuhuayco 3-69 y Calle Vieja \\ Casilla Postal 2074 \\ Cuenca, Ecuador \\ PBX: (+593 7) 2050000 \\ Fax: (+593 7) 4088958 \\ E-mail: rpublicas@ups.edu.ee \\ CANJE \\ Se acepta canje con otras publicaciones periódicas. \\ Dirigirse a: \\ Secretaría Técnica de Comunicación y Cultura \\ Universidad Politécnica Salesiana \\ Av. Turuhuayco 3-69 y Calle Vieja \\ Casilla Postal: 2074 PBX: (+593 7) 4088958 \\ E-mail: rpublicas@ups.edu.ee \\ www.ups.edu.ee \\ Cuenca-Ecuador
}

\section{LA GRANJA:}

\section{REVISTA DE CIENCIAS DE LA VIDA}

Para canje, por favor complete el formulario a continuación y envíe a la Secretaría Técnica de Comunicación y Cultura, Universidad Politécnica Salesiana

Nombre

Título de la publicación de canje

Institución

Dirección

Provincia o Estado

País

Teléfono

Fax

Correo electrónico

Portal electrónico. 